\author{
Universidade de São Paulo \\ Instituto de Física de São Carlos
}

MARCELA DE FREITAS MENDONÇA

\title{
Projeto e construção de um amplificador paramétrico óptico operando no infravermelho médio
}

São Carlos

2010 



\section{MARCELA DE FREITAS MENDONÇA}

\section{Projeto e construção de um amplificador paramétrico óptico operando no infravermelho médio}

Dissertação apresentada ao Programa de PósGraduação em Física do Instituto de Física de São Carlos da Universidade de São Paulo, para obtenção do título de Mestre em Ciências

Área de Concentração: Física Aplicada

Orientador: Prof. Dr. Paulo Barbeitas Miranda

São Carlos 


\begin{abstract}
AUTORIZO A REPRODUÇÃO E DIVULGAÇÃO TOTAL OU PARCIAL DESTE TRABALHO, POR QUALQUER MEIO CONVENCIONAL OU ELETRÔNICO, PARA FINS DE ESTUDO E PESQUISA, DESDE QUE CITADA A FONTE.
\end{abstract}

Ficha catalográfica elaborada pelo Serviço de Biblioteca e Informação IFSC/USP

Mendonça, Marcela de Freitas

Projeto e construção de um amplificador paramétrico óptico operando no infravermelho médio./ Marcela de Freitas Mendonça; orientador Paulo Barbeitas Miranda-- São Carlos, 2010.

$108 \mathrm{p}$.

Dissertação (Mestrado - Programa de Pós-Graduação em Física - Área de concentração: Física Aplicada) - Instituto de Física de São Carlos da Universidade de São Paulo.

1. Óptica não-linear. 2. Ampliação paramétrica. 3. Supercontínuo de luz branca. I. Título. 


\section{FOLHA DE APROVAÇÃO}

\section{Marcela de Freitas Mendonça}

Dissertação apresentada ao Instituto de Física de São Carlos da Universidade de São Paulo para obtenção do título de Mestre em Ciências.

Área de Concentração: Fisica Aplicada

Aprovada em: 24/05/2010

\section{Comissão Julgadora}

Prof. Dr. Christiano José Santiago de Matós/

Instituiçăo: Mackenzie

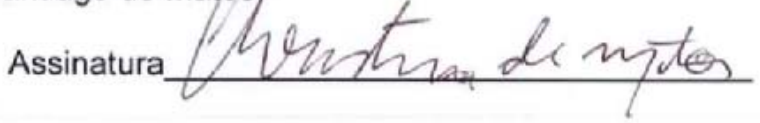

Prof. Dr. Cleber Renato Mendonça

Instituiçăo: IFSC/USP

Assinatura

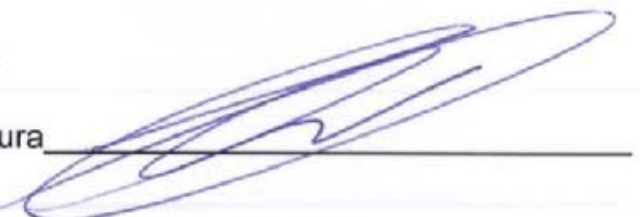

Prof. Dr. Paulo Barbeitas Miranda

Instituição: IFSC/USP

Assinatura

Mando Minouda 

Dedico este trabalho aos meus avós, Eva e Deolindo, pelo amor e apoio oferecidos. 



\section{Agradecimentos}

Ao Prof. Paulo Barbeitas Miranda, pelos conhecimentos transmitidos durante esses anos de convivência, pelo apoio, paciência e principalmente pela amizade.

Ao Prof. Lino Misoguti por várias discussões úteis.

Ao Prof. Sérgio Carlos Zílio por todas as oportunidades dadas.

Aos funcionários do IFSC, em especial ao pessoal da oficina mecânica pela presteza e eficiência nos serviços prestados.

Ao pessoal do laboratório de óptica não-linear do grupo de fotônica do IFSC, por todo o apoio dado.

Aos amigos do laboratório: Francisco, Heurison, Marcelo, Moema, Murilo, e Thiers que contribuíram para que eu concluísse este trabalho.

Aos meus amigos: Alexandre, Bruno, Cristian, Rodrigo e Vinicius, por estarem sempre presentes.

A minha mãe, Vera, que acreditou em mim e esteve ao meu lado me dando apoio e principalmente pelo exemplo de vida que sempre me mostrou.

Aos meus irmãos, Alexandre e Junior, pela paciência e ajuda prestada durante todos esses anos.

Ao Sergio, pessoa maravilhosa que sempre recorro em momentos difíceis.

A Capes pelo apoio financeiro. 



\section{Resumo}

MENDONÇA, Marcela de Freitas. Projeto e construção de um amplificador paramétrico óptico operando no infravermelho médio. 2010. 108p. Dissertação (Mestrado) - Instituto de Física de São Carlos, Universidade de São Paulo, São Carlos, 2010.

Um Amplificador Paramétrico Óptico (optical parametric amplifier - OPA) é uma fonte de luz coerente, de alta qualidade e sintonizável, baseada em processos ópticos não-lineares de segunda ordem. Alguns modelos possuem largura de banda estreita e um amplo intervalo de sintonia, podendo alcançar regiões que vão desde o ultravioleta até o infravermelho médio. A nossa motivação para construir este amplificador paramétrico óptico é sua utilização em experimentos de espectroscopia vibracional de superfícies através do processo óptico não-linear de segunda ordem, geração de soma de frequências ("sum-frequency generation" - SFG), que é uma técnica que exige fontes sintonizáveis no infravermelho médio e com altas intensidades de pico e largura de banda estreita. O objetivo desse trabalho foi projetar, montar e testar um amplificador paramétrico óptico capaz de produzir pulsos sintonizáveis de alta energia no infravermelho médio $(\lambda \sim 2,5$ a $10 \mu \mathrm{m})$ a partir de um laser de bombeio que fornece pulsos de $25 \mathrm{ps}$, com alta energia em $\lambda=1064 \mathrm{~nm}$. Para obter-se uma geração de infravermelho bastante eficiente, foi proposto um projeto inovador para amplificadores paramétricos de picossegundos, utilizando-se a geração de supercontínuo de "luz branca" como feixe sinal do estágio de amplificação paramétrica. O pulso de bombeio $(\lambda=1064 \mathrm{~nm}$ ) é dividido em duas partes: a primeira, de menor energia, é utilizada para gerar um pulso de alta largura espectral no infravermelho próximo (supercontínuo de "luz branca" de picossegundos). Uma fração espectral desse pulso é selecionada através de um monocromador e utilizada como semente do estágio de amplificação paramétrica. $\mathrm{O}$ cristal amplificador paramétrico (sulfeto de prata e gálio, $\mathrm{AgGaS}_{2}$ ) é então bombeado pelo restante do pulso de bombeio e simultaneamente amplifica a semente sintonizável no infravermelho próximo e gera um novo pulso de frequência complementar no infravermelho médio. Foram testados vários meios para geração de supercontínuo, mas os melhores resultados foram obtidos em uma cubeta de $10 \mathrm{~cm}$ de comprimento com uma mistura de água e água deuterada (3\% em volume de $\mathrm{H}_{2} \mathrm{O}$ em $\mathrm{D}_{2} \mathrm{O}$ ) e em uma fibra fotônica não-linear com $2 \mathrm{~m}$ de comprimento. Usando o supercontínuo como feixe semente, observou-se amplificação paramétrica no caso do feixe 
gerado na fibra fotônica com um ganho de 260 vezes, mas não com o feixe gerado na mistura de água/água deuterada, presumivelmente pela maior instabilidade desse supercontínuo.

Palavras-chave: Óptica não-linear. Amplificação paramétrica. Supercontínuo de luz branca. Fibra óptica fotônica. Pulsos ultracurtos. Geração de luz no infravermelho médio. 


\begin{abstract}
MENDONÇA, Marcela de Freitas. Design and construction of an optical parametric amplifier operating in the mid-infrared. 2010. 108p. Dissertação (Mestrado) - Instituto de Física de São Carlos, Universidade de São Paulo, São Carlos, 2010.
\end{abstract}

An Optical Parametric Amplifier (OPA) is a tunable light source of high quality, coherent radiation, based on second-order nonlinear optical processes. Some models have a narrow spectral bandwidth and a tuning range from the ultraviolet to the mid-infrared. The motivation for building this optical parametric amplifier is its use in vibrational spectroscopy of surfaces by a second-order nonlinear optical process, sum-frequency generation (SFG), which is a technique that requires tunable sources in the mid-infrared with narrow bandwidth and high peak intensities. The purpose of this work is to design, implement and test an OPA to generate tunable high energy pulses tuneable in the mid-infrared $(\lambda \sim 2.5$ to $10 \mu \mathrm{m})$ from a pumping laser that provides $25 \mathrm{ps}$ pulses with high energy at $\lambda=1064 \mathrm{~nm}$. For an efficient mid-infrared generation, we propose an innovative design for picosecond parametric amplifiers, using the near infrared portion of a white-light supercontinuum pulse as the seed beam for the parametric amplifier. The pump pulse $(\lambda=1064 \mathrm{~nm})$ is divided into two parts: the first one, with lower energy, generates a high spectral width pulse in the near infrared (white-light supercontinuum picosecond pulse). A spectral fraction of this pulse is selected through a monochromator and is used as seed for the parametric amplification stage. The second part of the laser beam pumps the parametric amplifier crystal (silver gallium sulfide, $\mathrm{AgGaS}_{2}$ ) which simultaneously amplifies the tunable seed beam in the near infrared and generates a new pulse with complementary frequency in the mid-infrared. Several media were tested for supercontinuum generation, but the best results were obtained with a $10 \mathrm{~cm}$ long cuvette with a mixture of water and deuterated water ( $3 \%$ volume of $\mathrm{H}_{2} \mathrm{O}$ in $\mathrm{D}_{2} \mathrm{O}$ ) and with a $2 \mathrm{~m}$ long nonlinear photonic crystal fiber. Using the supercontinuum as a seed beam, we have obtained parametric amplification of the seed generated by the photonic fiber with a gain of 260 times, but not of the beam generated by the water mixture, presumably because of its significantly higher instability. 
Keywords: Nonlinear optics. Parametric amplification. White-light supercontinuum. Photonic crystal fiber. Ultrashort pulses. Generation of mid-infrared radiation. 


\section{Lista de Figuras}

Figura 1 - Ilustração do processo de amplificação paramétrica óptica em um cristal não linear.

Figura 2 - Ilustração (a) do diagrama de energia do processo de amplificação paramétrica e (b) dos vetores de onda na situação em que não há casamento de fase entre as velocidades de fase das ondas.

Figura 3 - Esquema simplificado do espectrômetro SFG do LENI.......................... 26

Figura 4 - Configuração experimental de um OPA de picossegundo........................ 27

Figura 5 - Esquema de um OPA em fs. DL: linha de atraso (delay line); DF: filtro dicróico (dichroic filter).

Figura 6 - Diagrama esquemático do projeto do OPA

Figura 7 - Ilustração do processo de geração de diferença de freqüências: uma onda de freqüência $\omega 3$ e uma onda de freqüência $\omega 1$ incidem sobre um meio com suscetibilidade de segunda ordem gerando uma onda de freqüência $\omega_{2}=\omega_{3}-\omega_{1}$

Figura 8 - Dependência das amplitudes $A_{1}$ e $A_{2}$ com a distância $z$ percorrida no cristal para o processo de amplificação paramétria óptica em que há casamento de fase.

Figura 9 - Feixe de luz ordinário incidindo em um cristal uniaxial........................... 39

Figura 10 - Feixe de luz extraordinário incidindo em um cristal uniaxial................... 39

Figura 11 - Auto-focalização da luz....................................................................... 42

Figura 12 - Self-Trapping da luz no material....................................................... 42

Figura 13 - (a) Dependência temporal do pulso incidente. (b) Variação da freqüência instantânea do pulso ao ser transmitido por um meio com $\mathrm{n}_{2}$ positivo......

Figura 14 - Varredura de freqüência no processo de auto-modulação de fase............. 45

Figura 15 - Espalhamento Raman Estimulado........................................................... 47

Figura 16 - Confinamento da luz em uma fibra óptica.......................................... 49

Figura 17 - Seção transversal de uma fibra fotônica com estrutura hexagonal............. 51 
Figura 18 - Aparato experimental do OPA a ser construído. Aqui o bloco OPA refere-se ao OPA comercial existente no laboratório.

Figura 19 - Seção transversal da fibra fotônica de alta não-linearidade utilizada nesse projeto.

Figura 20 - Curva de dispersão da fibra "Nonlinear Photonic Fiber - SC-5.0-1040" utilizada neste trabalho.

Figura 21 - Arranjo esquemático de um monocromador cujo elemento dispersivo é uma grade de difração.

Figura 22 - Processo de difração por uma grade reflexiva.

Figura 23 - Condição blaze. NF é a normal à face do sulco e NG é a normal à grade.. 62

Figura 24 - Um micrômetro atua sobre o suporte da grade fazendo com que esta gire de um ângulo $\Phi$.

Figura 25 - Ilustração simplificada do estágio de rotação da grade de difração.

Figura 26 - Curva de sintonia do OPA para o casamento de fase tipo-I no cristal AgGaS2 em função do ângulo interno $\theta_{\mathrm{pm}}$

Figura 27 - Ângulos de incidência e refração dos feixes na superfície do cristal AgGaS2, para uma onda ordinária (a) e para uma onda extraordinária (b) e (c).

Figura 28 - Esquema simplificado do estágio de rotação do cristal não-linear.

Figura 29 - Energia do feixe idler em função dos parâmetros $z$ e $\mathrm{I}_{3}$ calculada para $\mathrm{o}$ nosso OPA, onde realizamos nos cálculos a aproximação de ondas planas

Figura 30 - Exemplo dos efeitos de comprimento do cristal e da intensidade do bombeio na intensidade do idler calculados a partir da equação 3.38..

Figura 31 - Exemplo ilustrativo da energia do idler em função da intensidade de bombeio calculada a partir da eq. 3.38 para um dado comprimento do cristal.

Figura 32 - Exemplo ilustrativo da energia calculada do idler em função da energia do feixe-sinal que incide no cristal para três diferentes comprimentos de onda do feixe sinal $(460,570$ e $660 \mathrm{~nm})$.

Figura 33 - Medida de absorção linear da água deuterada feita em uma cubeta de $2 \mathrm{~mm}$ de comprimento 
Figura 34 - Foto da projeção em um anteparo preto do supercontínuo gerado na água deuterada, onde a energia e a largura temporal do bombeio são respectivamente $2,97 \mathrm{~mJ}$ e $54 \mathrm{ps}$.....

Figura 35 - Espectro medido da parte central do supercontínuo gerado em uma cubeta de $10 \mathrm{~cm}$ de comprimento contendo água deuterada, sendo a energia e a largura temporal do bombeio respectivamente $2,97 \mathrm{~mJ}$ e 54 ps. O espectrômetro utilizado para a medida foi um NIR-512.

Figura 36 - Espectro medido do supercontínuo gerado em uma cubeta de $10 \mathrm{~cm}$ de comprimento contendo água deuterada com a energia e a largura temporal do bombeio dados respectivamente por $2,97 \mathrm{~mJ}$ e 54 ps. O espectrômetro utilizado para a medida foi um NIR-512

Figura 37 - Medidas espectrais do supercontínuo gerado em água deuterada em função da diferença angular entre o eixo do polarizador (posicionado na saída da cubeta) e a direção de polarização do bombeio. $\mathrm{O}$ espectrômetro utilizado para a medida foi um NIR-512.

Figura 38 - Medida de absorção linear da água feita em uma cubeta de $2 \mathrm{~mm}$ de comprimento. $\mathrm{O}$ espectrômetro utilizado para a medida foi um Cary $17 . .$.

Figura 39 - Medida do espectro do supercontínuo gerado em uma cubeta de $30 \mathrm{~cm}$ de comprimento contendo " $50 \%$ de água deuterada $+50 \%$ de água" com a energia e a largura temporal do bombeio dados respectivamente por 4,3 $\mathrm{mJ}$ e 54 ps. O espectrômetro utilizado para a medida foi um NIR-512......

Figura 40 - Medidas espectrais no visível do supercontínuo gerado em uma cubeta de $30 \mathrm{~cm}$ de comprimento contendo " $50 \%$ de água deuterada $+50 \%$ de água" com a energia e a largura temporal do bombeio dados respectivamente por $4,3 \mathrm{~mJ}$ e 54 ps. O espectrômetro utilizado para a medida foi um USB-2000 (Ocean Optics Inc, EUA).

Figura 41 - Medidas espectrais do supercontínuo gerado em uma cubeta de $30 \mathrm{~cm}$ de comprimento contendo " $50 \%$ de água deuterada $+50 \%$ de água" em função da diferença angular entre o eixo do polarizador (posicionado na saída da cubeta) e a direção de polarização do bombeio. O espectrômetro utilizado para a medida foi um USB-200. A energia e a largura temporal do bombeio são respectivamente $4,3 \mathrm{~mJ}$ e 54 os.

Figura 42 - Espectro medido do supercontínuo gerado em uma cubeta de $10 \mathrm{~cm}$ de comprimento contendo uma mistura de " $97 \%$ de água deuterada $+3 \%$ de água" com a energia e a largura temporal do bombeio dados respectivamente por $3 \mathrm{~mJ}$ e 54 ps. O espectrômetro utilizado para a medida foi um NIR-512. 
Figura 43 - Esquema do arranjo experimental utilizado na geração de luz suprcontínua no bastão de vidro................................................................

Figura 44 - Evolução temporal do espectro da luz supercontínua gerada em um bastão de BK7. E0 corresponde a energia de bombeio e a largura temporal do mesmo é $25 \mathrm{ps}$

Figura 45 - Fotos do supercontínuo gerado em um bastão BK7 com $20 \mathrm{~cm}$ de comprimento. A duração e energia do laser de bombeio são

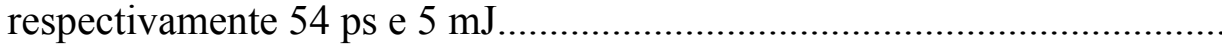

Figura 46 - Foto tirada do supercontínuo gerado na fibra Nonlinear Photonic Fiber SC-5.0-1040. Com a energia e a largura temporal do bombeio dados respectivamente por $1,6 \mu \mathrm{J}$ e 54 os.

Figura 47 - Eficiência do monocromador como função do comprimento de onda (Figura retirada do manual do equipamento)

Figura 48 - Responsividade espectral do foto-diodo em função do comprimento de onda (Figura retirada do manual do equipamento).

Figura 49 - Espectro medido da luz supercontínua gerada na fibra Nonlinear Photonic Fiber - SC-5.0-1040. Com a energia e a largura temporal do bombeio dados respectivamente por $1,42 \mu \mathrm{J}$ e $54 \mathrm{ps}$, e um acoplamento do feixe de bombeio dado por $\sim 41 \%$. 


\section{Lista de Tabelas}

Tabela 1 - Especificações do laser de bombeio utilizado no projeto do OPA

Tabela 2 - Parâmetros da fibra "Nonlinear Photonic Fiber - SC-5.0-1040" utilizada no projeto.

Tabela 3 - Parâmetros da fibra e do pulso de bombeio utilizados para o cálculo de $\mathrm{L}_{\mathrm{NL}}$ e $\mathrm{L}_{\mathrm{D}}$, bem como os respectivos resultados.

Tabela 4 - Dados obtidos para calcular o ângulo de incidência no cristal do feixesinal.

Tabela 5 - Dados obtidos para calcular o ângulo de incidência no cristal do feixe de bombeio.

Tabela 6 - Medidas da energia e da estabilidade da parte central do espectro gerado.

Tabela 7 - Medidas da energia e da estabilidade de todo o contínuo gerado.

Tabela 8 - Medidas da energia e da estabilidade da parte central do espectro gerado em uma mistura de " $50 \%$ de água deuterada $+50 \%$ de água" em uma cubeta de $30 \mathrm{~cm}$ de comprimento.

Tabela 9 - Medidas da energia e da estabilidade da parte central do contínuo gerado em uma cubeta de $10 \mathrm{~cm}$ de comprimento contendo uma mistura de "97\% de água deuterada $+3 \%$ de água".

Tabela 10 - Valores medidos do limiar de energia do bombeio para gerar supercontínuo e limiar de energia do bombeio que danifica a fibra "SC5.0-1040". O acoplamento do bombeio na fibra era de 40\%

Tabela 11 - Valores medidos para a energia e estabilidade do contínuo gerado na fibra Nonlinear Photonic Fiber - SC-5.0-1040. Com a energia e a estabilidade do bombeio sendo $1,4 \mu \mathrm{J}$ e $10 \%$, respectivamente

Tabela 12 - Energias medidas do feixe-sinal nas situações sem e com amplificação paramétrica 



\section{Sumário}

\section{Introdução}

2 Fundamentos Teóricos.

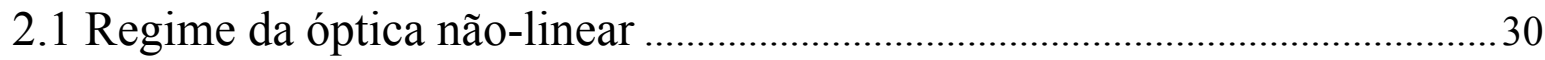

2.1.1 A polarização não-linear agindo como fonte de novas frequências ..........................31

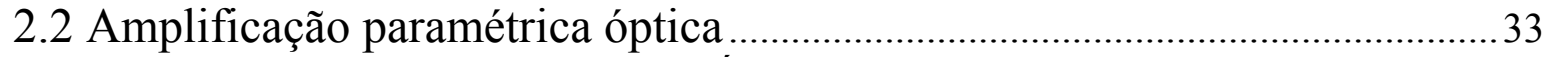

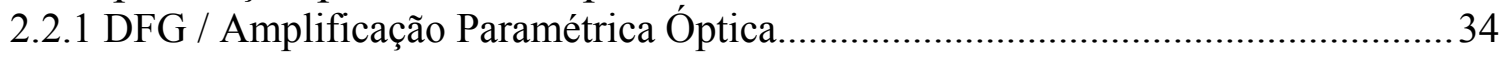

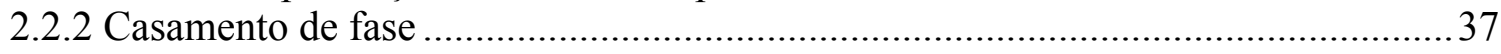

2.3 Geração de supercontínuo de "luz branca" ..........................................................40

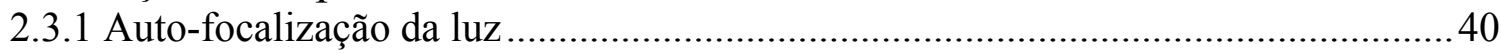

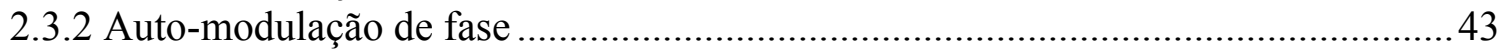

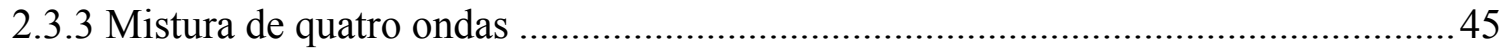

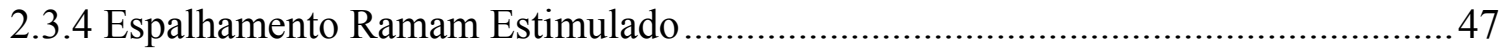

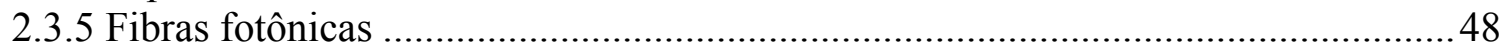

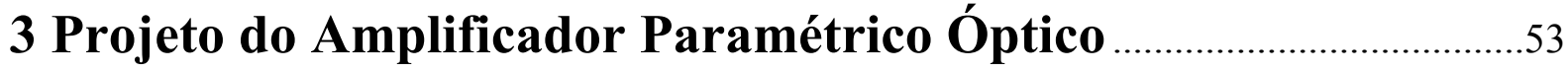

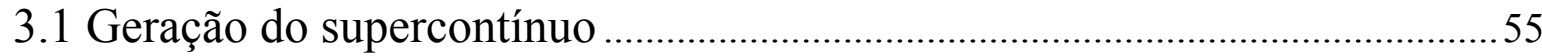

3.1.1 Escolha da fibra fotônica a ser utilizada ................................................................5

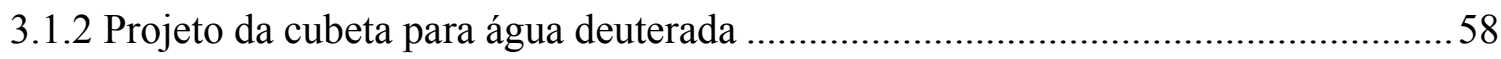

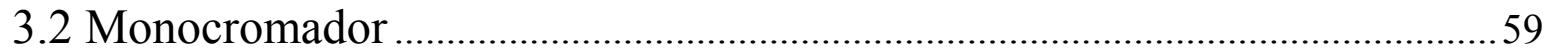

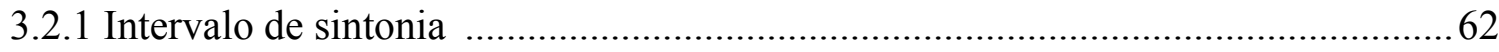

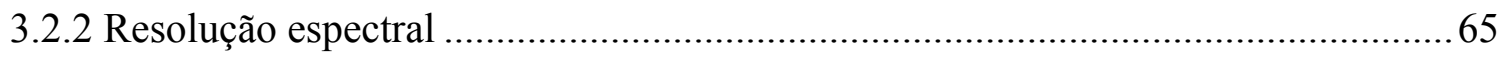

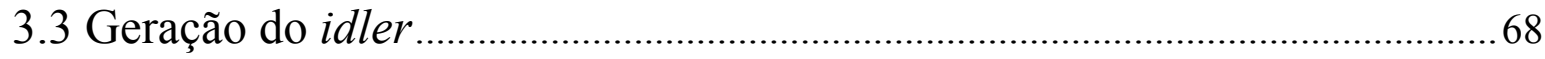

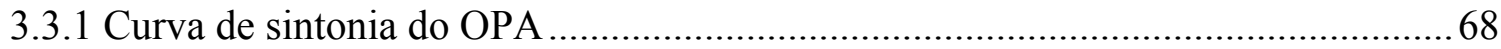

3.3.2 Projeto do suporte do cristal não-linear.............................................................. 70

3.3.3 Conversão de energia no OPA ………………………........................................

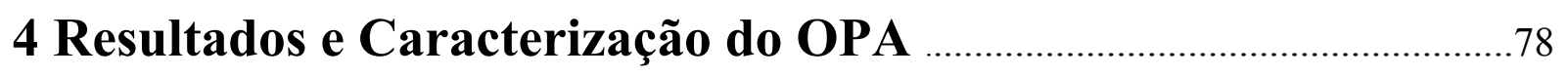

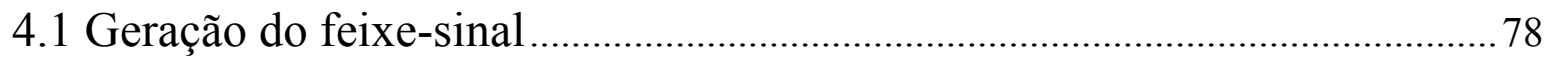

4.2 Seleção da semente do OPA pelo monocromador …………………………........97

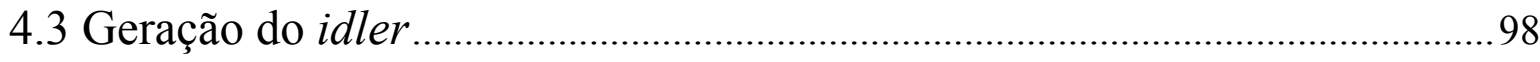

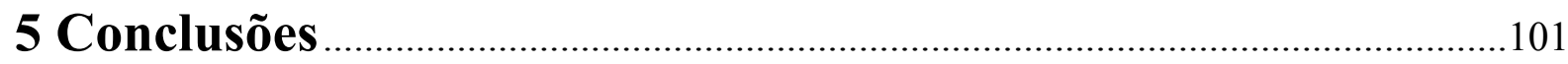

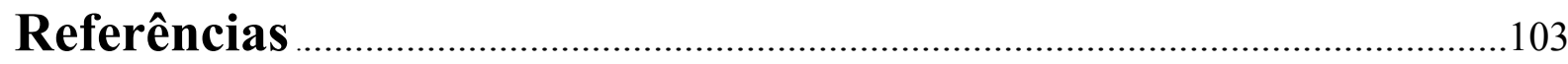





\section{Introdução}

Um amplificador paramétrico óptico (optical parametric amplifier - OPA) é uma fonte de luz coerente sintonizável sobre um amplo intervalo espectral que funciona baseado no processo de amplificação paramétrica óptica. A amplificação paramétrica óptica é um fenômeno não-linear de mistura de três ondas, que envolve a conversão de energia de um feixe bastante intenso (denominado feixe de bombeio, $\omega_{3}$ ) para um feixe de baixa intensidade (denominado feixe-sinal, $\omega_{1}$ ) e para um feixe gerado (denominado idler, $\omega_{2}$ ) quando estes se propagam por um meio não-linear ${ }^{1}$, geralmente um cristal não-linear, como ilustrado na figura 1 , onde a conservação de energia durante o processo é dada pela relação $\omega_{3}=\omega_{1}+\omega_{2}$ que está ilustrada na parte (a) da figura 2. Em geral denomina-se idler o feixe de mais baixa frequência $\left(\omega_{1}>\omega_{2}\right)$.

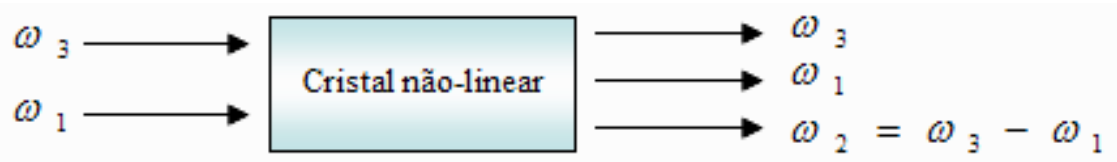

Figura 1 - Ilustração do processo de amplificação paramétrica óptica em um cristal não linear.

No entanto, para que a transferência de energia entre as ondas seja eficiente, deve ocorrer um casamento de fase entre as velocidades de fase das ondas, ou seja, é necessário que a relação entre os vetores de onda $\vec{K}_{3}=\vec{K}_{1}+\vec{K}_{2}$ seja satisfeita, e assim as contribuições às ondas $\omega_{1}$ e $\omega_{2}$ geradas em posições diferentes ao longo do cristal sejam somadas de forma coerente na face de saída. A figura 2 ilustra a situação em que o casamento de fase entre as ondas não é satisfeito, ou seja, a situação em que se tem $\Delta \vec{K}=\vec{K}_{3}-\vec{K}_{1}-\vec{K}_{2} \neq \overrightarrow{0}$, que é usual em um meio isotrópico dispersivo. Para conseguir o casamento de fases, geralmente utiliza-se a birrefringência do cristal não-linear. 
(a)

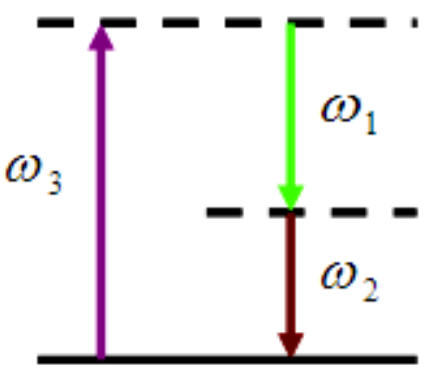

(b)

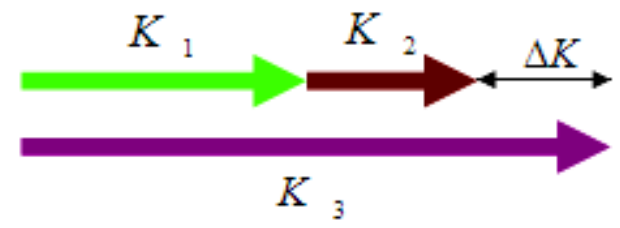

Figura 2 - Ilustração (a) do diagrama de energia do processo de amplificação paramétrica e (b) dos vetores de onda na situação em que não há casamento de fase entre as velocidades de fase das ondas.

A teoria do processo paramétrico de mistura de três ondas foi apresentada inicialmente em 1962 por Armstrong et al, onde a interação da luz com meios não-lineares foi tratada para situações em que há casamento de fase ou não ${ }^{2}$. O primeiro experimento que reportou uma amplificação paramétrica com ganho não trivial data de $1965^{3}$ e foi realizado por Wang e Racette, que relataram um ganho paramétrico da ordem de $1 \mathrm{db}$ na amplificação de um feixe de luz em $623 \mathrm{~nm}$ propagando-se por um cristal de fosfato de dihidrogênio e amônio (ADP), utilizando como bombeio o segundo harmônico de um laser de rubi. Em seguida, Boyd e Ashkin apresentaram medidas de amplificação paramétrica em um cristal de niobato de lítio $\left(\mathrm{LiNbO}_{3}\right.$ ), utilizando como bombeio um laser $\mathrm{CW}$ e comparando seus resultados com valores teóricos que levavam em conta uma distribuição gaussiana no perfil transversal dos feixes ${ }^{4}$. Em 1979 foram Baumgartener e Byer que contribuíram de forma significativa para a área, ao examinarem a solução teórica da amplificação paramétrica no regime em que há conversão de energia do feixe de bombeio para os feixes sinal e idler e compararem as soluções com resultados experimentais obtidos em amplificações paramétricas realizadas em cristais de fosfato de potássio deuterado $\left(\mathrm{KD}^{*} \mathrm{P}\right)$ e $\mathrm{LiNbO}_{3}{ }^{5}$. Contudo, havia limitações experimentais que comprometiam os resultados obtidos, tais limitações se deviam as baixas não-linearidades e baixos limiares de danos ópticos apresentados pelos cristais disponíveis na época, além da pouca qualidade das fontes de bombeio. Mas com o avanço na tecnologia dos lasers e cristais disponíveis, a comunidade cientifica passou a reconhecer a amplificação óptica paramétrica como uma versátil fonte de radiação laser sintonizável e os estudos e investigações desse processo se tornaram cada vez mais frequentes na literatura ${ }^{6,7,8}$.

Fontes de lasers pulsados de alta qualidade sintonizáveis na região do visível ao infravermelho médio são amplamente utilizadas em vários campos da ciência. Pulsos no regime de nanossegundos são muito utilizados, por exemplo, para estudar a atmosfera e monitorar a poluição através da técnica LIDAR (Laser Induced Detection And Ranging) ${ }^{9,10}$. Já as fontes pulsadas no regime de femtossegundos são uma importante ferramenta utilizada em 
espectroscopia ultra-rápida ${ }^{11,12}$. Entretanto, a grande largura espectral desses pulsos ultracurtos limita sua aplicação em espectroscopia de alta resolução. Essas limitações podem ser superadas com a espectroscopia multi-dimensional via transformada de Fourier $^{13}$, mas os experimentos ficam mais complexos e sua análise e interpretação tornam-se mais trabalhosas. Por outro lado, pulsos com duração de picossegundos permitem obter alta resolução espectral e ampla faixa de sintonia. Assim, pulsos ópticos coerentes de picossegundos, com alta potência e sintonizáveis sobre um amplo intervalo espectral são utilizados em muitas aplicações, como por exemplo, em espectroscopia resolvida no tempo para obter informações sobre propriedades fundamentais dos materiais, ou para caracterizar novos materiais ópticos não-lineares com boa resolução espectral.

O nosso principal objetivo em construir este OPA é a sua utilização em experimentos de espectroscopia vibracional e eletrônica de interfaces que se baseiam no processo óptico não-linear de geração de soma de frequências (sum-frequency generation - SFG) ${ }^{14,15}$. A espectroscopia vibracional de interfaces por SFG é uma técnica que possibilita obter a orientação média e a conformação das moléculas numa interface, além de possibilitar o estudo de interações moleculares (pontes de hidrogênio, interações eletrostáticas, e outras que modifiquem os modos vibracionais moleculares). Para SFG em interfaces, um feixe de frequencia fixa no visível $\left(\omega_{\mathrm{vis}}\right)$ e outro sintonizável no infravermelho médio $\left(\omega_{\mathrm{IV}}\right)$ incidem na amostra com ângulos de incidência $\theta_{1}$ e $\theta_{2}$, respectivamente. $O$ sinal refletido de frequência $\omega_{\text {soma }}=\omega_{\mathrm{IV}}+\omega_{\text {vis }}$ é emitido com ângulo de reflexão $\theta_{3}$ e passa por filtros espectrais e espaciais para então ser detectado por uma fotomultiplicadora. A figura 3 ilustra um esquema simplificado do espectrômetro SFG disponível em nosso laboratório de espectroscopia de interfaces (LENI). 


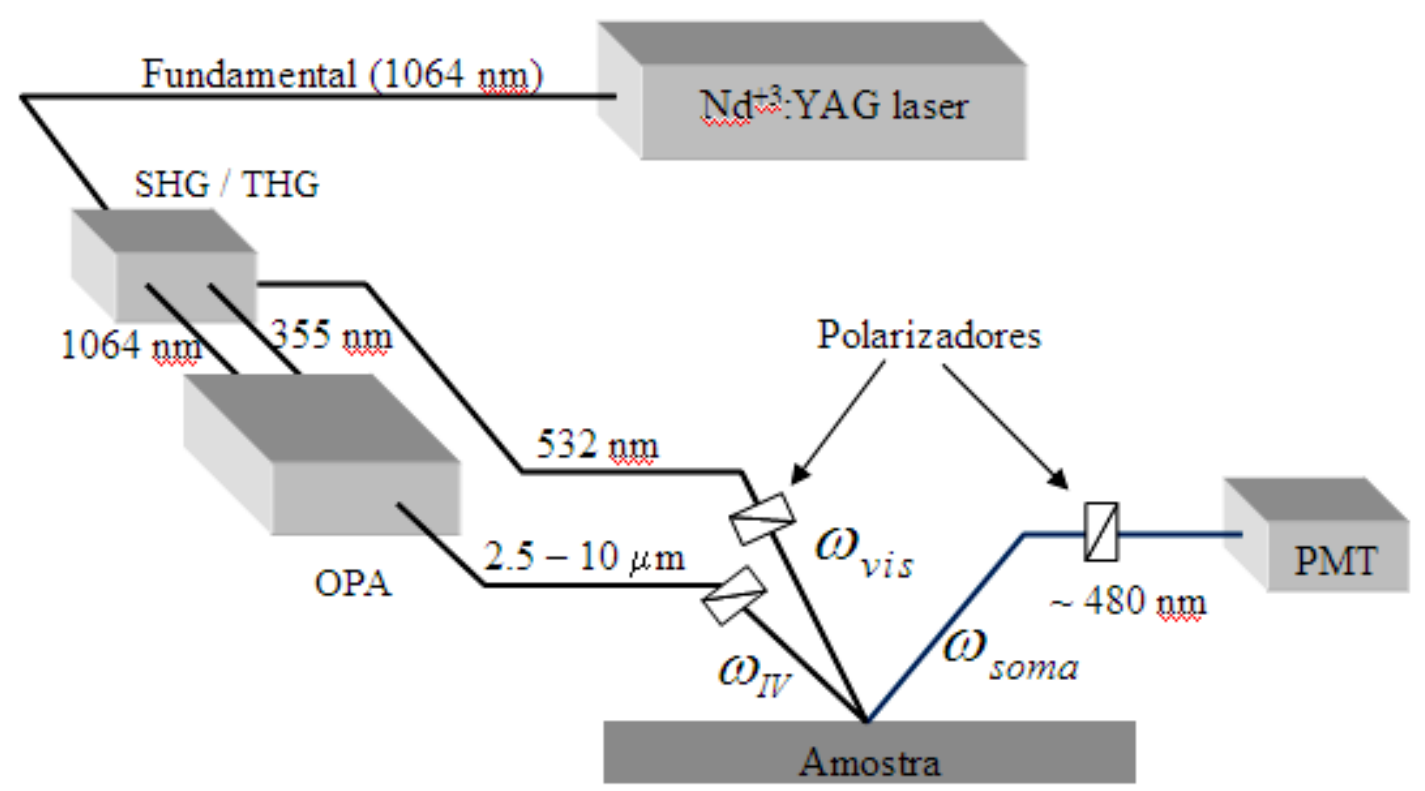

Figura 3 - Esquema simplificado do espectrômetro SFG do LENI.

Um laser de alta potência $\left(\mathrm{Nd}^{+3}\right.$ :YAG amplificado, $\lambda=1064 \mathrm{~nm}$, pulsos de $\sim 25 \mathrm{ps}, \sim$ $30 \mathrm{~mJ} /$ pulso, taxa de repetição $20 \mathrm{~Hz}$ ) bombeia um gerador/amplificador paramétrico (OPG/OPA), que produz o feixe sintonizável no infravermelho médio $(2,7$ a $10 \mu \mathrm{m})$ que é utilizado para excitar as vibrações moleculares $\left(\omega_{\mathrm{IV}}\right)$. O outro feixe visível de frequência fixa $\left(\omega_{\text {vis }}\right)$ é o segundo harmônico do laser de bombeio $(\lambda=532 \mathrm{~nm})$. Apesar do LENI já contar com um OPA comercial, um segundo OPA permitirá utilizar feixes independentemente sintonizáveis no infravermelho médio e no visível, abrindo a possibilidade de fazer espectroscopia não-linear duplamente ressonante, ou evitar dano óptico às amostras escolhendo $\omega_{\text {vis }}$ fora da região de absorção da amostra.

Os OPAs disponíveis no domínio de picossegundos são compostos em geral por dois estágios, como ilustrado na figura 4; a geração paramétrica óptica (Optical Parametric Generation - OPG) e a amplificação paramétrica óptica (optical parametric amplification OPA) $)^{16,17}$. 


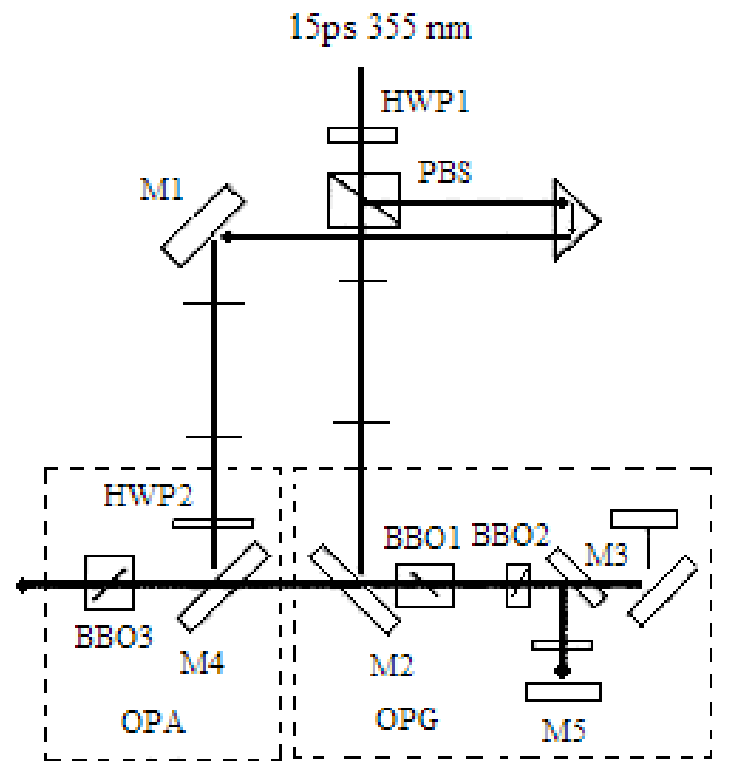

Figura 4 - Configuração experimental de um OPA de picossegundo ${ }^{18}$.

O feixe de bombeio é dividido em duas partes: uma é usada para bombear o estágio de geração paramétrica e a outra é usada para bombear o estágio de amplificação paramétrica. No estágio OPG dois pulsos sintonizáveis são gerados a partir da amplificação do vácuo ou ruído quântico (fluorescência paramétrica) através de um processo não-linear de segunda ordem, onde a amplificação ocorre para os comprimentos de onda que tem a condição de casamento de fase satisfeita. O intervalo de frequência gerado no estágio OPG é usado como semente para o estágio de amplificação óptica. No estágio de amplificação, o feixe sinal (ou idler) gerado no estágio OPG interage com o feixe de bombeio promovendo a amplificação do feixe sinal (ou idler) e a geração do feixe idler (ou sinal). Em alguns casos, utiliza-se ainda um estágio de geração de diferença de frequências (DFG) para estender a faixa de sintonia no infravermelho médio através da geração de $\left(\omega_{\mathrm{B}}-\omega_{\mathrm{I}}\right)$, onde $\omega_{\mathrm{B}}$ é um feixe de bombeio de frequência fixa apropriada e $\omega_{\mathrm{I}}$ é, por exemplo, o feixe idler do estágio de amplificação paramétrica. Trata-se, portanto, de dispositivos relativamente complexos devido a grande quantidade de elementos ópticos envolvidos.

Os OPAs no domínio de femtossegundos também são encontrados na configuração ilustrada pela figura 4, contudo, a técnica mais comum para geração da semente é a geração de supercontínuo de "luz branca", ilustrada na figura 5. O OPA é bombeado por um laser Ti:safira $(\lambda \sim 800 \mathrm{~nm}, \tau \sim 100 \mathrm{fs})$. Uma pequena parcela do bombeio é utilizada para gerar a "luz branca" em uma fina placa de safira (1 ou $2 \mathrm{~mm}$ de espessura); a fração no infravermelho próximo do contínuo gerado é então amplificada no estágio de amplificação paramétrica formada por dois cristais de $\beta$-borato de bário (BBO). 


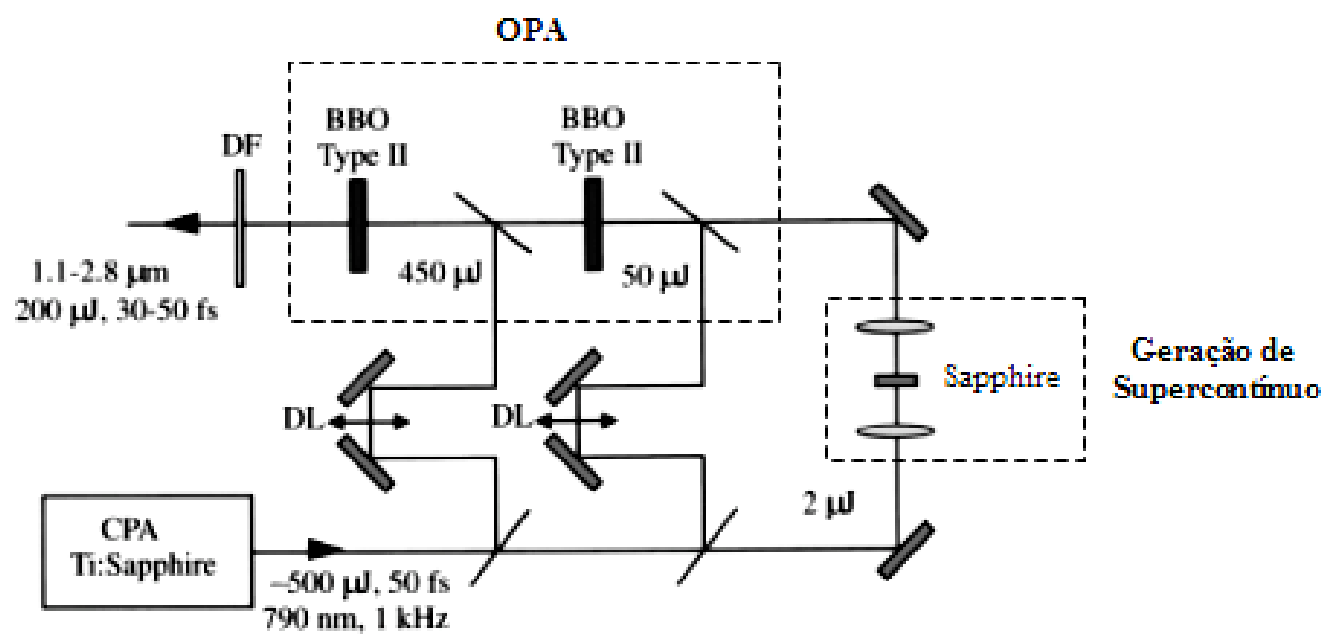

Figura 5 - Esquema de um OPA em fs. DL: linha de atraso (delay line); DF: filtro dicróico (dichroic filter) ${ }^{19}$.

A geração de luz supercontínua é um fenômeno físico que ocorre devido a uma combinação de processos não-lineares, onde um pulso centrado em uma dada frequência tem seu espectro alargado ao se propagar por um meio material transparente com não-linearidade de terceira ordem. Por exemplo, quando um feixe de laser em $800 \mathrm{~nm}$, com pulsos de $100 \mathrm{fs}$ é focalizado em uma placa de safira (com espessura entre 1 e $3 \mathrm{~mm}$ ), o espectro do contínuo gerado se estende do visível $(\sim 420 \mathrm{~nm})$ até o infravermelho próximo $(\sim 1500 \mathrm{~nm})^{19}$.

Inspirados pelo design dos OPAs que operam no regime de femtossegundos e na tentativa de obtermos uma geração de infravermelho bastante eficiente, propomos um projeto inovador para amplificadores paramétricos de picossegundos, utilizando a geração de supercontínuo de "luz branca" como feixe-sinal do amplificador paramétrico óptico. A figura 6 ilustra um diagrama esquemático do OPA a ser construído. O pulso de bombeio $(\lambda=1064$ $\mathrm{nm})$ é dividido em duas partes: a primeira, de menor energia, gera um pulso de alta largura espectral no infravermelho próximo (supercontínuo de "luz branca" de picossegundos) que deverá cobrir o intervalo entre 1200 e $1800 \mathrm{~nm}$. Uma fração espectral desse pulso é selecionada através de um monocromador e utilizada como semente no estágio de amplificação paramétrica. O cristal amplificador paramétrico é bombeado pelo restante do pulso de bombeio e simultaneamente amplifica o sinal sintonizável no infravermelho próximo e gera um novo pulso de frequência complementar no infravermelho médio. Esse esquema é semelhante ao utilizado em OPA's de pulsos ultracurtos $(\sim 100 \mathrm{fs})^{19,20}$, exceto que é introduzido um monocromador para reduzir a largura espectral do pulso semente que determina a largura de banda do pulso final no infravermelho médio. Tal configuração apresenta a vantagem de ser mais simples e potencialmente bem mais eficiente, visto que 
elimina a necessidade de usar harmônicos do laser como feixe de bombeio, além de eliminar os estágios OPG e DFG. O maior desafio será conseguir uma geração de supercontínuo de ps estável o suficiente e com a largura espectral desejada.

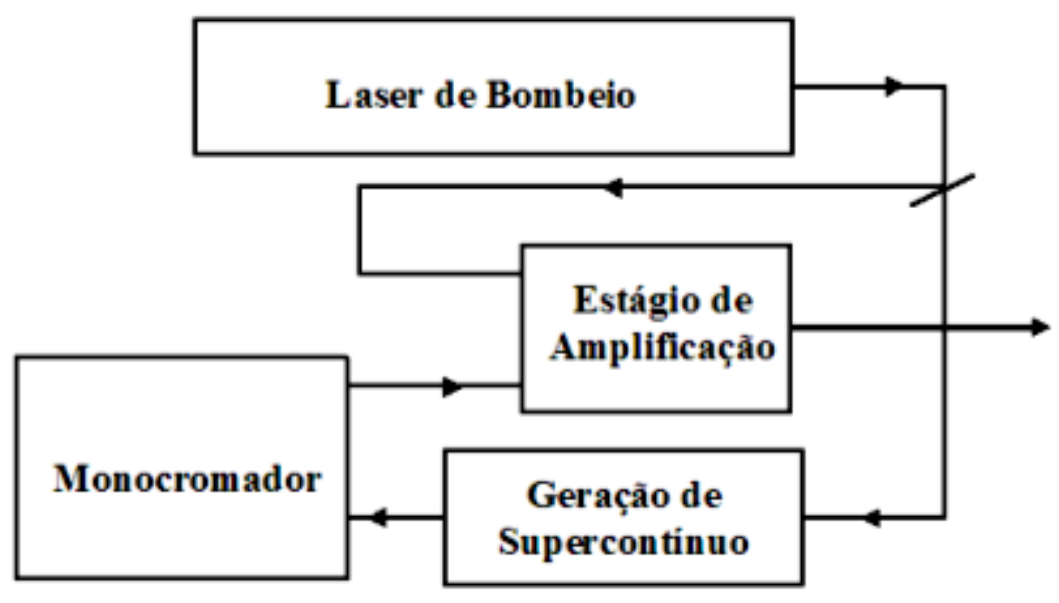

Figura 6 - Diagrama esquemático do projeto do OPA.

Por se tratar o OPA de um dispositivo cujo principio de funcionamento está baseado em efeitos de óptica não-linear, uma revisão de tais efeitos torna-se necessária para a discussão dos resultados obtidos. Dessa forma, o capítulo 2 é dedicado à revisão dos efeitos não-lineares mais pertinentes a esse trabalho. O capítulo 3 é dedicado ao projeto do OPA, que foi dividido em três unidades principais: geração de supercontínuo, monocromador e amplificador paramétrico. No capítulo 4 encontra-se a montagem e caracterização do OPA. No capítulo 5 o trabalho é então concluído. 


\section{Fundamentos Teóricos}

\subsection{Regime da óptica não-linear}

A óptica não-linear é a área da Física que engloba os estudos da interação da luz com a matéria no regime em que a amplitude do campo óptico aproxima-se da ordem do campo atômico, sendo assim, experimentos no campo da óptica não-linear só foram possíveis de serem realizados a partir de 1961 com o advento do laser, uma fonte de alta intensidade.

No regime da óptica linear a polarização induzida em um meio pela incidência de um campo elétrico é dada por $^{21}$ :

$$
\vec{P}=\vec{\chi}^{(1)} \vec{E}
$$

onde a constante $\vec{\chi}^{(1)}$ é conhecida como suscetibilidade linear do meio e para materiais anisotrópicos é um tensor de posto dois.

Já no regime de altas intensidades, essa polarização pode ser expressa por uma expansão em série de potências do campo elétrico:

$$
\vec{P}=\vec{\chi}^{(1)} \vec{E}+\vec{\chi}^{(2)}: \vec{E}^{2}+\vec{\chi}^{(3)}: \vec{E}^{3}+\cdots
$$

As quantidades $\ddot{\chi}^{(2)}$ e $\ddot{\chi}^{(3)}$ são conhecidas como suscetibilidade não-linear de segunda e terceira ordem respectivamente, que nesse caso são respectivamente tensores de posto três e quatro. Ao escrevermos as eqs (2.1) e (2.2), assumimos a resposta da polarização como sendo instantânea com o campo elétrico, o que pelas relações de Kramers-Kronig implica em um material sem perda e sem dispersão ${ }^{21,22}$. Podemos então separar a polarização induzida no meio em um termo linear e um termo não-linear:

$$
\vec{P}=\overrightarrow{P^{(1)}}+\overrightarrow{P^{N L}}
$$


onde o papel do termo não-linear da polarização é o de agir como fonte de novas frequências em processos não-lineares.

\subsubsection{A polarização não-linear agindo como fonte de novas frequências}

Para que fique mais claro qual a origem das novas componentes de frequências ópticas que surgem em um processo não-linear, vamos apresentar a equação de onda no domínio da óptica não-linear.

No sistema gaussiano de unidades, as equações de Maxwell são escritas na forma ${ }^{21}$ :

$$
\begin{gathered}
\vec{\nabla} \times \vec{E}=-\frac{1}{c} \frac{\partial \vec{B}}{\partial t} \\
\vec{\nabla} \times \vec{H}=\frac{1}{c} \frac{\partial \vec{D}}{\partial t}+\frac{4 \pi \vec{J}}{c} \vec{J} \\
\vec{\nabla} \cdot \vec{D}=4 \pi \rho \\
\vec{\nabla} \cdot \vec{B}=0
\end{gathered}
$$

onde $\vec{E}$ e $\vec{H}$ são os vetores campo elétrico e magnético respectivamente, $\vec{D}$ e $\vec{B}$ são as correspondentes densidades de fluxo elétrico e magnético dadas pelas relações constitutivas:

$$
\begin{aligned}
& \vec{D}=\vec{E}+4 \pi \vec{P} \\
& \vec{B}=\vec{H}+4 \pi \vec{M}
\end{aligned}
$$

com $\vec{P}$ sendo a polarização elétrica dada pela eq. (2.2) e $\vec{M}$ a magnetização induzidas no meio. 
Em regiões do espaço caracterizadas pala ausência de cargas livres $(\rho=0)$ e correntes livres $(\vec{J}=0)$ e ainda tratando-se de materiais não-magnéticos $(\vec{B}=\vec{H})$, podemos obter a equação de onda que descreve a propagação da luz em um meio dielétrico calculando-se inicialmente o rotacional da eq. (2.4), invertendo-se a ordem das derivadas no tempo e no espaço e em seguida utilizando as eqs. (2.5) e (2.8) respectivamente para obtermos a forma mais geral da equação de onda no domínio da óptica não-linear:

$$
\vec{\nabla} \times \vec{\nabla} \times \vec{E}+\frac{1}{c^{2}} \frac{\partial^{2} \vec{E}}{\partial t^{2}}=-\frac{4 \pi}{c^{2}} \frac{\partial^{2} \vec{P}}{\partial t^{2}}
$$

Para tornar ainda mais explicita a função do termo não-linear da polarização na eq. (2.10), substituiremos a eq. (2.3) na eq. (2.8) e então escreveremos a densidade de fluxo magnético em função de suas partes linear e não-linear:

$$
\vec{D}=\overrightarrow{D^{(1)}}+4 \pi \overrightarrow{P^{N L}}
$$

com a parte linear dada por:

$$
\overrightarrow{D^{(1)}}=\vec{E}+4 \pi \overrightarrow{P^{(1)}}
$$

Isolando o campo elétrico, $\vec{E}$, na eq. (2.12) e substituindo o mesmo junto com a eq. (2.3) na eq. (2.10), temos:

$$
\vec{\nabla} \times \vec{\nabla} \times \vec{E}+\frac{1}{c^{2}} \frac{\partial^{2} \overrightarrow{D^{(1)}}}{\partial t^{2}}=-\frac{4 \pi}{c^{2}} \frac{\partial^{2} P^{N L}}{\partial t^{2}}
$$

Para o caso de um meio dispersivo onde a dissipação pode ser ignorada, a relação entre cada componente de frequência de $\vec{D}^{(1)}$ e $\vec{E}$ pode ser expressa em termos de um tensor real dependente da frequência ${ }^{21}$ :

$$
\overrightarrow{D^{(1)}}(\omega)=\varepsilon^{(1)}(\omega) \cdot \vec{E}(\omega)
$$


Inserindo a eq. (2.14) na eq. (2.13) e calculando a derivada temporal, chegamos finalmente na equação de onda:

$$
\vec{\nabla} \times \vec{\nabla} \times \vec{E}-\varepsilon^{(1)}(\omega) \frac{\omega^{2}}{c^{2}} \vec{E}(\omega)=4 \pi \frac{\omega^{2}}{c^{2}} \overrightarrow{P^{N L}}(\omega)
$$

que é válida para cada componente de frequência do campo elétrico.

A equação de onda escrita na forma dada pela eq. (2.13) ou (2.15) torna explícito o papel da polarização não-linear na descrição dos fenômenos ópticos não-lineares, que é agir como fonte de novas componentes do campo eletromagnético, onde esses fenômenos podem ser classificados como sendo processos de segunda ou terceira ordem dependendo se é a suscetibilidade de segunda ordem, $\chi^{(2)}$, ou a suscetibilidade de terceira ordem, $\chi^{(3)}$, a responsável por tais processos.

\subsection{Amplificação paramétrica óptica}

Processos ópticos não-lineares de segunda ordem como geração de soma de frequências (Sum-Frequency Generation - SFG), geração de diferença de frequência (Difference-Frequency Generation - DFG), geração paramétrica óptica (Optical Parametric Generation - OPG), e amplificação paramétrica óptica (Optical Parametric Amplification OPA) são comumente conhecidos como conversores de frequência e são amplamente utilizados em sistemas de conversão de luz laser em um amplo intervalo espectral sintonizável. Assim como o processo de geração de diferença de frequência, os processos de geração e amplificação paramétrica são processos de mistura de três ondas, envolvendo a conversão de energia de um feixe de bombeio com frequência $\omega_{3}$ para um feixe-sinal de frequência $\omega_{1}$ e para um feixe idler de frequência complementar $\omega_{2}=\omega_{3}-\omega_{1}$, com a diferença que na geração paramétrica apenas o feixe de bombeio incide sobre o meio nãolinear, sendo gerados os feixes sinal e idler, enquanto que no processo de geração de diferença de frequência e na amplificação paramétrica incidem sobre o cristal o feixe de bombeio e o feixe-sinal, sendo gerado o feixe idler e amplificado o feixe-sinal. A única diferença entre os 
processos de geração de diferença de frequência e amplificação paramétrica é que no segundo a intensidade do feixe-sinal é muito menor que a do feixe de bombeio ${ }^{23}$.

\subsubsection{DFG / Amplificação Paramétrica Óptica}

Uma vez que uma das unidades principais do OPA é o estágio de amplificação paramétrica, que como vimos anteriormente trata-se de um fenômeno não-linear de geração de diferença de frequências, vamos descrever em mais detalhes tais processos.

Vamos considerar a situação ilustrada na figura 7, onde um feixe de bombeio com frequência $\omega_{3}$ e um feixe-sinal de frequência $\omega_{1}$ incidem em um meio com não-linearidade de segunda ordem gerando um feixe idler de frequência $\omega_{2}=\omega_{3}-\omega_{1}$.

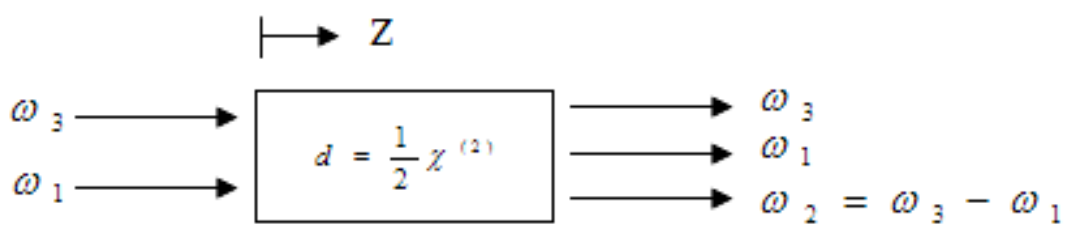

Figura 7 - Ilustração do processo de geração de diferença de frequências: uma onda de frequência $\omega_{3}$ e uma onda de frequência $\omega_{1}$ incidem sobre um meio com suscetibilidade de segunda ordem gerando uma onda de frequência $\omega_{2}=\omega_{3}-\omega_{1}$.

Considerando que os feixes que incidem no material são ondas planas e monocromáticas e que a incidência é normal, podemos escrever os campos elétricos das ondas que participam do processo na forma:

$$
\begin{aligned}
& E_{1}(z, t)=A_{1}(z) e^{i K_{1} z} e^{-i \omega_{1} t}+c . c . \\
& E_{2}(z, t)=A_{2}(z) e^{i K_{2} z} e^{-i \omega_{2} t}+c . c . \\
& E_{3}(z, t)=A_{3}(z) e^{i K_{3} z} e^{-i \omega_{3} t}+\text { c.c. }
\end{aligned}
$$

onde c.c. significa complexo conjugado. 
Vamos considerar que a onda $\omega_{3}$ é muito mais intensa que as outras e, portanto, a amplitude $A_{3}$ do campo elétrico do feixe de bombeio pode ser considerada constante. Também vamos considerar que o comprimento do cristal $L_{C}$, é menor que o comprimento de interação não-linear $L_{N L}$, definido como o comprimento do meio não-linear necessário para que haja uma transferência de energia significativa entre as ondas acopladas. A situação descrita anteriormente é conhecida como regime sem depleção do feixe de bombeio.

Temos que $K_{i}$ é o vetor de onda da i-ésima onda e é dado por:

$$
K_{i}=\frac{n_{i} \omega_{i}}{c}=\frac{\sqrt{\varepsilon^{(1)}\left(\omega_{i}\right)} \omega_{i}}{c}
$$

O processo de DFG / OPA é descrito por uma polarização não-linear da forma ${ }^{21}$ :

$$
\vec{P}\left(\omega_{3}-\omega_{1}\right)=4 d \vec{E}_{3} \vec{E}_{1}^{*}
$$

que pode ser obtida somando dois campos óptico de frequências distintas incidentes em um meio não-linear caracterizado por uma suscetibilidade $\chi^{(2)}$ e substituindo o campo resultante na eq. (2.2) e em seguida separando os termos associados à suscetibilidade de segunda ordem que oscilam na frequência $\left(\omega_{3}-\omega_{1}\right)$.

Fazendo uso das equações (2.20), (2.16) e (2.17), podemos representar as polarizações não-lineares induzidas no meio pelas ondas $\omega_{1}, \omega_{2}$ e $\omega_{3}$ como:

$$
\begin{aligned}
& \vec{P}_{1}(z, t)=\vec{P}\left(\omega_{3}-\omega_{2}\right)=4 d \vec{A}_{3} \vec{A}_{2}^{*} \exp \left\{i\left(K_{3}-K_{2}\right) z\right\} \exp \left\{-i \omega_{1} t\right\}+c . c . \\
& \vec{P}_{2}(z, t)=\vec{P}\left(\omega_{3}-\omega_{1}\right)=4 d \vec{A}_{3} \vec{A}_{1}^{*} \exp \left\{i\left(K_{3}-K_{1}\right) z\right\} \exp \left\{-i \omega_{2} t\right\}+c . c .
\end{aligned}
$$

Substituindo as eqs. (2.16), (2.19) e (2.21) na equação de onda dada pela eq. (2.15) e, utilizando a aproximação da amplitude variando lentamente no tempo (slowly-varyingamplitude), onde temos que $\left|\frac{d^{2} A_{1}}{d z^{2}}\right|<<\left|\mathrm{K}_{1} \frac{d A_{1}}{d z}\right|$, chegamos em: 


$$
\frac{d A_{1}}{d z}=\frac{8 \pi i d \omega_{1}^{2}}{K_{1} c^{2}} A_{3} A_{2}^{*} \exp \{i \Delta K . z\}
$$

Analogamente, utilizando as eqs. (2.17) e (2.22) obtemos:

$$
\frac{d A_{2}}{d z}=\frac{8 \pi i d \omega_{2}^{2}}{K_{2} c^{2}} A_{3} A_{1}^{*} \exp \{i \Delta K . z\}
$$

onde introduzimos a grandeza denominada phase mismatch, $\Delta K=K_{3}-K_{1}-K_{2}$.

Enquanto a eq. (2.23) mostra como a amplitude da onda $\omega_{1}$ depende das amplitudes das ondas $\omega_{3}$ e $\omega_{2}$, a eq. (2.24) mostra como a amplitude da onda $\omega_{2}$ depende das amplitudes das ondas $\omega_{3}$ e $\omega_{1}$, sendo portanto equações acopladas.

Para o caso em que temos $\Delta K=0$, dizemos que há casamento de fase perfeito (nesse caso a intensidade do feixe gerado alcança um valor máximo) e podemos resolver facilmente as eqs. acopladas (2.23) e (2.24) no regime sem depleção do bombeio ( $A_{3}=$ constante), chegando nas equações das amplitudes dos campos $\omega_{1}$ e $\omega_{2}$ :

$$
\begin{gathered}
A_{1}(z)=A_{1}(0) \cosh (\kappa z) \\
A_{2}(z)=i\left(\frac{n_{1} \omega_{2}}{n_{2} \omega_{1}}\right)^{1 / 2} \frac{A_{3}}{\left|A_{3}\right|} A_{1}^{*}(0) \sinh (\kappa z)
\end{gathered}
$$

onde introduzimos a constante de acoplamento, $\kappa$, dada pela relação:

$$
\kappa^{2}=\frac{64 \pi^{2} d^{2} \omega_{1}^{2} \omega_{2}^{2}}{K_{1} K_{2} c^{4}}\left|A_{3}\right|^{2}
$$

Na figura 8 podemos observar como as amplitudes dos campos ópticos se comportam em função da distância percorrida pela luz no cristal. Como podemos observar, tanto o feixesinal, quanto o feixe idler, são amplificados conforme se propagam pelo cristal e é devido a essa amplificação do feixe-sinal que o processo é conhecido por amplificação paramétrica óptica. O processo DFG é análogo, mas com a intensidade inicial do feixe-sinal comparável à do feixe de bombeio. 


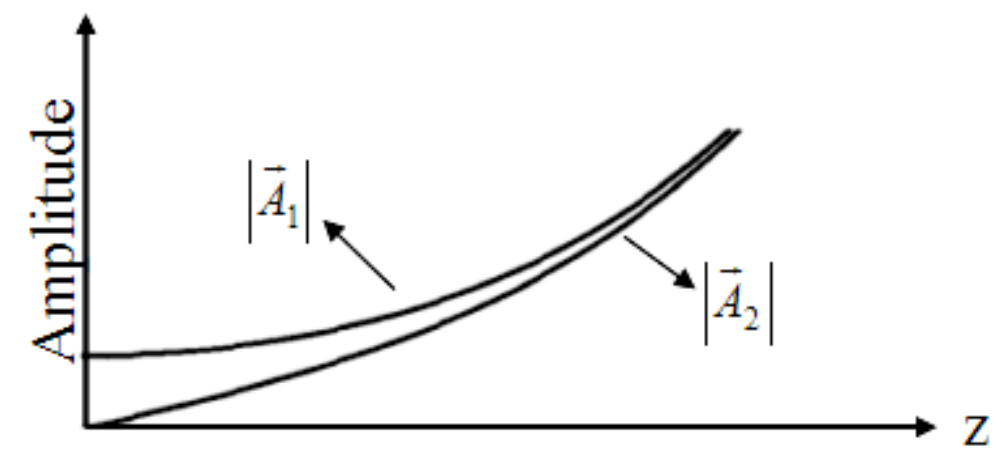

Figura 8 - Dependência das amplitudes $\vec{A}_{1}$ e $\vec{A}_{2}$ com a distância $z$ percorrida no cristal para o processo de amplificação paramétria óptica em que há casamento de fase. Figura adaptada da referência 21.

Para o caso geral, em que $\Delta \vec{K} \neq 0$, a evolução espacial das intensidades do feixe idler $\vec{A}_{2}$, e do feixe-sinal $\vec{A}_{1}$, dependerão do mismatch dos vetores de onda e o ganho do processo será menor, podendo as intensidades apresentar variações senoidais ${ }^{2}$. A solução para esse caso geral pode ser encontrada no capítulo 2 da referência 21 .

\subsubsection{Casamento de fase}

Como vimos na seção anterior, a eficiência do processo de DFG / OPA depende diretamente da condição de casamento de fase, $\Delta K=0$, que em termos do índice de refração podemos escrever para o caso colinear como sendo (utilizando a eq. 2.19):

$$
n_{3} \omega_{3}-n_{1} \omega_{1}-n_{2} \omega_{2}=0
$$

Contudo, quando tratamos de materiais isotrópicos a eq. (2.28) não pode ser satisfeita no regime de dispersão normal, que é quando o índice de refração diminui com o aumento do comprimento de onda, mas apenas no regime de dispersão anômala, que é quando o índice de refração aumenta com o aumento do comprimento de onda. Podemos visualizar com maior facilidade essa afirmação reescrevendo a eq. (2.28) na seguinte forma:

$$
n_{3}-n_{1}=\left(n_{2}-n_{1}\right) \frac{\omega_{2}}{\omega_{3}}
$$


Note que no caso do fenômeno de DFG / OPA temos $\omega_{3}>\omega_{1}>\omega_{2}$, logo, teremos sempre $n_{3}>n_{1}>n_{2}$, ou seja, no regime de dispersão normal o lado esquerdo da eq. (2.29) assumirá sempre valores positivos enquanto que o lado direito valores negativos. Uma outra forma de satisfazer a eq. (2.28) é com o uso da birrefringência em cristais ópticos não-lineares anisotrópicos. Nesses cristais, a birrefringência faz com que o índice de refração experimentado por um feixe dependa da sua polarização e direção de propagação.

\section{$\underline{\text { Cristais Uniaxiais }}$}

No presente projeto iremos trabalhar com o cristal óptico não-linear sulfeto de prata e gálio ( $\left.\mathrm{AgGaS}_{2}-\mathrm{AGS}\right)$, que é um cristal uniaxial, o que justifica uma breve discussão sobre os mesmos.

Um cristal uniaxial possui uma direção particular chamada de eixo óptico (ou eixo Z), o plano que contem o eixo óptico mais o vetor de onda, $\vec{K}$, da onda incidente é conhecido como plano principal. O feixe de luz que possui polarização perpendicular ao plano principal é chamado de feixe ordinário e experimenta um índice de refração que não depende da sua direção de propagação (índice de refração ordinário), como ilustrado na figura 9.

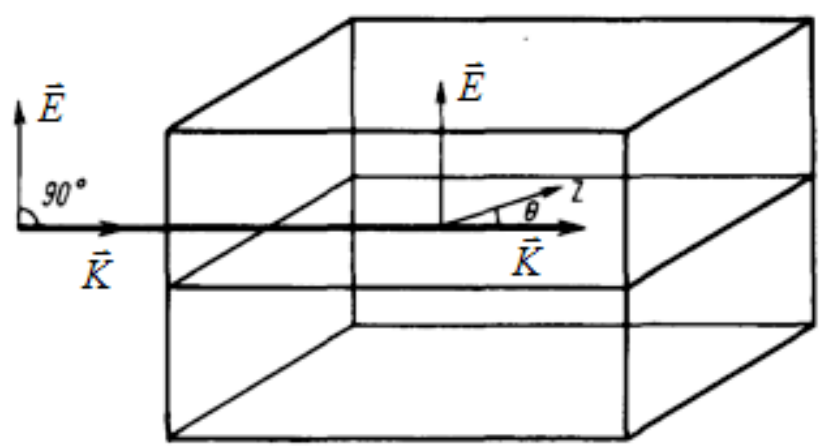

Figura 9 - Feixe de luz ordinário incidindo em um cristal uniaxial ${ }^{24}$.

O feixe de luz que apresenta polarização paralela ao plano principal é chamado de feixe extraordinário e experimenta um índice de refração que depende da sua direção de propagação no cristal, ou seja, este índice (denominado índice de refração extraordinário), em 
geral depende do ângulo $\theta$ formado entre o eixo $\mathrm{Z}$ e o vetor de onda da luz, conforme dado pela eq. $(2.30)^{24}$ e indicado na figura 10 .

$$
n^{e}(\theta)=n_{o} \sqrt{\frac{1+\tan ^{2} \theta}{1+\left(n_{o} / n_{e}\right)^{2} \tan ^{2} \theta}}
$$

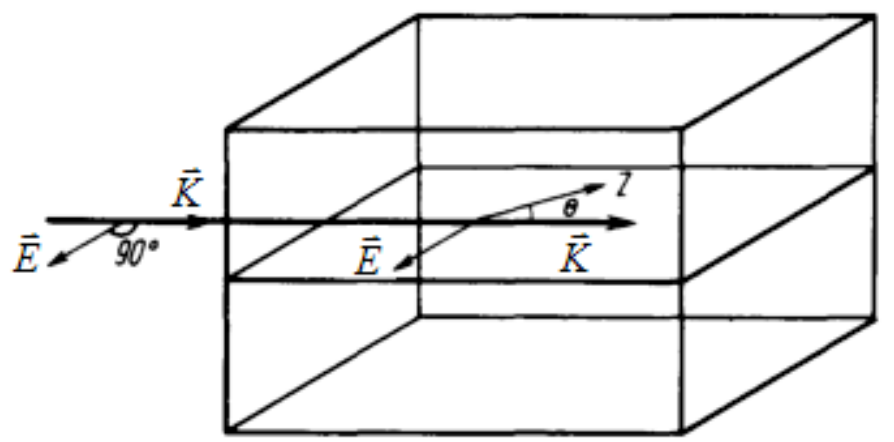

Figura 10 - Feixe de luz extraordinário incidindo em um cristal uniaxial ${ }^{24}$.

Na eq. (2.30), $n_{o}$ e $n_{e}$ são respectivamente os índices de refração ordinário e extraordinário no plano normal ao eixo óptico, conhecidos como valores principais do índice de refração. $\mathrm{O}$ cristal é dito uniaxial positivo se $n_{o}<n_{e}$ e é dito negativo caso $n_{o}>n_{e}$.

Ao analisarmos a eq. (2.29) podemos observar que para que essa seja satisfeita com o uso de um cristal uniaxial, é necessário que a onda de maior frequência seja polarizada na direção que corresponde ao menor índice de refração.

Caso as duas ondas de menor frequência tenham a mesma polarização teremos o chamado casamento de fase tipo I, caso estas sejam ortogonais teremos o casamento de fase tipo II.

Desta forma, a otimização do processo de DFG / OPA consiste em encontrar o ângulo $\theta$ que forneça o valor de $n^{e}(\theta)$ capaz de satisfazer a condição $\Delta K=0$; este ângulo é conhecido como ângulo de casamento de fase. 


\subsection{Geração de supercontínuo de "luz branca"}

A geração de "luz branca" é um fenômeno físico que ocorre devido a processos nãolineares de terceira ordem, e portanto descritos pelo coeficiente $\chi^{(3)}$ da eq. (2.2). O fenômeno de geração de supercontínuo de "luz branca" foi demonstrado pela primeira vez por Alfano e Shapiro em 1970 que, ao bombearem diversas amostras com pulsos de picossegundos e comprimento de onda em $530 \mathrm{~nm}$, obtiveram nas saídas das amostras luz branca cobrindo uma ampla faixa espectral ${ }^{25}$. Desde então, esse fenômeno vem sendo alvo de inúmeros estudos e investigações nos mais diversos meios, sejam esses meios líquidos ${ }^{26,27}$, sólidos ${ }^{28}$, ou gases $^{29}$, tendo sido relatados alargamentos espectrais nas regiões do visível ${ }^{30}$, infravermelho ${ }^{31}$ e ultravioleta ${ }^{32}$.

Durante a geração do supercontínuo, há diversos processos físicos que contribuem para o alargamento espectral, contudo, são fatores como o regime de bombeio e o material bombeado que vão determinar os processos que predominam. Entre os efeitos não-lineares que estão presentes na geração de supercontínuo temos; auto-focalização da luz, self-trapping da luz, auto-modulação de fase, espalhamento Raman estimulado e mistura de quatro ondas.

\subsubsection{Auto-focalização da luz}

Cristais com estrutura centro-simétrica que exibem simetria de inversão, possuem seu coeficiente $\chi^{(2)}$ com valor nulo, ou seja, nesses cristais só poderão ocorrer processos nãolineares de ordem ímpar com o campo elétrico ${ }^{21,22}$. Nesse caso a polarização induzida no meio dada anteriormente pela eq. (2.2), pode agora ser escrita na forma:

$$
\vec{P}=\vec{\chi}^{(1)} \cdot \vec{E}+\vec{\chi}^{(3)}: \vec{E}^{3}
$$

No caso mais geral, em que o campo óptico incidente no cristal é composto por varias componentes de frequências distintas, é muito complicado estudar analiticamente a resposta 
do meio a este campo. Contudo, com o objetivo de apenas ilustrar o fenômeno, podemos considerar o caso mais simples em que o campo incidente é monocromático e dado por:

$$
\vec{E}(t)=\vec{E}_{0} \cos (\omega t)
$$

Substituindo a eq. (2.32) na eq. (2.31) temos que a polarização induzida no meio é dada por:

$$
\vec{P}=\vec{\chi}^{(1)} \cdot \vec{E}_{0} \cos (\omega t)+\vec{\chi}^{(3)} \vdots \vec{E}_{0}^{3}\left[\frac{1}{4} \cos (3 \omega t)+\frac{3}{4} \cos (\omega t)\right]
$$

onde o segundo termo desta equação corresponde a contribuição de terceira ordem para a polarização total, no qual podemos notar um termo que descreve uma resposta do meio a uma frequência $3 \omega$ (geração de terceiro harmônico), e um termo que descreve uma contribuição não-linear para a polarização com a mesma frequência que o campo incidente. $O$ índice de refração na presença deste tipo de não-linearidade passa a depender da intensidade óptica da radiação que se propaga através desse meio, essa dependência pode ser escrita na forma:

$$
n=n_{0}+n_{2} I
$$

onde $n_{0}$ é o índice de refração do material na ausência do campo elétrico, $I=\left(n_{0} c / 8 \pi\right) E_{0}^{2}$ é a intensidade do campo óptico e $n_{2}$ é o índice de refração não-linear do material. Onde o índice de refração não-linear está relacionado com a parte real de $\chi^{(3) 21}$ :

$$
n_{2}=\frac{12 \pi^{2}}{n_{0}^{2} c} \operatorname{Re}\left[\chi^{(3)}\right]
$$

O índice de refração não-linear de um determinado material pode ser tanto positivo quanto negativo; quando o mesmo é positivo um fenômeno muito interessante ocorre, a autofocalização. Um pulso óptico que apresenta um perfil transversal de intensidade, como o ilustrado na figura 11, ao incidir em um material com o índice de refração dado pela eq. (2.34), terá a sua região central experimentando um índice de refração maior que a sua região periférica, ou seja, o caminho óptico percorrido pelo centro do feixe será maior que o percorrido pela borda do feixe, conferindo um efeito de lente convergente ao material. 


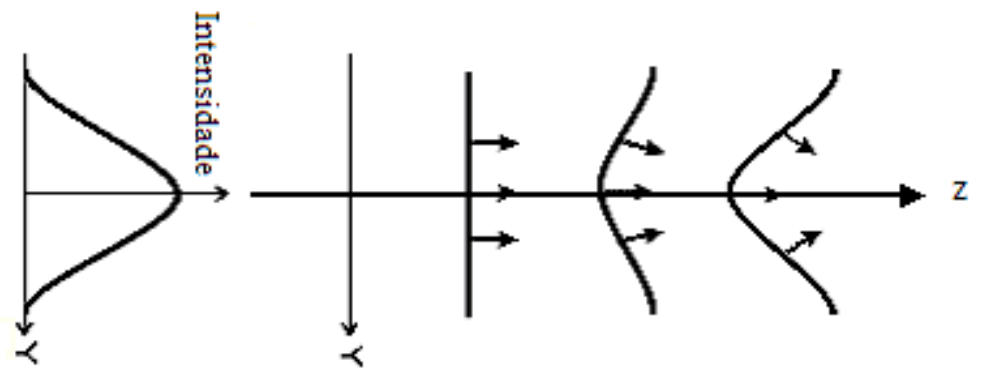

Figura 11 - Auto-focalização da luz.

Quando a tendência do feixe de se auto-focalizar compensa a divergência natural do mesmo devido à difração, ocorre um fenômeno conhecido por self-trapping da luz, que é a formação de um filamento com um diâmetro, $d$, bem definido por uma longa distância dentro do material e com altíssimas intensidades.

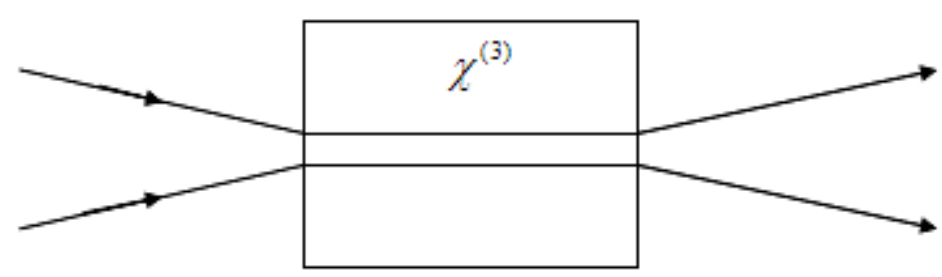

Figura 12 - Self-Trapping da luz no material.

Existe uma potência óptica especifica para a qual o self-trapping pode ocorrer, a chamada potência critica, que é obtida ao igualarmos o ângulo de difração $\left(\theta_{d i f}=0,61 \lambda / n_{0} d\right)^{21}$ ao ângulo de auto-focalização $\left(\theta_{s f}=\sqrt{2 n_{2} I / n_{0}}\right)^{21}$ do feixe, e é dada por:

$$
P_{c r}=\frac{\pi(0,61)^{2} \lambda^{2}}{8 n_{0} n_{2}}
$$

onde $\lambda$ refere-se ao comprimento de onda da luz incidente no meio. Para potências menores que a potência critica o feixe diverge e para potências maiores o feixe converge, podendo até mesmo provocar danos ópticos no material. Quando a potência óptica é maior que a potência crítica pode ocorrer também a formação de múltiplos filamentos dentro do material, resultando em uma maior instabilidade espacial da luz gerada. 
O ponto interessante nesse fenômeno é que quando ocorre o self-trapping temos a luz se propagando no meio como em um guia, com altíssima intensidade, amplificando os efeitos não-lineares.

\subsubsection{Auto-modulação de fase}

A auto-modulação de fase (Self-Phase Modulation - SPM) é um fenômeno óptico nãolinear com origem na variação da fase de uma onda eletromagnética ao se propagar por um meio material com não-linearidade de terceira ordem devido à dependência do índice de refração desse material com a intensidade do pulso óptico. É o principal mecanismo responsável pela geração de luz supercontínua no regime de picossegundos, tendo uma resposta quase instantânea à intensidade do pulso ${ }^{33}$.

Um pulso óptico, cujo perfil de intensidade apresenta uma dependência temporal $I(t)$, ao se propagar por um material que apresenta o índice de refração como o dado pela eq. (2.34), terá uma mudança na sua fase dada pela adição do termo:

$$
\Phi_{N L}(t)=-\frac{n_{2} I(t) \omega_{0} L}{c}
$$

onde $\Phi_{N L}$ e $L$ são respectivamente a fase não-linear acumulada pela onda do pulso incidente e o comprimento do meio.

Podemos notar pela eq. (2.37) que a fase não-linear do pulso também apresenta uma dependência temporal, o que resulta em uma modificação no espectro do pulso transmitido. Tal modificação ocorre devido à variação, $\delta \omega(t)$, da frequência instantânea do pulso:

$$
\omega(t)=\omega_{0}+\delta \omega(t)
$$

onde

$$
\delta \omega(t)=\frac{\partial}{\partial t} \Phi_{N L}(t)=-\frac{n_{2} \omega_{0} L}{c} \frac{\partial I(t)}{\partial t}
$$


A eq (2.39) nos diz que novas frequências são criadas no espectro do pulso enquanto este se propaga pelo meio, como ilustrado na figura 13, onde mostramos a variação instantânea da frequência de um pulso com perfil temporal de intensidade dado por uma função do tipo $\operatorname{sech}^{2}$ ao se propagar por um meio com $n_{2}$ positivo.

\section{(a)}

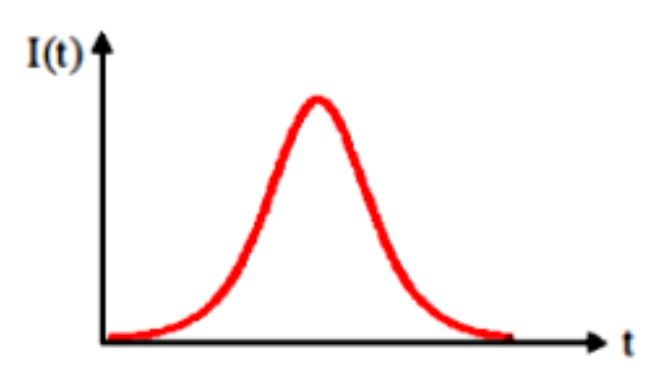

(b)

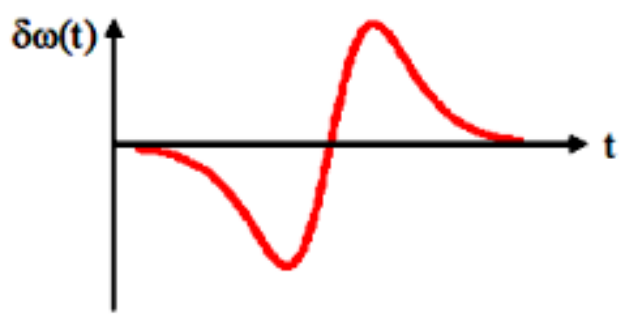

Figura 13 - (a) Dependência temporal do pulso incidente. (b) Variação da frequência instantânea do pulso ao ser transmitido por um meio com $n_{2}$ positivo.

Podemos observar na parte (b) da figura 13 que na borda dianteira do pulso (tempos menores) a frequência instantânea é deslocada para frequências menores, enquanto que na borda traseira do pulso (tempos maiores) a frequência instantânea é deslocada para frequências maiores. O pulso resultante apresentará então uma varredura de frequência similar à que ocorre em meios dispersivos, como ilustrado na figura 14 .
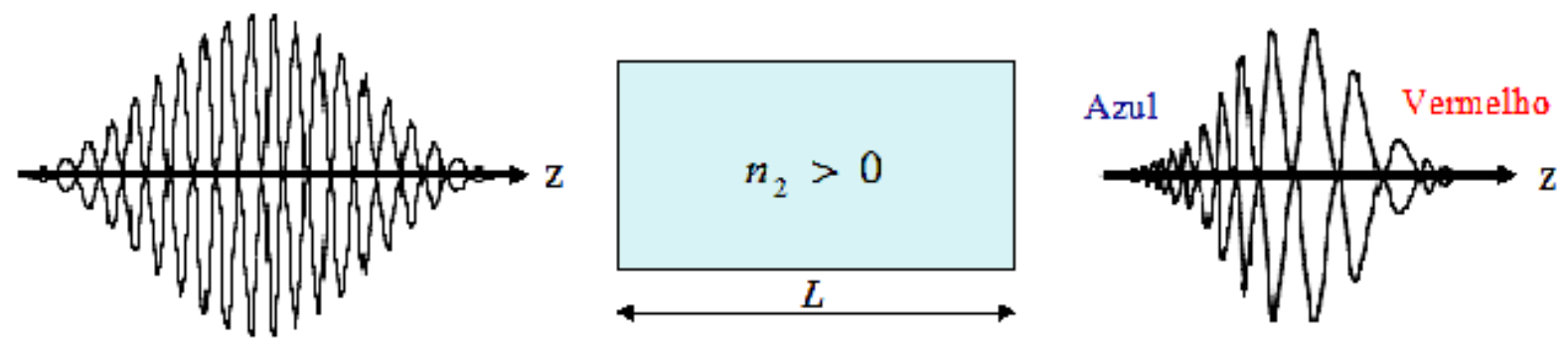

Figura 14 - Varredura de frequência no processo de auto-modulação de fase.

A variação máxima de frequência será da ordem de: 


$$
\delta \omega_{\max } \cong \frac{\Delta \phi_{N L}^{\max }}{\tau_{0}}
$$

onde $\Delta \Phi_{N L} \cong \frac{n_{2} I_{0} \omega_{0} L}{c}$. Espera-se que a auto-modulação de fase ocorra de forma significativa sempre que $\delta \omega_{\max }$ exceda a largura espectral do pulso incidente, que é da ordem de $1 / \tau_{0}$ para pulsos limitados pela transformada de Fourier. Isso leva à seguinte condição para que a auto-modulação de fase seja relevante:

$$
\Delta \Phi_{N L}=\frac{n_{2} I_{0} \omega_{0} L}{c}>1
$$

\subsubsection{Mistura de quatro ondas}

Um outro processo que pode contribuir para o alargamento espectral do pulso de bombeio é a Mistura de Quatro Ondas (Four-Wave Mixing - FWM). Do ponto de vista da mecânica quântica, o FWM é caracterizado pelo aniquilamento de fótons de uma ou mais ondas, com a correspondente criação de novos fótons com diferentes frequências onde tanto a energia quanto o momento são conservados durante a interação paramétrica. Existem dois tipos de FWM, o primeiro corresponde ao caso em que três fótons transferem suas energia para um único fóton de frequência $\omega_{4}=\omega_{1}+\omega_{2}+\omega_{3}$, como exemplo desse caso temos a geração de terceiro harmônico, onde temos $\omega_{1}=\omega_{2}=\omega_{3}$. Já o segundo tipo de FWM corresponde ao caso em que dois fótons de frequências $\omega_{1}$ e $\omega_{2}$ são aniquilados, com a criação simultânea de dois fótons de frequências $\omega_{3}$ e $\omega_{4}$, onde

$$
\omega_{3}+\omega_{4}=\omega_{1}+\omega_{2}
$$

Este processo deve satisfazer as condições de casamento de fase:

$$
\vec{K}_{3}+\vec{K}_{4}=\vec{K}_{1}+\vec{K}_{2}
$$


No caso em que os fótons aniquilados têm a mesma frequência chamamos o processo de degenerado. Fisicamente temos uma intensa onda de bombeio com frequência $\omega_{0}$, criando duas outras componentes de frequências $\omega_{s}$ e $\omega_{a}$ simetricamente deslocadas da frequência de bombeio, onde se adota por definição que $\omega_{s}<\omega_{a}$. A nova componente gerada em regiões de frequência abaixo da frequência de bombeio $\left(\omega_{s}\right)$ é denominada componente Stokes, e a nova componente gerada em regiões de frequência acima da frequência de bombeio é referida como componente anti-Stokes $\left(\omega_{a}\right)$. Assim, o FWM pode contribuir para a geração de novas frequências em torno da frequência central $\omega_{0}$.

\subsubsection{Espalhamento Raman Estimulado}

O espalhamento Raman é o resultado da interação da luz com os modos vibracionais das moléculas que constituem o meio espalhador. O espalhamento Raman espontâneo pode transferir uma pequena parcela da potência do campo óptico incidente para um outro campo, cuja frequência é deslocada da frequência do campo incidente por uma quantidade determinada pelos modos vibracionais do meio ${ }^{34}$. Do ponto de vista quântico, esse efeito pode ser interpretado como a criação espontânea de um fóton de energia $\hbar \omega_{s}$ quando um fóton de bombeio, com energia $\hbar \omega_{p}$, provoca uma transição vibracional da molécula, onde $\omega_{s}<\omega_{p}$, como ilustrado na figura 15. A essa componente gerada, com frequência menor que a do campo óptico de bombeio dá-se o nome de componente Stokes, ou seja, a luz incidente no material funciona como um bombeio gerando novas frequências, as componentes Stokes. 


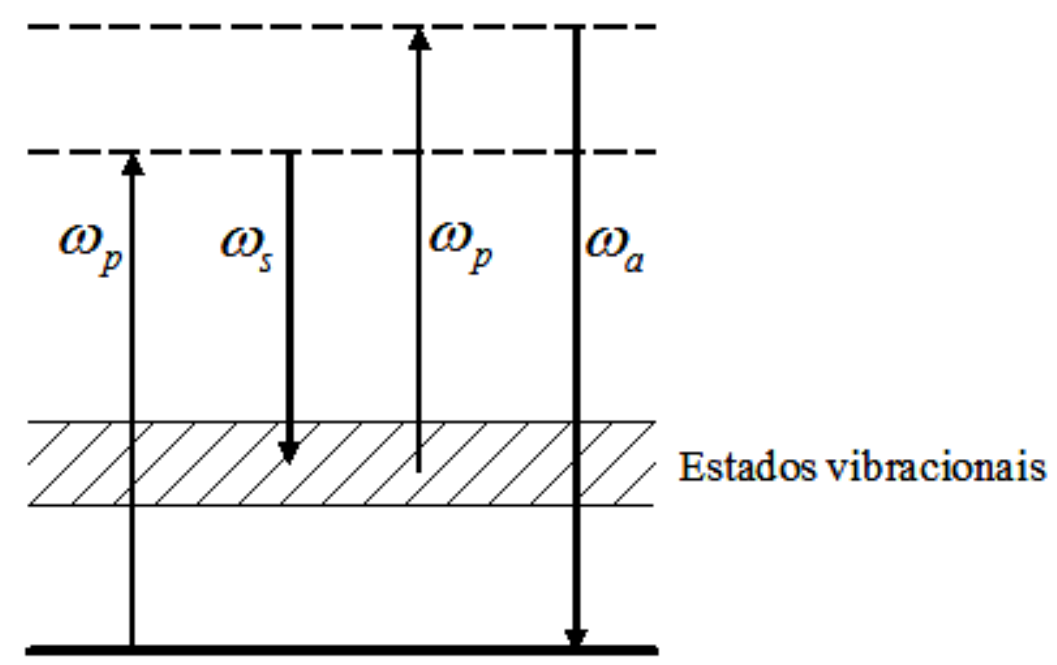

Figura 15 - Espalhamento Raman Estimulado.

Em 1962 foi observado que para campos ópticos de bombeio com alta intensidade poderia ocorrer com a propagação no material uma maior transferência da energia da onda de bombeio para a componente Stokes gerada ${ }^{34}$, bem como o surgimento de uma componente anti-Stokes muito mais intensa que o usual. Esse é o fenômeno óptico não-linear conhecido como Espalhamento Raman Estimulado (Stimulated Raman Scattering - SRS), que pode ser entendido como uma amplificação de $\omega_{s}$ e geração simultânea de $\omega_{a}$ por um processo de FWM. A intensidade crítica, $I_{0}^{c r}$, para que o SRS aconteça é definida como sendo a potência óptica do bombeio na entrada do meio para a qual as potências da componente Stokes e do bombeio na saída do material sejam iguais, e é dada pela equação ${ }^{34}$ :

$$
G_{R} I_{0}^{c r} L_{e f f} \approx 16
$$

onde $G_{R}$ representa o coeficiente de ganho Raman e $L_{\text {eff }}{ }^{34}$ é o comprimento efetivo que toma o lugar do comprimento real do meio, o que ocorre quando as perdas do meio são levadas em consideração.

O coeficiente de ganho Raman é o principal termo utilizado para descrever o SRS, entre outros fatores ele depende da diferença entre as frequências da onda de bombeio e da onda Stokes, ou seja, temos que $G_{R}=G_{R}\left(\Omega=\omega_{p}-\omega_{s}\right)$, e é através dos picos da curva do ganho Raman para um determinado meio (correspondentes às transições vibracionais Raman) que temos as frequências para as quais a energia do bombeio é mais eficientemente convertida. 


\subsubsection{Fibras fotônicas}

Recentemente foi demonstrada a geração de luz supercontínua em fibras ópticas fotônicas ${ }^{35,36}$. Como utilizaremos esse sistema ao longo desse trabalho, discutiremos a seguir os conceitos básicos de fibras ópticas convencionais e fibras ópticas fotônicas.

Fibras ópticas convencionais são dispositivos ópticos utilizados para guiar a luz através do principio básico de reflexão interna total ${ }^{37}$. De uma forma simples, uma fibra óptica consiste de um filamento constituído por um material com índice de refração maior, o núcleo, envolto por uma camada constituída por um material de índice de refração menor, a casca. Um parâmetro importante de uma fibra óptica é o número de modos que esta suporta: se apenas um modo pode propagar-se pela fibra esta é dita monomodo, caso contrário esta é dita multimodo. O número de modos suportados por uma determinada fibra para um dado comprimento de onda irá depender do raio do núcleo dessa fibra e da diferença relativa entre os índices núcleo-casca $\left(\Delta=\left(n_{n}-n_{c}\right) / n_{n}\right)^{34}$. Outro parâmetro de suma importância com relação às fibras ópticas é a abertura numérica da fibra (AN), definida como o seno do ângulo máximo $(\sigma)$ formado entre o eixo de simetria da fibra e um raio de luz incidente, ainda capaz de sofrer a reflexão total interna necessária para que a luz se propague pela fibra (veja a figura 16):

$$
A N=\sin \sigma
$$

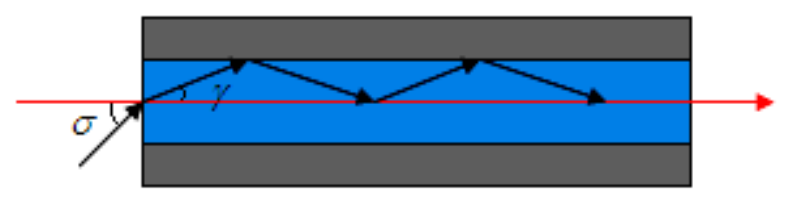

Figura 16 - Confinamento da luz em uma fibra óptica.

Em geral, quando uma onda eletromagnética interage com os elétrons ligados de um dielétrico, a resposta do meio dependerá da frequência dessa onda, a esta característica damos o nome de dispersão cromática que se manifesta através da dependência do índice de refração do meio com a frequência óptica do campo, $n(\omega)$. Matematicamente, os efeitos de dispersão de um pulso óptico em uma fibra são explicados pela expansão da constante de propagação modal em uma serie de Taylor em torno da frequência central, $\omega_{0}$, da portadora: 


$$
\beta(\omega)=n(\omega) \frac{\omega}{c}=\beta_{0}+\beta_{1}\left(\omega-\omega_{0}\right)+\frac{1}{2} \beta_{2}\left(\omega-\omega_{0}\right)^{2}+\cdots
$$

com

$$
\beta_{m}=\left(\frac{d^{m} \beta}{d \omega^{m}}\right)_{\omega=\omega_{0}} \quad(m=0,1,2, \ldots)
$$

Com os parâmetros $\beta_{1}$ e $\beta_{2}$ sendo relacionados ao índice de refração e suas derivadas através das relações ${ }^{34}$ :

$$
\begin{gathered}
\beta_{1}=\frac{1}{v_{g}}=\frac{n_{g}}{c}=\frac{1}{c}\left(n+\omega \frac{d n}{d \omega}\right) \\
\beta_{2}=\frac{1}{c}\left(2 \frac{d n}{d \omega}+\omega \frac{d^{2} n}{d \omega^{2}}\right)
\end{gathered}
$$

onde $n_{g}$ é o índice de refração de grupo e $v_{g}$ é a velocidade de grupo, que é a velocidade com que o envelope de um pulso óptico se move. O parâmetro $\beta_{2}$ corresponde a dispersão da velocidade de grupo e é o responsável pelo alargamento temporal do pulso, fenômeno este conhecido por Group-Velocity Dispersion (GVD) onde $\beta_{2}$ é o parâmetro GVD. Porém, o parâmetro de dispersão, $D$, é o mais utilizado na prática e é definido como:

$$
D=\frac{d \beta_{1}}{d \lambda}=-\frac{2 \pi c}{\lambda^{2}} \beta_{2}
$$

Dessa forma, tendo em mãos a expressão de $n(\omega)$ para uma dada fibra, podemos utilizar as eqs (2.49) e (2.50) para obtermos uma curva de $D$ ou de $\beta_{2}$ em função do comprimento de onda, conhecida como curva de dispersão do material. Essa curva tem como principal característica a existência de um comprimento de onda para o qual ambos, $D$ e $\beta_{2}$ são zeros, esse comprimento de onda, $\lambda_{D}$, é conhecido como o comprimento de onda de dispersão nula. Uma vez que o parâmetro de dispersão depende de parâmetros relacionados ao design da fibra, como por exemplo, o raio do núcleo e a diferença relativa entre os índices núcleo-casca, estas variáveis podem ser utilizadas para deslocar $\lambda_{D}$ para regiões 
convenientes. Assim, é possível obtermos situações em que um pulso com portadora centrada em $\lambda_{D}$ propaga-se ao longo da fibra sem alargar-se, ou dois pulsos (de largura temporal $\tau_{0}$ ) com portadoras centradas em diferentes comprimentos de onda separem-se apenas após percorrem uma distância $L_{w}=\tau_{0} / d_{12}$. O parâmetro $d_{12}=v_{g}^{-1}\left(\lambda_{1}\right)-v_{g}^{-1}\left(\lambda_{2}\right)$, conhecido como walk-off parameter, governa uma importante característica em fenômenos não-lineares: pulsos com portadoras em diferentes comprimentos de onda viajarão dentro da fibra a diferentes velocidades, e portanto os efeitos não-lineares deixarão de ocorrer a partir de uma distância da ordem de $\mathrm{L}_{\mathrm{w}}$.

A fibra fotônica é um guia de onda óptico que permite que seu comprimento de onda de dispersão nula seja deslocado, por exemplo, para a região em que existem lasers de alta potência. A figura 17 mostra a seção transversal de uma fibra fotônica típica, a qual é formada basicamente por um arranjo estruturado de buracos de ar em um bastão de sílica, onde a ausência de um buraco de ar no centro da estrutura é responsável por gerar o núcleo da fibra ${ }^{35}$. Os principais parâmetros geométricos desse tipo de fibra são o diâmetro do buraco de ar, $d, \mathrm{e}$ o pitch, $\Lambda$, que é a distância entre os centros de dois buracos de ar adjacentes.

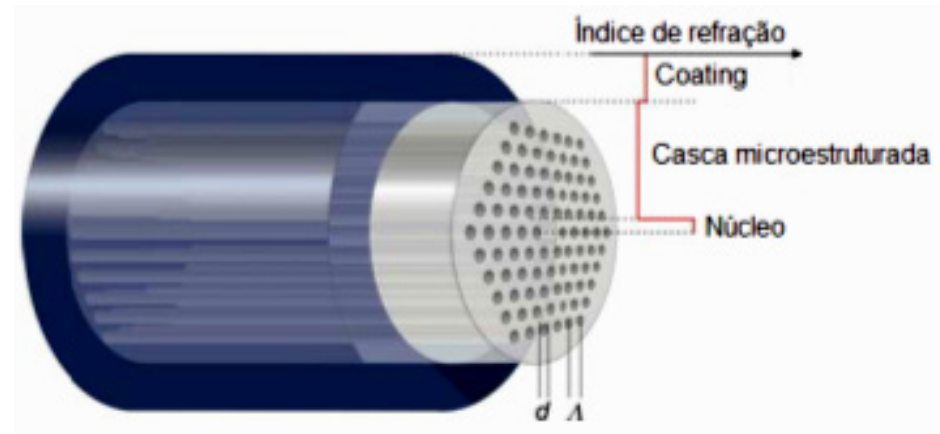

Figura 17 - Seção transversal de uma fibra fotônica com estrutura hexagonal ${ }^{38}$.

Existem duas classes de fibras fotônicas. A primeira, que é o objeto de nosso trabalho, guia a luz através do fenômeno de reflexão interna total (já que o índice de refração efetivo da região microestruturada é menor que o da casca tradicional), assim como as fibras ópticas tradicionais, e engloba as fibras com núcleo sólido. Já a segunda classe guia a luz por meio de um efeito de gap fotônico ${ }^{39,40}$ e engloba as fibras com núcleo oco. Vale ressaltar que qualquer referência posterior nesse trabalho a fibras fotônicas, referir-se-á à primeira classe mencionada.

A primeira observação da geração de supercontínuo em uma fibra fotônica data do ano de 2000, quando um pulso com 100 fs de largura temporal proveniente de um laser de 
Ti:safira bombeando uma fibra fotônica com $75 \mathrm{~cm}$ de comprimento promoveu um alargamento espectral que estendeu-se de 400 a $1500 \mathrm{~nm}^{41}$. O impacto que este experimento causou na comunidade cientifica foi imediato, dando-se inicio a uma série de experimentos e estudos nessa área.

A geração de supercontínuo em fibras ópticas é um fenômeno que ocorre devido a uma complexa combinação de processos não-lineares de terceira ordem, como os descritos anteriormente (SPM, SRS, FWM, etc.), e a contribuição relativa desses processos depende, entre outros parâmetros, do deslocamento entre o comprimentos de onda do bombeio e $\lambda_{D}{ }^{42}$. Isso atribui uma grande vantagem às fibras fotônicas em relação às fibras convencionais, no que diz respeito a geração de luz supercontínua, uma vez que a fibra fotônica permite a manipulação do seu perfil de dispersão através de modificações em suas estruturas geométricas, ou seja, através de modificações dos seu parâmetros $d$ e $\Lambda$. Além disso, a fibra fotônica possui menor área modal efetiva, o que resulta em um maior confinamento do campo óptico e um aumento dos efeitos não-lineares ${ }^{43}$. A duração do pulso de bombeio é um importante parâmetro que determina os efeitos que terão maior influência no espectro gerado. Para pulsos de picossegundos, a radiação do bombeio pode ser convertida em radiação supercontínua principalmente através dos processos de Espalhamento Raman e Mistura de Quatro Ondas ${ }^{44,45}$.

Outro parâmetro da fibra fotônica de suma importância para a geração do supercontínuo é o comprimento da fibra $(L)$. Visto que é a comparação do valor do referido parâmetro com os valores de comprimento de dispersão $\left(L_{D}\right)$ e comprimento não linear $\left(L_{N L}\right)$ que fornece qual o regime dominante na propagação do pulso pela fibra. O comprimento de dispersão é a distância de propagação na qual a ação da dispersão torna-se relevante, e é definido como ${ }^{3434}$ :

$$
L_{D}=\frac{\tau_{0}^{2}}{\beta_{2}}
$$

onde $\tau_{0}$ corresponde a largura temporal do pulso de bombeio e $\beta_{2}$ como dito anteriormente é o parâmetro GVD. O comprimento não-linear por sua vez é a distância de propagação para a qual os efeitos não-lineares se tornam importantes e é definido como ${ }^{34}$ : 


$$
L_{N L}=\frac{1}{\gamma P_{0}}
$$

onde $\gamma$ é o coeficiente não linear da fibra e $P_{0}$ corresponde a potência de pico do pulso de bombeio. Para o caso em que $L<<L_{D}$ mas $L \sim L_{N L}$ os efeitos de dispersão não são significativos durante a propagação do pulso, e este por sua vez é governado pelos efeitos não lineares. Esta é a situação ideal para a geração de supercontínuo em uma fibra fotônica. 


\section{Projeto do Amplificador Paramétrico Óptico}

O projeto do OPA é dividido em três unidades principais; a geração do sinal (luz supercontínua), a seleção do sinal pelo monocromador e a geração do idler pelo cristal, iremos detalhar cada uma dessas unidades nas seções que se seguem. Contudo, vamos inicialmente fornecer na tabela 1 os parâmetros do laser utilizado como laser de bombeio, uma vez que os fenômenos ópticos que ocorrerão no OPA apresentam uma alta dependência desses parâmetros.

Tabela 1 - Especificações do laser de bombeio utilizado no projeto do OPA.

\begin{tabular}{|lc|}
\hline \multicolumn{2}{|c|}{ Laser mode-locked Nd:YAG (PY 2143A-SS/20, Ekspla) } \\
\hline Comprimento de onda: & $1064 \mathrm{~nm}$ \\
Duração do pulso: & $25 \mathrm{ps}$ \\
Estabilidade da energia do pulso: & $\pm 1,5 \%$ \\
Energia do pulso: & $40 \mathrm{~mJ} *$ \\
Diâmetro do feixe: & $8 \mathrm{~mm}$ \\
Taxa de repetição: & $20 \mathrm{~Hz}$ \\
\hline
\end{tabular}

(*) utilizamos apenas $10 \mathrm{~mJ}$ para bombeio desse OPA, enquanto que o restante é utilizado para bombear um OPA comercial.

O amplificador paramétrico óptico a ser construído está esquematizado na figura 18. O laser de bombeio envia pulsos de 25 ps em $\lambda=1064 \mathrm{~nm}$ para um OPA comercial já montado no laboratório e para o que está sendo construído. O feixe é então dividido em dois por um semi-espelho (SE). Um deles percorrerá um longo caminho para chegar ao cristal não-linear C sincronizado com o outro pulso semente (sincronia conseguida através do ajuste da posição do prisma P). O comprimento desse percurso foi escolhido de modo que os pulsos gerados no infravermelho médio por esse OPA e pelo OPA comercial estejam aproximadamente sincronizados na estação de espectroscopia SFG. O pulso semente, por sua vez, é gerado pela outra parte do feixe de bombeio, que passa por um filtro (F) para ter sua potência ajustada (fazemos isso para não danificar o material utilizado para gerar o contínuo de "luz branca") e 
por uma lente $\mathrm{L}_{\mathrm{V}}$ de distância focal variável (dependendo do material utilizado para gerar a semente), que serve apenas para focalizar o feixe no material. Segue então para o meio com não-linearidade de terceira ordem, no qual ocorrem os fenômenos não-lineares que resultam na geração de supercontínuo. $\mathrm{O}$ feixe segue passando por uma lente $\left(\mathrm{L}_{1}\right)$, uma abertura (pinhole, $\mathrm{PH}$ ), cuja função é colimar a luz gerada, e um espelho. O raio então incide em uma grade de difração (GD) e uma fração do espectro gerado será selecionada pelo sistema de lentes $\mathrm{L}_{2}-\mathrm{L}_{3}$ e pela abertura localizada entre essas lentes, que agem como um monocromador, produzindo um feixe colimado com um determinado intervalo de frequências. É importante ressaltar que essa grade estará posicionada em um estágio de rotação que permitirá que um feixe de frequência desejada passe pela abertura. Este feixe semente encontra a outra parte do feixe inicial num espelho dicróico, de onde seguem para o cristal não-linear C (também montado em um estágio de rotação) no qual ocorrerá o processo de amplificação paramétrica do feixe-sinal e geração do feixe idler no infravermelho médio.

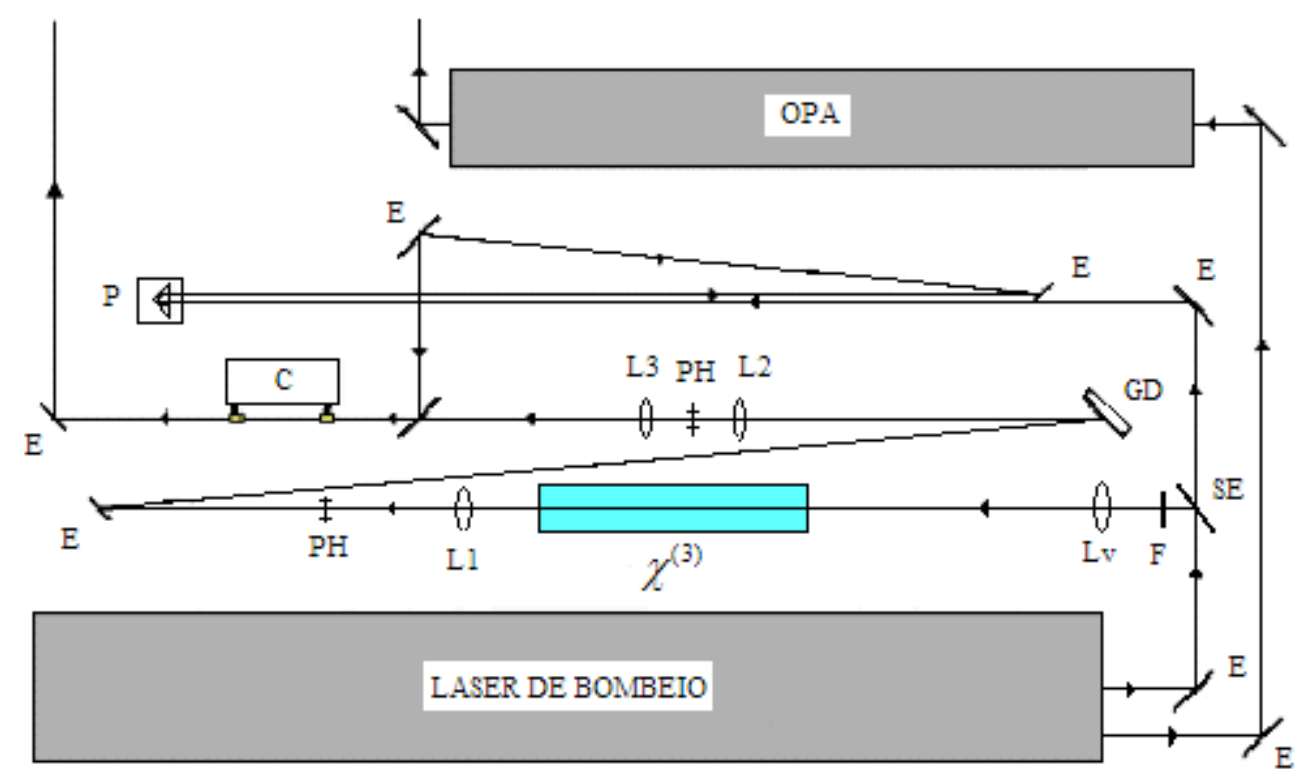

Figura 18 - Aparato experimental do OPA a ser construído. Aqui o bloco OPA refere-se ao OPA comercial existente no laboratório. 


\subsection{Geração do supercontínuo}

Como mencionamos anteriormente, a semente do OPA provém de um pulso de alta largura espectral no IV próximo, ou seja, de um pulso de luz supercontínua e, como vimos no capitulo anterior, a geração de luz supercontínua envolve a manifestação de diversos efeitos não-lineares de terceira ordem, como a auto-focalização, a auto-modulação de fase, o espalhamento Raman estimulado e a mistura de quatro ondas. Contudo, as contribuições desses efeitos para o alargamento espectral e para estabilidade na intensidade dos pulsos vão depender de fatores como o material a ser bombeado ${ }^{25,46}$, o comprimento de interação desse material $^{47}$ e o regime de bombeio (largura temporal ${ }^{48}$ e energia do pulso $^{49}$ ). Dessa forma, testamos a geração de luz supercontínua em água, água deuterada, vidro BK7, fluoreto de bário, cloreto de potásssio, fibra óptica fotônica de baixa não-linearidade e fibra fotônica de alta não-linearidade, a fim de obtermos o espectro mais largo possível em conjunto com a maior estabilidade possível na intensidade dos pulsos gerados. Os testes consistiram em bombear cada material mencionado acima, variando-se a potência do pulso de bombeio e/ou o comprimento do material quando possível e analisar o espectro resultante bem como realizar as respectivas medidas de estabilidade do contínuo gerado. Os testes com o bastão de vidro BK7, com o fluoreto de bário, com o cloreto de potásssio e com a fibra óptica fotônica de baixa não-linearidade foram feitos com os materiais disponíveis e, portanto sem otimizar o comprimento de interação desses materiais.

\subsubsection{Escolha da fibra fotônica a ser utilizada}

Como mencionamos no capitulo anterior, o alargamento espectral de um pulso laser propagando-se em uma fibra fotônica está diretamente ligado com a diferença de valores existente entre o comprimento de onda do pulso de bombeio $\left(\lambda_{0}\right)$ e o comprimento de dispersão zero $\left(\lambda_{D}\right)$ da fibra utilizada. Nos casos em que $\lambda_{0}<\lambda_{D}$, a fibra é dita por exibir dispersão normal ( $\mathrm{D}>0$, ou $\beta_{2}<0$ ), e as componentes do pulso óptico com alta frequência viajam mais lentamente que as componentes com baixa frequência. $\mathrm{O}$ oposto ocorre no 
regime de dispersão anômala da fibra, que ocorre quando $\lambda_{0}>\lambda_{D}$. A geração de um espectro largo de luz supercontínua se mostrou mais eficiente para pulsos de $\sim 25$ ps quando $\lambda_{0}$ é ligeiramente deslocado para a região de dispersão anômala ${ }^{42}$, sendo assim, a fibra fotônica selecionada para esse projeto, cuja geometria está esquematizada na figura 19, corresponde à fibra "Nonlinear Photonic Fiber - SC-5.0-1040" (Crystal-Fibre Inc., Reino Unido), que apresenta a medida de dispersão mostrada na figura 20.

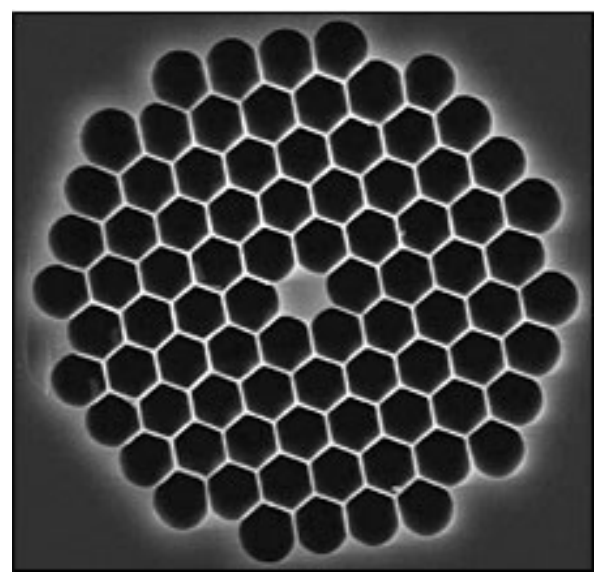

Figura 19 - Seção transversal da fibra fotônica de alta não-linearidade utilizada nesse projeto ${ }^{50}$.

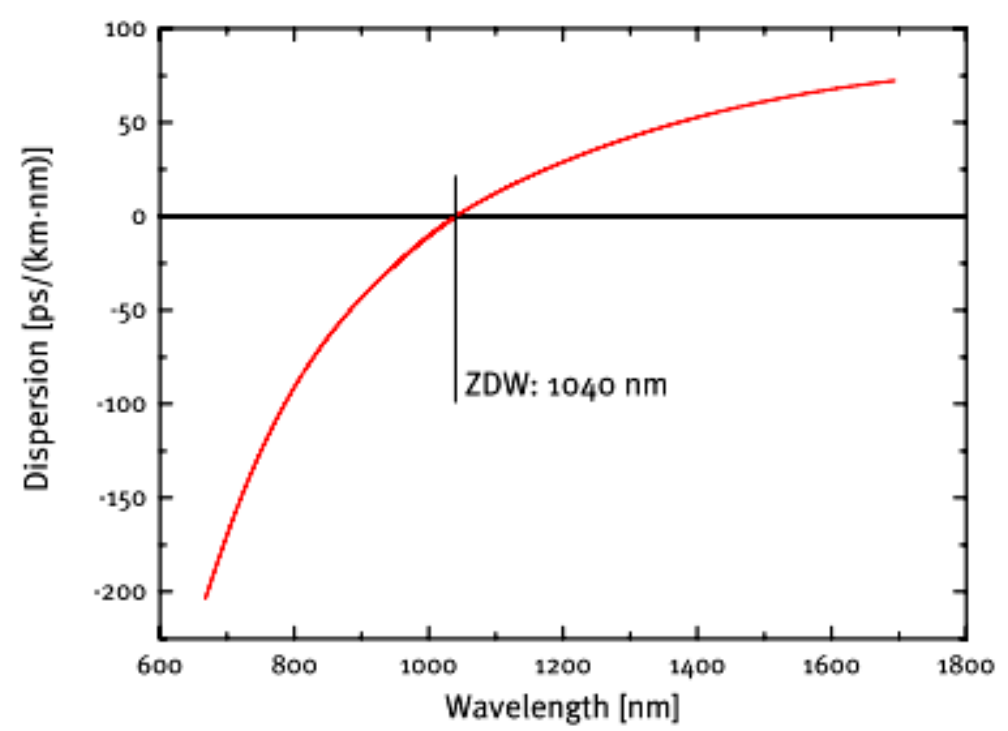

Figura 20 - Curva de dispersão da fibra "Nonlinear Photonic Fiber - SC-5.0-1040" utilizada neste trabalho ${ }^{51}$.

onde o eixo da ordenada (Dispersion) corresponde ao parâmetro de dispersão $(D)$. As propriedades ópticas e físicas da fibra estão disponibilizadas na tabela 2. 
Tabela 2 - Parâmetros da fibra "Nonlinear Photonic Fiber - SC-5.0-1040" utilizada no projeto.

\begin{tabular}{|lc|}
\hline Comprimento de onda de dispersão zero: & $1040 \pm 10 \mathrm{~nm}$ \\
Coeficiente não-linear a $1060 \mathrm{~nm}:$ & $11(\mathrm{WKm})^{-1}$ \\
Diâmetro de campo modal: & $4,0 \pm 0,2 \mu \mathrm{m}$ \\
Abertura numérica a $1060 \mathrm{~nm}:$ & $0,20 \pm 0,05$ \\
Material: & Sílica pura \\
Diâmetro do cladding: & $125 \pm 3 \mu \mathrm{m}$ \\
Diâmetro do núcleo: & $4,8 \pm 0,2 \mu \mathrm{m}$ \\
\hline
\end{tabular}

Fazendo uso das eqs. (2.51) e (2.52) respectivamente, calculamos o $L_{D}$ e o $L_{N L}$ da fibra, onde os parâmetros necessários para os cálculos bem como os resultados obtidos estão ilustrados na tabela 3 .

Tabela 3 - Parâmetros da fibra e do pulso de bombeio utilizados para o cálculo de e $\mathrm{L}_{\mathrm{D}}$ e $\mathrm{L}_{\mathrm{NL}}$, bem como os respectivos resultados.

\begin{tabular}{|cccccc|}
\hline$\gamma(\mathrm{WKm})^{-1}$ & $\beta_{2}\left(\mathrm{ps}^{2} / \mathrm{Km}\right)$ & $P_{0}(\mathrm{GW})$ & $\tau_{0}(\mathrm{ps})$ & $L_{D}(\mathrm{Km})$ & $L_{N L}(\mathrm{~mm})$ \\
\hline 11 & $-4,18 \times 10^{-12}$ & 0,20 & 25 & 150 & 0,45 \\
\hline
\end{tabular}

onde $\beta_{2}$ foi calculado através da sua relação com o parâmetro de dispersão $D$ dada pela eq. (2.50) e o valor de $D(\sim 7 \mathrm{ps} / \mathrm{Km} . \mathrm{nm}$ a $1064 \mathrm{~nm})$ foi estimado através da curva de dispersão da fibra, ilustrada na figura 20. Em notas publicadas pelo fabricante da fibra fotônica ${ }^{52}$ observou-se a geração de supercontínuo em regimes em que $L \cong 1050 \times L_{N L}$. Seguindo esta proporção, calculamos o comprimento necessário de fibra para alcançarmos o regime nãolinear, o resultado obtido então foi $L \cong 47 \mathrm{~cm}$. Ou seja, para uma fibra com comprimento maior ou igual a quarenta e sete centímetros, esperamos a geração do supercontínuo. $\mathrm{O}$ comprimento de fibra comprado para o projeto foi de:

$$
L \cong 2 m
$$

Valor este que satisfaz as condições desejadas; $L<<L_{D}$ e $L>>L_{N L}$. Poderíamos utilizar valores mais elevados para $L$ e ainda permanecer no regime $L<<L_{D}$, contudo, a 
geração de um contínuo com espectro mais largo já se mostrou mais eficiente em fibras fotônicas com três metros de comprimento do que em fibras com dez metros de comprimento $^{47}$. Além disso, uma fibra muito longa acarretaria em problemas de ordem prática na implementação da linha de atraso para sincronizar os pulsos de bombeio e sinal, uma vez que estes precisam chegar juntos no cristal amplificador, tanto espacialmente quanto temporalmente.

\subsubsection{Projeto da cubeta para água deuterada}

A geração de "luz branca" na água e na água deuterada já foi reportada utilizando cubetas com comprimentos entre 0,2 e $30 \mathrm{~cm}^{53,54}$, contudo, como não disponibilizamos de água deuterada em abundância para realização de muitos testes, e tão pouco de cubetas com comprimentos distintos, calculamos o comprimento necessário da cubeta a ser confeccionada para que pudéssemos observar a geração de supercontínuo.

A relação dada pela eq. (2.41) na seção 2.3.2 nos dá a condição para que os efeitos de auto-modulação de fase sejam relevantes, o que nos leva a expressão que fornece o comprimento mínimo que um dado material deve ter para que tal efeito ocorra:

$$
L_{S F} \geq \frac{\lambda_{0}}{n_{2} I_{0}}
$$

Para o nosso caso em que temos a intensidade de pico da ordem de $68 \mathrm{GW} / \mathrm{cm}^{2}$ e sendo o índice de refração não-linear da água deuterada dado por $n_{2}=6,29 \times 10^{-23} \mathrm{~cm}^{2} \mathrm{~s} / \mathrm{erg}^{54}$ e o índice de refração dado por $n_{0}=1,33$, temos que:

$$
L_{S F} \geq 2,5 \mathrm{~cm}
$$

O limite superior do comprimento da cubeta foi calculado de forma que após percorrer toda a extensão da cubeta, o feixe de bombeio ainda carregasse $80 \%$ da sua energia inicial. Esse cálculo foi realizado a partir do espectro de absorção da água deuterada apresentado na figura 
33, o resultado obtido foi que para uma cubeta com $10,5 \mathrm{~cm}$ de comprimento, $80 \%$ da energia do bombeio seria transmitida.

\subsection{Monocromador}

Os componentes ópticos que compõem o monocromador do OPA estão ilustrados na figura 18: a lente $L_{1}$, cuja função é colimar o contínuo gerado, a grade de difração $G$, as lentes $L_{2}$ (distância focal de $150 \mathrm{~mm}$ ) e $L_{3}$ (distância focal de $200 \mathrm{~mm}$ ) e a abertura posicionada entre essas lentes (com diâmetro de $50 \mu \mathrm{m}$ ). O projeto do monocromador consiste de duas etapas principais; a primeira é o projeto do suporte mecânico da grade de difração, uma vez que a semente do OPA será selecionada através da rotação dessa grade, a segunda etapa refere-se a escolha das lentes a fim de otimizarmos a separação espacial entre as componentes espectrais adjacentes, a largura espectral do pulso de semente e o diâmetro do feixe-sinal que chega no cristal.

Monocromadores são instrumentos ópticos cuja função é selecionar faixas espectrais de uma determinada fonte de luz. A figura 21 ilustra o arranjo esquemático dos componentes ópticos em um monocromador. Uma fonte de luz, $F$, ilumina a fenda de entrada, $S_{1}$, a qual é posicionada no plano focal de uma lente colimadora, $L_{1}$, produzindo então um feixe de luz colimado que incide sobre o elemento dispersivo (no nosso caso, uma grade de difração, $G$ ). Esta por sua vez separa duas ondas de frequências próximas de um ângulo $\Delta \theta$ devido a dispersão angular. As imagens da fenda de entrada são então formadas pela lente $L_{2}$ em seu plano focal, sendo essas imagens lateralmente espaçadas devido à dispersão linear do sistema $\left(G+L_{2}\right)$. Utilizando uma fenda na saída do sistema podemos selecionar apenas um pequeno intervalo espectral no plano focal de $L_{2}$. 


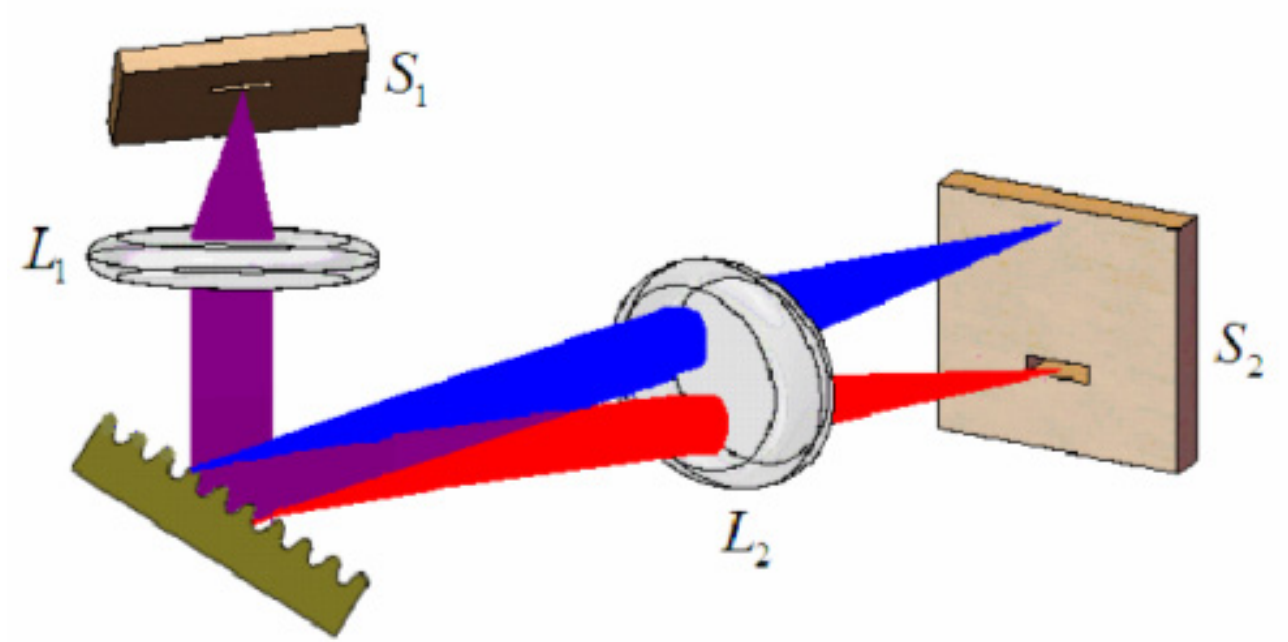

Figura 21 - Arranjo esquemático de um monocromador cujo elemento dispersivo é uma grade de difração.

\section{Grade de difração}

Uma grade de difração é um elemento óptico que contém uma série de elementos refletivos ou transmissíveis, paralelos e separados por uma distância comparável ao comprimento de onda da luz sob estudo. A figura 22 mostra um raio de luz de comprimento de onda $\lambda$ sendo difratado por uma grade de difração reflexiva.

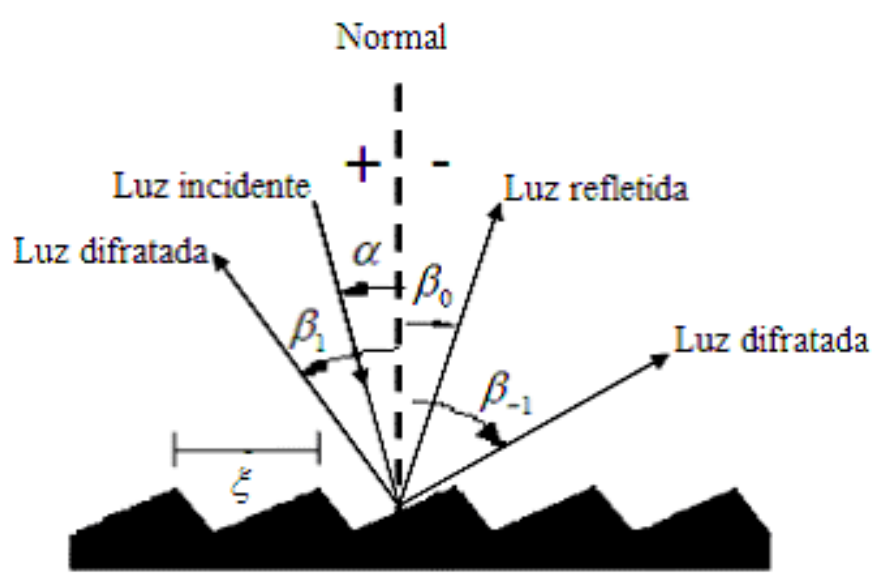

Figura 22 - Processo de difração por uma grade reflexiva.

O feixe de luz incide sobre a grade a um ângulo $\alpha$ e é difratado pela mesma ao longo de um conjunto de ângulos $\beta_{m}$, que por convenção têm sinal positivo se estão do mesmo lado que a luz incidente e sinal negativo caso contrário. Pelo principio de interferência construtiva temos que apenas quando a diferença de caminho óptico entre dois raios difratados que 
incidiram sobre dois sulcos adjacentes for igual a $\lambda$ ou a um múltiplo inteiro de $\lambda$, a luz proveniente desses sulcos adjacentes estarão em fase resultando em interferência construtiva. Situação essa que nos leva a relação conhecida como equação da grade de difração ${ }^{55}$ :

$$
m \lambda=\xi(\sin \alpha+\sin \beta)
$$

onde $m$ é a ordem de difração e $\xi$ é a separação entre linhas adjacentes da grade.

O principal objetivo de uma grade de difração é dispersar a luz angularmente em função do seu comprimento de onda, sendo assim, um feixe de luz branca ao incidir sobre uma grade de difração terá suas componentes espectrais separadas angularmente. Para um dado espectro de ordem $m$, a dispersão angular corresponde a separação angular entre as componentes $\lambda$ e $\lambda+\Delta \lambda$ por unidade de comprimento de onda ${ }^{55}$ :

$$
\mathcal{D}=\frac{d \beta}{d \lambda}=\frac{\sin \alpha+\sin \beta}{\lambda \cos \beta}
$$

que foi obtida pela diferenciação da eq. (3.4) considerando-se o ângulo de incidência constante. Já a dispersão linear é dada pelo produto da dispersão angular ( $\mathscr{D})$ pela distância focal efetiva do sistema.

Outro parâmetro importante a ser considerado em uma grade é a sua eficiência na distribuição da potência de um dado comprimento de onda difratado nas suas várias ordens. Essa distribuição de potência dependerá de vários fatores, como por exemplo, a potência e a polarização da luz incidente, os ângulos de incidência e difração, o espaçamento entre os sulcos. Uma regra simples e muito usada para maximizar a eficiência nesse processo de distribuição da potência óptica é que a inclinação da face do sulco seja tal que a luz incidente refletida por essa face coincida com o ângulo de difração da ordem desejada. Um caso prático especial (e muito utilizado) é o que a luz é difratada na direção do feixe incidente (ou seja, $\alpha=\beta$ para todos os $\lambda$ ). Essa situação é conhecida como configuração Littrow, onde o espectro é escaneado pela rotação da grade, com as equações da grade e de dispersão tornando-se respectivamente:

$$
m \lambda=2 \xi \sin \alpha
$$




$$
\mathcal{D}=\frac{d \beta}{d \lambda}=\frac{2 \tan \alpha}{\lambda}
$$

Nesse caso particular, a condição de máxima eficiência de difração, conhecida como condição de blaze, é dada por:

$$
m \lambda=2 \xi \sin \theta_{B}
$$

onde o ângulo $\theta_{B}$ é conhecido como ângulo blaze da grade e corresponde ao ângulo entre a face do sulco e o plano da grade (como ilustrado na figura 23).

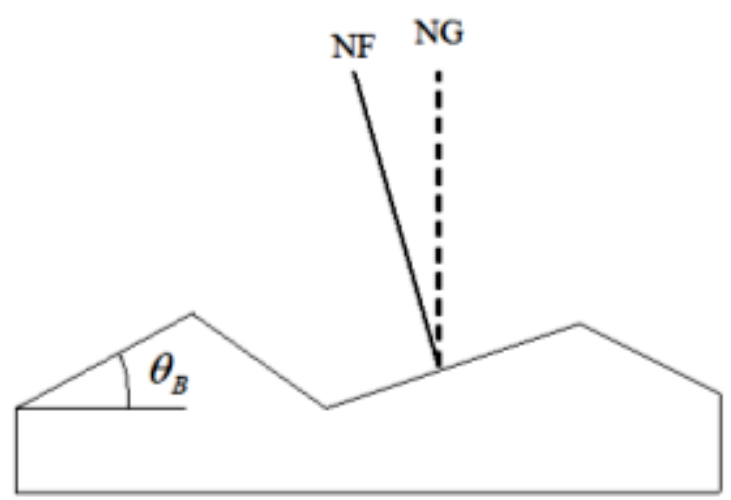

Figura 23 - Condição blaze. NF é a normal à face do sulco e NG é a normal à grade.

A grade comprada para ser utilizada no monocromador é a modelo 53004BK02-560R (Newport Corporation, EUA), com 600 linhas $/ \mathrm{mm}, \lambda_{B}=1250 \mathrm{~nm}$, recobrimento de ouro e dimensões 30x30x10mm.

\subsubsection{Intervalo de sintonia}

O ângulo de rotação da grade de difração (veja figura 24), $\phi$, que determina o comprimento de onda selecionado é dado pela relação ${ }^{55}$ :

$$
2 \phi=\alpha+\beta
$$




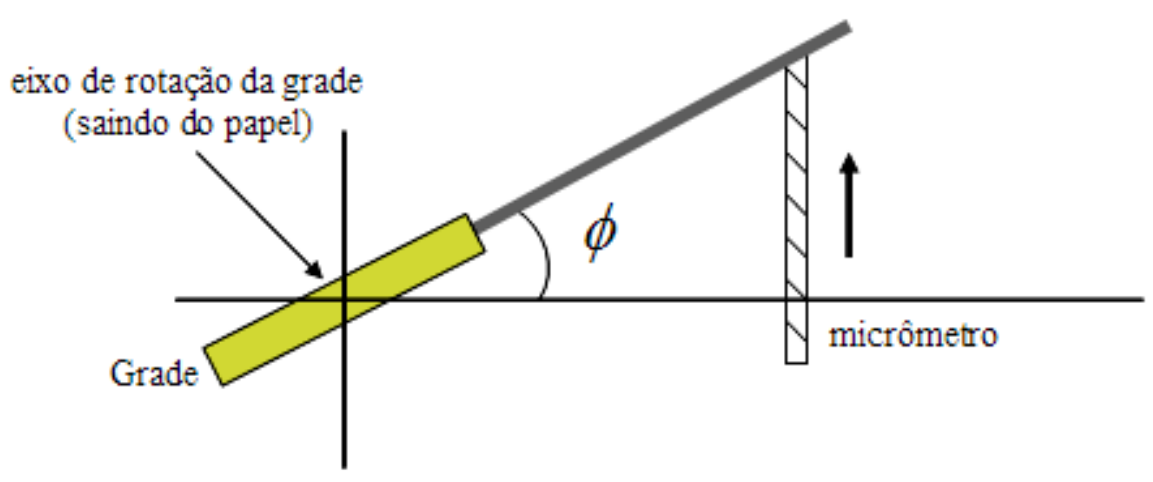

Figura 24 - Um micrômetro atua sobre o suporte da grade fazendo com que esta gire de um ângulo $\phi$.

A equação da grade pode ser expressa então ser expressa em função de $\phi$ :

$$
m \lambda=2 \xi \cos \kappa \sin \phi
$$

onde $2 \kappa$ é o ângulo de desvio entre as direções incidente e difratada:

$$
2 \kappa=\alpha-\beta=\text { const }
$$

O ângulo de incidência, o ângulo de desvio e o ângulo de rotação podem ser relacionados da seguinte forma:

$$
\alpha(\lambda)=\phi(\lambda)+\kappa
$$

Em nosso projeto iremos trabalhar em uma configuração muito próxima a Littrow, onde temos então $\alpha \approx \beta$, o que resulta em um ângulo de desvio nulo. Logo, temos que a eq. (3.10) pode ser escrita para a primeira ordem de difração na forma:

$$
\sin \phi=\frac{\lambda}{2 \xi}
$$

Calculamos a partir da eq. (3.13) os valores dos ângulos de rotação para os extremos da faixa de sintonia da semente. Esta faixa foi projetada para que o feixe idler gerado no cristal satisfaça a relação $2,5 \mu \mathrm{m}<\lambda_{I R}^{\text {médio }}<10 \mu \mathrm{m}$, o que corresponde respectivamente ao intervalo de comprimentos de onda do feixe sinal dado por $1,8 \mu \mathrm{m}>\lambda_{I R}^{\text {próximo }}>1,2 \mu \mathrm{m}$. Os valores obtidos para $\phi$ são: 


$$
\begin{aligned}
& \phi=21,2^{0} \quad, \quad \lambda_{\mathrm{S}}=1,2 \mu \mathrm{m} \\
& \phi=32,8^{0} \quad, \quad \lambda_{\mathrm{S}}=1,8 \mu \mathrm{m}
\end{aligned}
$$

Os valores obtidos nas eqs. (3.14) e (3.15) nos dão o intervalo de rotação que o suporte da grade deverá ter, para garantir o alcance no estágio de amplificação de toda a faixa espectral da semente necessária.

$\mathrm{Na}$ figura 25 é apresentada uma ilustração do projeto do estágio de rotação da grade de difração. Um micrômetro atua sobre uma haste presa ao poste onde se encontra a grade, e o poste por sua vez se encontra livre para girar. O movimento do micrômetro é controlado por um motor de passo através de uma correia dentada que conecta as polias dos dois. O projeto foi feito em um software de desenho 3D, o SolidWorks, onde foram realizadas simulações de movimento antes da confecção das peças, a fim de verificar a validade dos cálculos realizados.

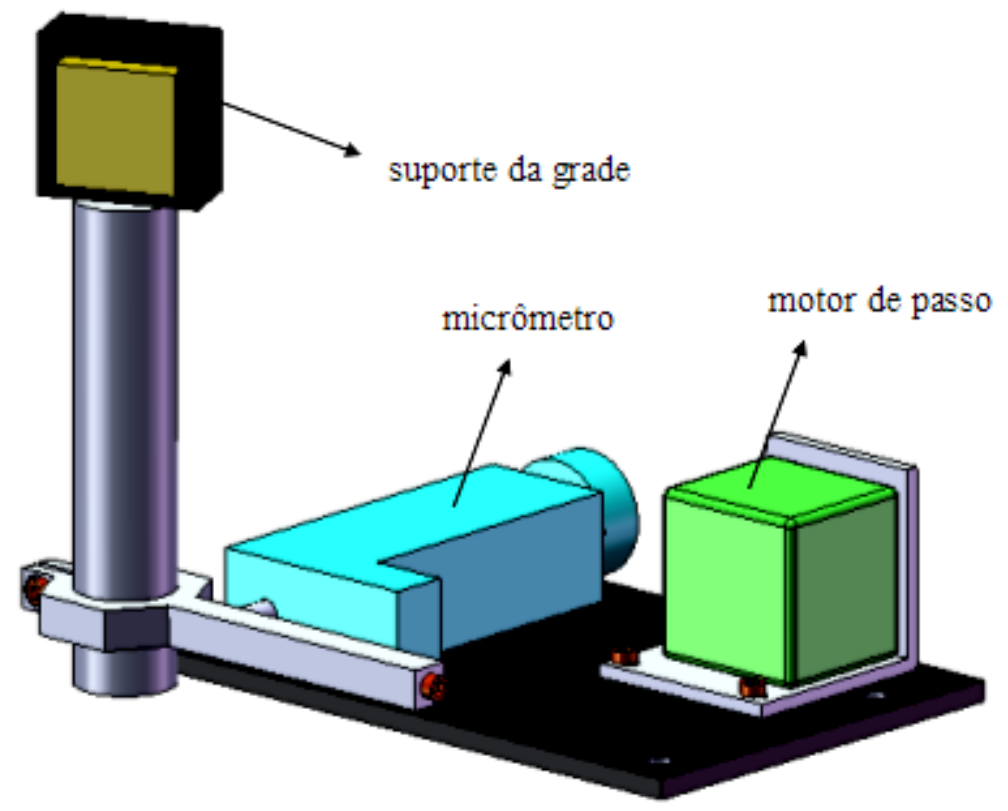

Figura 25 - Ilustração simplificada do estágio de rotação da grade de difração. 


\subsubsection{Resolução espectral}

Como mencionamos anteriormente, as imagens da fenda de entrada são formadas no plano focal de $L_{2}$ e separadas lateralmente devido a dispersão linear do sistema, dessa forma, a separação entre duas imagens correspondentes as linhas $\lambda$ e $\lambda+\Delta \lambda \mathrm{e}^{56}$ :

$$
\Delta x_{2}=f_{2} \frac{d \beta}{d \lambda} \Delta \lambda
$$

onde o termo $f_{2} \frac{d \beta}{d \lambda}$ corresponde a dispersão linear do sistema e $f_{2}$ à distância focal da lente $L_{2}$. Ou seja, quanto maior for a distância focal da lente imageadora, maior será a separação espacial entre as imagens.

Como vimos, o termo $\frac{d \beta}{d \lambda}$ é a dispersão angular da grade de difração, ao inserirmos sua relação correspondente a configuração Littrow dada pela eq. (3.7) na eq. (3.16) teremos:

$$
\Delta x_{2}=2 f_{2} \tan \alpha \frac{\Delta \lambda}{\lambda}
$$

Visto que $\frac{\Delta \lambda}{\lambda}=\frac{\Delta \widetilde{v}}{\widetilde{v}}$, onde $\widetilde{v} \equiv 1 / \lambda$ é o número de onda e, substituindo na equação anterior, temos que a separação das imagens é dada por:

$$
\Delta x_{2}=2 f_{2} \tan \alpha \frac{\Delta \tilde{v}}{\tilde{v}}
$$

Da óptica geométrica temos que para esse sistema a largura da imagem, $\delta x_{2}$, é dada em função da largura do objeto (fenda de entrada), $\delta x_{1}$, através da relação:

$$
\delta x_{2}=\frac{f_{2}}{f_{1}} \delta x_{1}
$$


Para resolver as duas linhas $\lambda$ e $\lambda+\Delta \lambda$, a separação $\Delta x_{2}$ tem que ser pelo menos igual a $\delta x_{2}$ :

$$
\Delta x_{2}=\delta x_{2}
$$

Para satisfazer a eq. (3.20) utilizamos as eqs (3.18) e (3.19), e chegamos na condição:

$$
\tan \alpha \frac{\Delta \widetilde{v}_{\min }}{\widetilde{v}}=\frac{\delta x_{1}}{2 f_{1}}
$$

Seja $d$ o diâmetro do filamento formado dentro do material devido ao efeito de selftrapping da luz, consideraremos $d$ como sendo o diâmetro de um feixe gaussiano no plano focal de $L_{1}$, temos:

$$
d=\delta x_{1}=\frac{4 \lambda f_{1}}{\pi D}
$$

onde $D$ é o diâmetro do feixe de luz supercontínua que chega na grade de difração depois de ser colimado pela lente $L_{1}$, como ilustrado na figura 18 , temos então que:

$$
\delta x_{1}=\frac{4 \lambda f_{1}}{\pi D}
$$

que substituindo na eq. 3.21 nos leva a equação para a resolução espectral mínima do monocromador em função do diâmetro $D$ do feixe de luz que chega na grade de difração:

$$
\Delta \tilde{v}_{\min }=\frac{2 \tilde{v} \lambda}{\pi D \tan \alpha}=\frac{2}{\pi D \tan \alpha}
$$


Fibra "Nonlinear Photonic Fiber - SC-5.0-1040"

Para o caso em que temos $\delta x_{1}$ correspondendo ao diâmetro do núcleo da fibra "Nonlinear Photonic Fiber - SC-5.0-1040" $(4,8 \mu \mathrm{m})$ e $D=16 \mathrm{~mm}$ (obtido experimentalmente para $f_{1}=35 \mathrm{~mm}$ ), podemos calcular a resolução espectral mínima esperada para o OPA a partir da eq. (3.24) para os extremos da faixa de sintonia da semente, que correspondem aos comprimentos de onda $1,2 \mu \mathrm{m}\left(\alpha=21^{0}\right)$ e $1,8 \mu \mathrm{m}\left(\alpha=33^{\circ}\right)$ respectivamente:

$$
\begin{array}{ll}
\Delta \widetilde{v}_{\min }=1,04 \mathrm{~cm}^{-1}, & \lambda_{\mathrm{S}}=1,2 \mu \mathrm{m} \\
\Delta \widetilde{v}_{\min }=0,61 \mathrm{~cm}^{-1}, & \lambda_{\mathrm{S}}=1,8 \mu \mathrm{m}
\end{array}
$$

Contudo, para estimarmos a resolução espectral do monocromador devemos fazer:

$$
\Delta \widetilde{v}=\Delta \widetilde{v}_{\min } \times \frac{2 r}{\delta x_{2}}
$$

onde $2 r$ é o diâmetro $(50 \mu \mathrm{m})$ da abertura posicionada entre as lentes $L_{2}$ e $L_{3}$ (ver figura 18) e $\delta x_{2}$ é a largura da imagem do espote do supercontínuo na saída do meio ( diâmetro do núcleo da fibra óptica), e pode ser calculada a partir da eq. (3.19). Fazendo uso da eq. (3.27), temos finalmente que para os extremos da faixa de sintonia da semente; $1,2 \mu \mathrm{m}$ e $1,8 \mu \mathrm{m}$, respectivamente:

$$
\begin{array}{ll}
\Delta \widetilde{v}=2,53 \mathrm{~cm}^{-1}, & \lambda_{\mathrm{S}}=1,2 \mu \mathrm{m} \\
\Delta \tilde{v}=1,48 \mathrm{~cm}^{-1}, & \lambda_{\mathrm{S}}=1,8 \mu \mathrm{m}
\end{array}
$$

Água deuterada

Para o caso da água deuterada em que temos $D$ igual a $8 \mathrm{~mm}$ (determinado experimentalmente para a região central mais brilhante do feixe supercontínuo) e a distância 
focal da lente $L_{1}$ dada por $f_{1}=500 \mathrm{~mm}$, teremos para os extremos da faixa de sintonia da semente, que correspondem aos comprimentos de onda $1,2 \mu \mathrm{m}\left(\alpha=21^{0}\right)$ e $1,8 \mu \mathrm{m}\left(\alpha=33^{0}\right)$, os seguintes valores para a resolução espectral mínima (calculados a partir da eq. 3.24) respectivamente:

$$
\begin{array}{ll}
\Delta \widetilde{v}_{\min }=2,07 \mathrm{~cm}^{-1}, & \lambda_{\mathrm{S}}=1,2 \mu \mathrm{m} \\
\Delta \widetilde{v}_{\min }=1,22 \mathrm{~cm}^{-1} \quad, \quad \lambda_{\mathrm{S}}=1,8 \mu \mathrm{m}
\end{array}
$$

Como mencionamos antes, a resolução espectral do monocromador é dada pela eq. (3.27), que nos dá para os extremos da faixa de sintonia da semente; $1,2 \mu \mathrm{m}$ e $1,8 \mu \mathrm{m}$, respectivamente:

$$
\begin{array}{ll}
\Delta \widetilde{v}=3,61 \mathrm{~cm}^{-1}, & \lambda_{\mathrm{S}}=1,2 \mu \mathrm{m} \\
\Delta \tilde{v}=1,42 \mathrm{~cm}^{-1}, & \lambda_{\mathrm{S}}=1,8 \mu \mathrm{m}
\end{array}
$$

\subsection{Geração do idler}

\subsubsection{Curva de sintonia do OPA}

As frequências do feixe sinal e do feixe idler na saída do OPA serão determinadas pela condição de casamento de fase colinear dada pela eq. (2.28) na seção 2.2.2 e, elas poderão ser sintonizadas pela rotação do cristal não-linear. Para que um cristal não-linear seja considerado apropriado para o projeto do OPA ele deverá satisfazer uma série de requisitos; possuir um intervalo de sintonia na faixa espectral de operação do OPA, ter um alto coeficiente não-linear e limiar de dano, ter uma baixa absorção tanto para o feixe de bombeio quanto para os feixes sinal e idler, ter um comprimento que permita uma alta eficiência de conversão sobre toda a 
faixa de sintonia e uma diferença mínima entre as velocidades de grupo do pulso de bombeio e dos pulsos gerados ${ }^{23}$.

Para OPAs com sintonia no infravermelho médio, os cristais $\mathrm{AgGaS}_{2}$ e $\mathrm{AgGaSe}_{2}$ são os mais utilizados. O cristal comprado para esse projeto é um $\mathrm{AgGaS}_{2}$ que é um cristal transparente de $500 \mathrm{~nm}$ a $12 \mu \mathrm{m}$, com coeficiente não-linear a $10,6 \mu \mathrm{m}$ dado por $12-18 \mathrm{pm} / \mathrm{V}$, e possui um limiar de dano em torno de 0,6 a $0,7 \mathrm{GW} / \mathrm{cm}^{2}$ quando bombeado por pulsos em $1064 \mathrm{~nm}$ e $35 \mathrm{ps}^{23}$. O cristal foi cortado para a condição de casamento de fase tipo-I com um ângulo de corte $\theta_{\mathrm{C}}$ entre a normal à superfície e o eixo óptico. Para determinar o ângulo $\theta_{\mathrm{C}}$ apropriado para nosso OPA, calculamos o ângulo de casamento de fases usando a eq. (2.30) e a relação de Selmeier para a dispersão de $n_{\mathrm{o}}$ e $n_{\mathrm{e}}$ do cristal $^{24}$. Como podemos observar na figura 26, para o intervalo de sintonia do idler ser de 2,5 a $10 \mu \mathrm{m}$, a orientação do feixe dentro do cristal em relação ao eixo óptico deve variar entre $36^{\circ}$ e $53^{\circ}$. O ângulo de corte $\theta_{\mathrm{C}}$ é escolhido então aproximadamente no centro dessa faixa, $\theta_{C}=45^{\circ}$, correspondendo a $\lambda_{2}=4,5$ $\mu \mathrm{m}$.

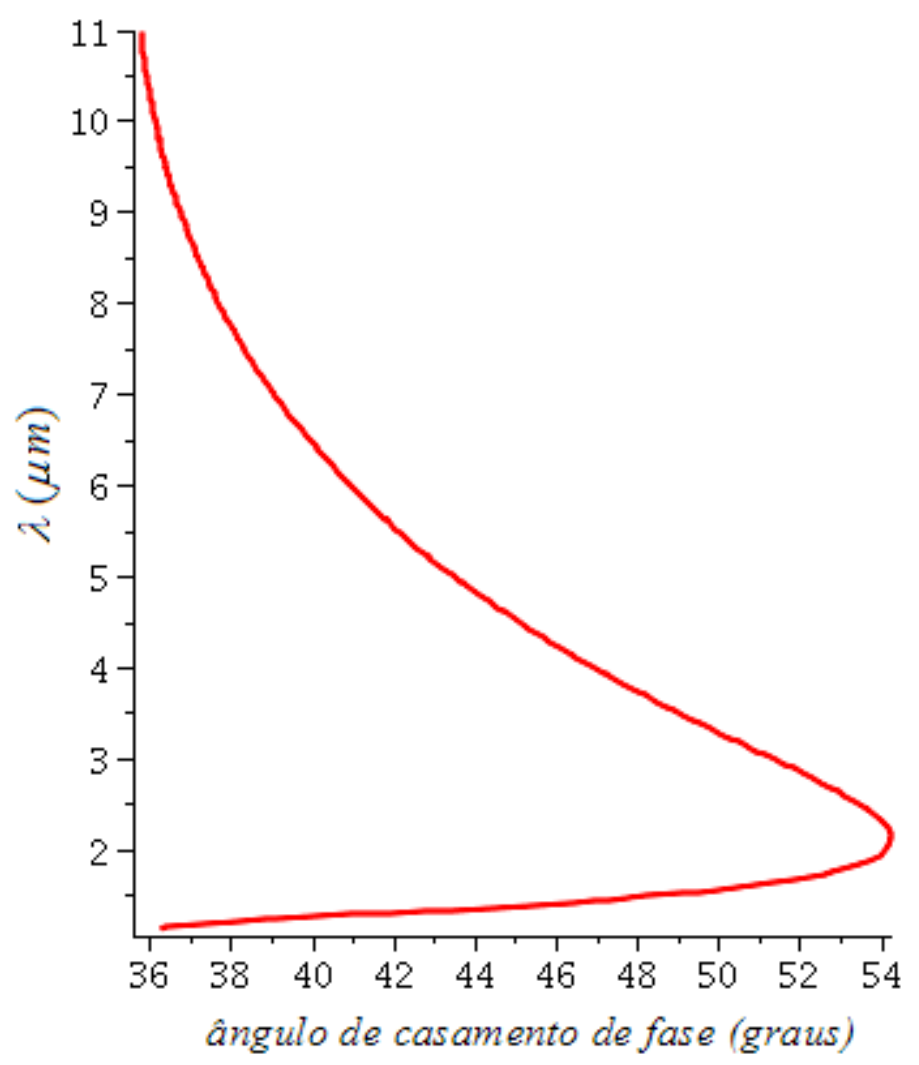

Figura 26 - Curva de sintonia do OPA para o casamento de fase tipo-I no cristal $\mathrm{AgGaS}_{2}$ em função do ângulo interno $\theta_{p m}$. 


\subsubsection{Projeto do suporte do cristal não-linear}

Para calcularmos o intervalo angular que o suporte do cristal deve percorrer a fim de cobrir toda a faixa do casamento de fase do cristal $\left(\theta_{\mathrm{pm}}=36^{\circ}\right.$ a $\left.53^{\circ}\right)$, é necessário que calculemos o ângulo de incidência $\alpha$ dos feixes na superfície do cristal.

Para o caso do feixe-sinal que possui polarização perpendicular ao plano principal do cristal, ou seja, que é um feixe ordinário, temos que ${ }^{24}$ :

$$
\sin \left(\alpha_{s}\right)=n_{0} \sin \left(\psi_{0}\right)
$$

onde o índice de refração ordinário principal $n_{0}$, é dado para o cristal $\mathrm{AgGaS}_{2}$ a temperatura de $20^{\circ} \mathrm{C}$ pela relação de dispersão ${ }^{24}$ :

$$
n_{0}^{2}=3,3970+\frac{2,3982 \lambda^{2}}{\lambda^{2}-0,09311}+\frac{2,1640 \lambda^{2}}{\lambda^{2}-950,0}
$$

e $\psi_{0}$ é o ângulo de refração, como ilustrado na parte (a) da figura 27.

(a)

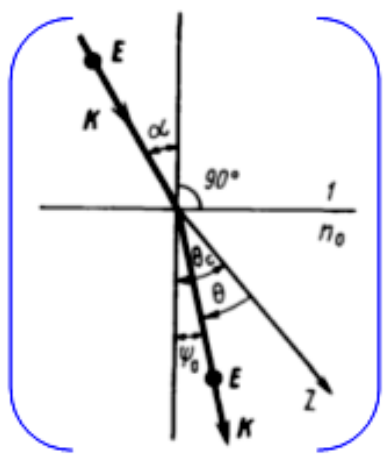

(b)

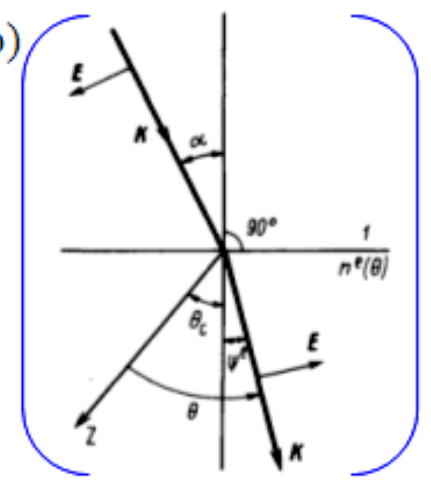

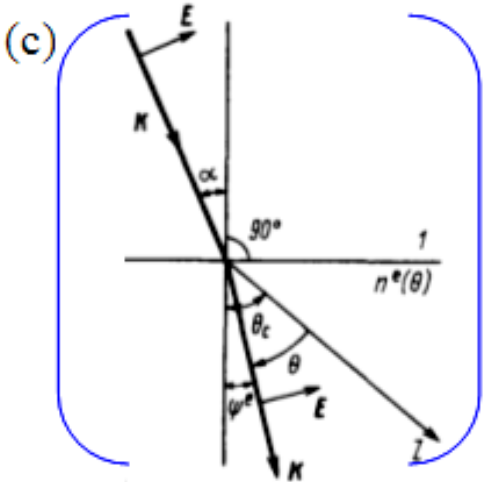

Figura 27 - Ângulos de incidência e refração dos feixes na superfície do cristal $\mathrm{AgGaS}_{2}$, para uma onda ordinária (a) e para uma onda extraordinária (b) e (c).

Da figura 27 tiramos que $\psi_{0}=\theta_{c}-\theta_{p m}$, onde $\theta_{c}$ corresponde como dissemos anteriormente ao ângulo de corte do cristal que como mencionamos é $45^{\circ}$, fazendo uso da curva de sintonia do cristal e das eqs. (3.34) e (3.35), chegamos nos valores de $\theta_{p m}, \psi_{0}$ e $\alpha_{s}$ (tabela 4). 
Tabela 4 - Dados utilizados para calcular o ângulo de incidência $(\alpha)$ no cristal para o feixe-sinal.

\begin{tabular}{|ccc|}
\cline { 2 - 3 } \multicolumn{1}{c|}{} & $\lambda=1,2 \mu m$ & $\lambda=1,8 \mu m$ \\
\hline$n_{0}$ & 2,4408 & 2,4205 \\
$\theta_{p m}($ graus $)$ & 36,1 & 53,4 \\
\hline$\psi_{0}($ graus $)$ & 8,9 & $-8,4$ \\
$\alpha_{s}($ graus $)$ & 22,19 & $-20,71$ \\
\hline
\end{tabular}

Para o caso do feixe de bombeio que possui polarização paralela ao plano principal do cristal, ou seja, que é um feixe extraordinário, temos que ${ }^{24}$ :

$$
\frac{\sin \left(\alpha_{s}\right)}{\sin \left(\psi^{e}\right)}=n^{e}(\theta)=\frac{n_{0} \sqrt{1+\tan ^{2}\left(\theta_{c} \pm \psi^{e}\right)}}{\sqrt{1\left(n_{0} / n_{e}\right)^{2} \tan ^{2}\left(\theta_{c} \pm \psi^{e}\right)}}
$$

onde $\psi^{e}$ é o ângulo de refração do feixe extraordinário, como ilustrado nas partes b e c da figura 27. Caso o vetor da onda e o eixo óptico $Z$ estejam do mesmo lado da normal à superfície do cristal (parte c da figura 27), então o sinal menos é usado na eq. (3.36), caso contrário o sinal mais é usado (parte b da figura 27). Enquanto que o índice de refração extraordinário principal $n_{e}$, é dado para o cristal $\mathrm{AgGaS}_{2}$ a temperatura de $20^{\circ} \mathrm{C}$ pela relação de dispersão ${ }^{24}$ :

$$
n_{e}^{2}=3,5873+\frac{1,9533 \lambda^{2}}{\lambda^{2}-0,11066}+\frac{2,3391 \lambda^{2}}{\lambda^{2}-1030,7}
$$

Através da curva de sintonia do cristal e das eqs. (3.36) e (3.37), temos que os valores de $\theta_{p m}, \psi^{e}$ e $\alpha_{p}$ são os mostrados na tabela 5:

Tabela 5 - Dados utilizados para calcular o ângulo de incidência $(\alpha)$ no cristal para o feixe de bombeio

\begin{tabular}{|c|c|c|}
\hline$n_{0}$ & 2,3978 & \\
\hline$n_{e}$ & 2,4510 & \\
\hline$\theta_{p m}($ graus $)$ & 36,1 & 53,4 \\
\hline$\psi^{e}$ (graus) & 8,9 & $-8,4$ \\
\hline$\alpha_{p}($ graus $)$ & 22,10 & $-20,81$ \\
\hline
\end{tabular}
$(1,064 \mu \mathrm{m})$. 
Logo, o suporte do cristal deverá cobrir uma faixa angular entre aproximadamente $21^{\circ}$ e $23^{\circ}$. Na figura 28 está ilustrado de forma simplificada o estágio de rotação projetado para o cristal.

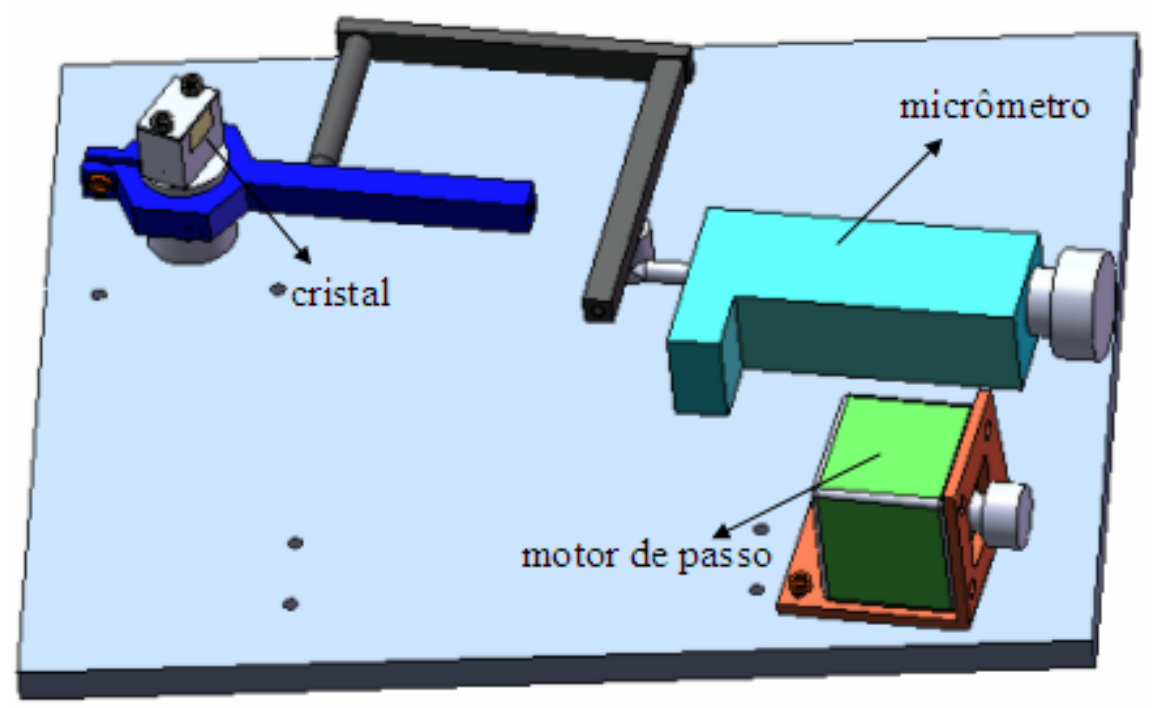

Figura 28 - Esquema simplificado do estágio de rotação do cristal não-linear.

Um micrômetro com curso de $25 \mathrm{~mm}$ atua sobre uma alavanca, que por sua vez atua sobre uma haste presa ao poste onde se encontra o suporte do cristal. O poste encontra-se livre para girar. O movimento do micrômetro é controlado por um motor de passo através de uma correia dentada que conecta as polias dos dois. Assim como o projeto do suporte da grade de difração, o projeto do suporte do cristal foi feito no software SolidWorks, onde foram realizadas simulações de movimento para verificar a validade dos cálculos realizados.

\subsubsection{Conversão de energia no OPA}

Um sistema OPA é dito eficiente quando apresenta uma alta conversão de energia do feixe de bombeio para os feixes sinal e idler e, portanto o projeto do referido sistema deve ser tal que proporcione a maximização dessa conversão de energia. Muitos parâmetros são conhecidos por influenciarem nesse processo de troca de energia entre os feixes; o comprimento do cristal não-linear, a intensidade do feixe de bombeio, a intensidade do feixe- 
sinal na entrada do cristal (que atua como semente no processo de amplificação), além do perfil espacial e temporal dos feixes envolvidos.

Saída do OPA em função do comprimento do cristal

Como mencionamos na seção 2.2.1, quando temos o caso em que o comprimento do cristal é menor que o comprimento de interação não-linear $\left(L_{c}<L_{N L}\right)$ e o feixe de bombeio é muito mais intenso que os feixes semente e idler, a solução encontrada para as intensidades dos feixes no regime sem depleção do bombeio, vista no capitulo 2 desse trabalho, torna-se apropriada e a saída do OPA apresentará uma dependência com o comprimento do cristal como a ilustrada na figura 8. Contudo, para configurações em que $L_{c}>L_{N L}$ (mas ainda considerando os feixes como ondas planas), uma significativa troca de energia é esperada entre os feixes acoplados, de tal maneira que as intensidades dos feixes envolvidos no processo passam a ter a mesma ordem de grandeza a partir de um determinado comprimento percorrido no cristal, ou seja, a aproximação feita de ausência de depleção do bombeio deixa de ter sentido e as eqs. (2.25) e (2.26) dão lugar a equações mais complexas ${ }^{5,23}$ :

$$
\begin{gathered}
I_{1}(z)=I_{1}(0)+\frac{\omega_{1}}{\omega_{3}} I_{3}(0)\left\{1-s n^{2}\left[N g_{0} z-\frac{K(N)}{N^{1 / 2}}, N\right]\right\} \\
I_{2}(z)=\frac{\omega_{2}}{\omega_{3}} I_{3}(0)\left\{1-s n^{2}\left[N g_{0} z-\frac{K(N)}{N^{1 / 2}}, N\right]\right\} \\
I_{3}(z)=I_{3}(0) s n^{2}\left[N g_{0} z-\frac{K(N)}{N^{1 / 2}}, N\right]
\end{gathered}
$$

onde $g_{0}=\left(\frac{32 \pi^{3} \omega_{1} \omega_{2} d_{e f f}^{2} I_{3}(0)}{c^{3} n_{1} n_{2} n_{3}}\right)^{1 / 2}$, sn é a função elíptica de Jacobi ${ }^{57}$, e $K(N)$ é a função elíptica completa de primeira ordem, com $N=\frac{1}{1+\left[\omega_{3} I_{1}(0)\right] /\left[\omega_{1} I_{3}(0)\right]}$. As eqs (3.38) a (3.40) mostram que para esse regime a intensidade do feixe de bombeio não é mais considerada 
constante, agora é levado em conta que uma parte da energia de $\omega_{3}$ é transferida para o sinal (promovendo sua amplificação) e uma outra parte dessa energia é utilizada para a geração do feixe idler.

Utilizando essa aproximação de ondas planas e assumindo um perfil temporal do tipo quadrado para os feixes, utilizamos a eq. (3.39) para calcular a saída do nosso OPA em função dos parâmetros $z$ e $I_{3}$ (comprimento do cristal e intensidade do feixe de bombeio), o resultado obtido pode ser visto na figura 29.

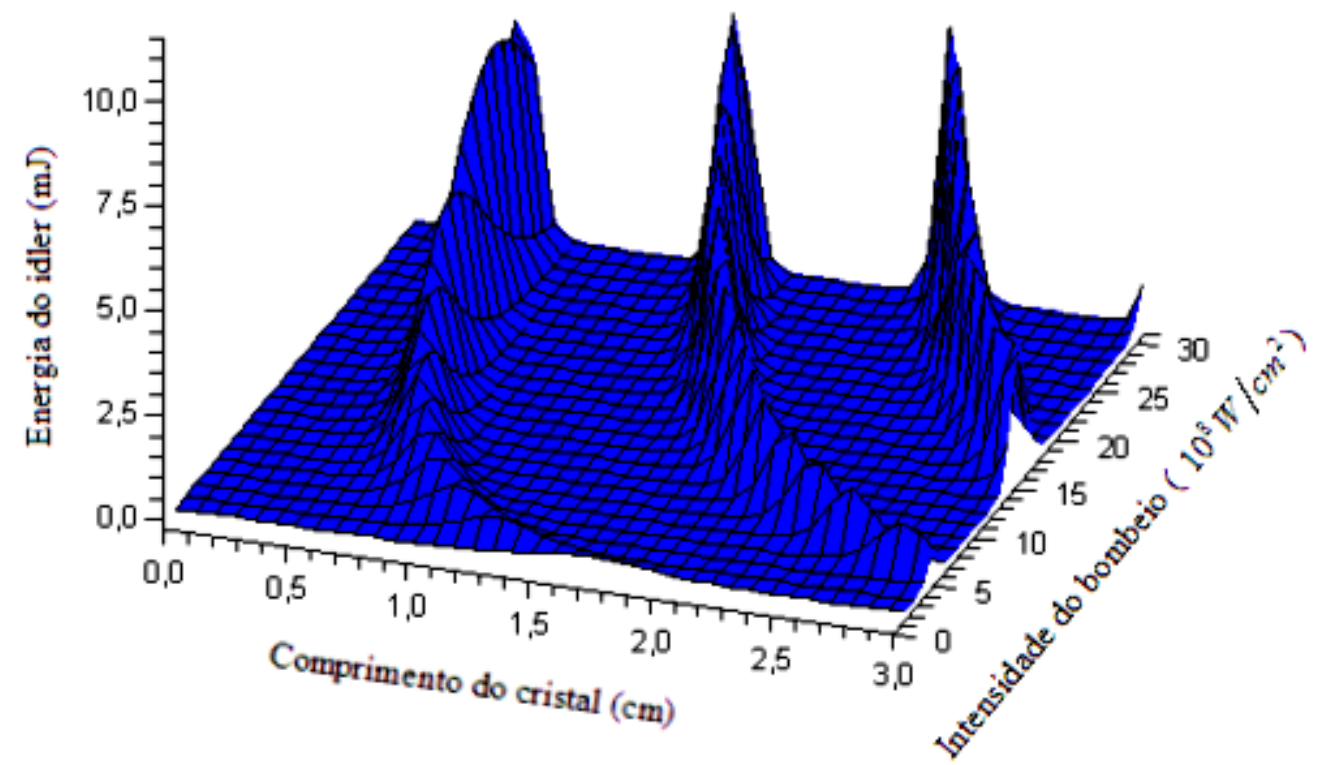

Figura 29 - Energia do feixe idler em função dos parâmetros $\mathrm{z}$ e $\mathrm{I}_{3}$ calculada para o nosso OPA, na aproximação de ondas planas, mas no regime de depleção do bombeio.

Nos cálculos para gerar o gráfico ilustrado na figura 29 fixamos a energia, o diâmetro e o comprimento de onda do feixe sinal em $0,4 \mu \mathrm{J} ; 8 \mathrm{~mm}$ e $1300 \mathrm{~nm}$ respectivamente (correspondendo a um índice de refração igual a 2,431), utilizamos o feixe idler em $5861 \mathrm{~nm}$ (correspondendo a um índice de refração dado por 2,399) e o feixe de bombeio em $1064 \mathrm{~nm}$ (correspondendo a um índice de refração dado por 2,398); utilizamos também nos cálculos $d_{\text {eff }}=18 \mathrm{pm} / \mathrm{V}$. Tendo em vista que o limiar de dano do cristal utilizado no estágio de amplificação paramétrica $\left(\mathrm{AgGaS}_{2}\right)$ é em torno de 0,6 a $0,7 \mathrm{GW} / \mathrm{cm}^{2}$ quando bombeado por pulsos em $1064 \mathrm{~nm}$ e $35 \mathrm{ps}^{23}$, a intensidade do pulso de bombeio será restrita a 0,5 $\mathrm{GW} / \mathrm{cm}^{2}$. Analisando o gráfico apresentado na figura 29, temos que para esse valor de intensidade de bombeio, o cristal que nos proporcionaria uma eficiência máxima na geração do idler teria que ter um comprimento de $0,96 \mathrm{~cm}$, gerando assim $1,1 \mathrm{~mJ}$ na saída do OPA (energia do idler), o que corresponde a uma eficiência de 12,5\% na conversão de energia do bombeio para 
o idler. Contudo, este cálculo é bastante aproximado, visto que foi utilizada a aproximação de ondas planas e assumiu-se um perfil temporal do tipo quadrado para os feixes. Uma situação mais realista seria considerar um perfil espacial e temporal gaussiano para os pulsos envolvidos no processo de conversão não-linear.

Para ilustrar a dependência da energia da onda gerada $E_{2}$ com o comprimento do cristal e com a intensidade do bombeio nessa situação mais realista, vamos apresentar um exemplo da literatura ${ }^{23,58}$ no qual um cristal BBO tipo I é bombeado pelo terceiro harmônico de um laser mode-locked Nd:YAG $(355 \mathrm{~nm})$ com o pulso sinal com cerca de $5 \mu \mathrm{J}$ a $550 \mathrm{~nm}$ e um feixe com perfil gaussiano com diâmetro de $2 \mathrm{~mm}$ (figura 30).

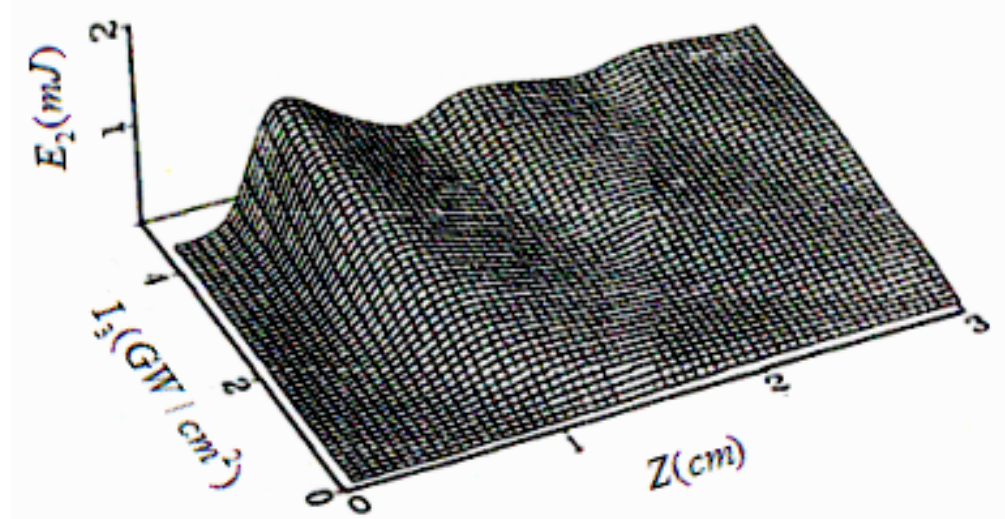

Figura 30 - Exemplo dos efeitos do comprimento do cristal e da intensidade do bombeio na intensidade do idler calculados a partir da equação (3.39) ${ }^{23}$.

Podemos notar na figura 30 que $I_{2}$ apresenta um comportamento oscilatório "amortecido" com o comprimento do cristal, onde os picos são menos intensos e definidos do que na aproximação de ondas planas, com a energia $E_{2}$ "distribuída" ao longo do eixo z (comprimento do cristal).

Saída do OPA em função da intensidade do bombeio

Na figura 30 também podemos observar que para um dado comprimento do cristal, a intensidade da saída do OPA aumenta com o aumento de $I_{3}$, além de apresentar uma fraca oscilação, esse comportamento pode ser melhor visualizado na figura 31 em que é feito um corte no gráfico $3 \mathrm{D}$ em $z=1,5 \mathrm{~cm}$. 


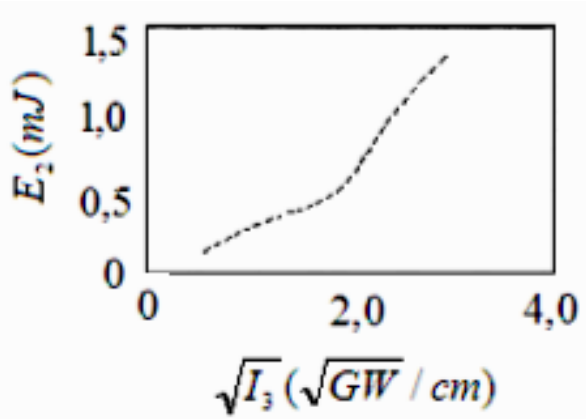

Figura 31 - Exemplo ilustrativo da energia do idler em função da intensidade de bombeio calculada a partir da eq. (3.39) para um dado comprimento do cristal $^{58}$.

Devido ao comportamento oscilatório das curvas ilustradas na figura 30, é possível que ao compararmos a saída de dois cristais não-lineares, onde o primeiro cristal apresente uma não-linearidade maior que o segundo cristal, sendo ambos bombeados por uma mesma intensidade, possamos ter a saída do segundo cristal maior que a do primeiro ${ }^{58}$. O que nos leva a conclusão que para a obtenção de um sistema OPA eficiente, o comprimento do cristal e a intensidade de bombeio devem ser escolhidos simultaneamente, uma vez que seus efeitos são complementares. Para uma operação segura do OPA com relação a integridade do cristal, o comprimento do cristal é escolhido em geral de forma que o OPA possa operar com uma intensidade de bombeio em torno de um fator entre 2 e 5 vezes menor que o limiar de dano do cristal $^{23}$.

Saída do OPA em função da intensidade da semente

Para ilustrar o comportamento esperado para a saída do OPA, ou seja, para a energia do idler em função da energia do feixe-sinal que incide no cristal, vamos utilizar o mesmo exemplo anterior para um cristal $\mathrm{BBO}^{23,58}$, onde a intensidade de bombeio nesse cálculo foi $2,4 \mathrm{GW} / \mathrm{cm}^{2}$. É mostrado o resultado para três diferentes comprimentos de onda do feixe sinal. 


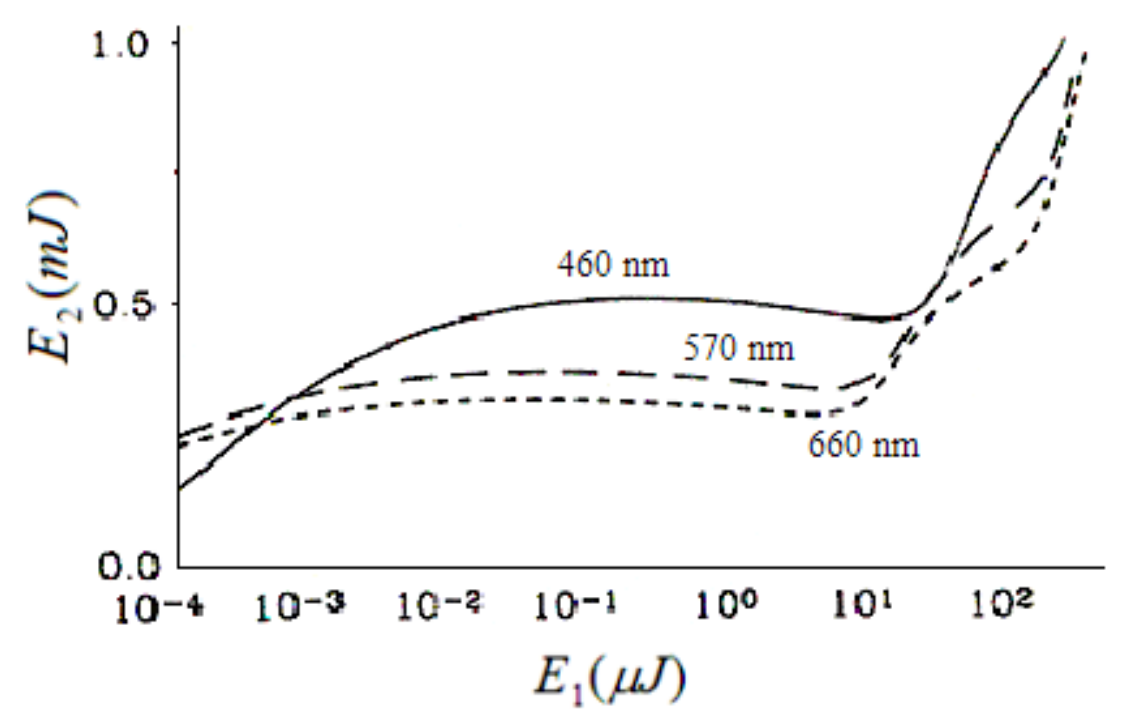

Figura 32 - Exemplo ilustrativo da energia calculada do idler em função da energia do feixe-sinal que incide no cristal para três diferentes comprimentos de onda do feixe sinal $(460,570 \text { e } 660 \mathrm{~nm})^{23}$.

Um resultado interessante que obtemos das curvas ilustradas na figura 32 é a existência de uma região bastante larga onde o sinal do idler parece ser insensível à variação da intensidade do sinal, região esta em que esperamos que o OPA seja mais estável em relação às flutuações do feixe sinal (semente).

Tendo em vista esse comportamento qualitativamente diferente dos resultados com feixes gaussianos em relação à aproximação de ondas planas, nossa estimativa do comprimento do cristal e eficiência de conversão devem ser reconsideradas. Esperamos então que o máximo de conversão ocorra para um comprimento do cristal um pouco maior, com uma redução na eficiência máxima do OPA. Já que o OPA comercial em operação no LENI utiliza um cristal de AGS de 1,4 cm de comprimento, iremos utilizar o mesmo comprimento para que o nosso cristal seja intercambiável com o do OPA comercial. 


\section{Resultados e Caracterização do OPA}

Inicialmente foi testada e caracterizada a geração de luz supercontínua em diversos materiais. Em seguida foi montado o monocromador e medida a largura de banda do pulso sinal em função do comprimento de onda na faixa de interesse. Finalmente foi montado o estágio de amplificação e testado o seu desempenho.

\subsection{Geração do feixe-sinal}

Como já mencionamos, a geração de luz supercontínua foi testada em diferentes materiais visando obter o espectro mais largo e a maior estabilidade possível na intensidade dos pulsos. Os materiais testados foram: água, água deuterada, vidro (BK7), fluoreto de bário, cloreto de potássio, fibra óptica fotônica de baixa não-linearidade e fibra fotônica de alta nãolinearidade.

\section{Geração de luz supercontínua em água deuterada}

Os testes consistiram em variarmos três parâmetros a fim de obtermos a geração do supercontínuo em uma cubeta com $10 \mathrm{~cm}$ de comprimento e otimizarmos a performance desse contínuo gerado. Os parâmetros variados foram; a distância focal da lente utilizada para focalizar o feixe, a distância entre a região focal da lente e a superfície de saída da cubeta e a energia do pulso de bombeio. A água deuterada, assim como a água, já vem sendo utilizada há décadas para a geração de supercontínuo no regime de picossegundos, tendo sido mostrado que o limiar de potência capaz de provocar danos ópticos (geração de plasma) aumenta com o aumento da distância focal da lente focalizadora, enquanto que o limiar de 
potência necessária para gerar o supercontínuo diminui com a distância focal da lente ${ }^{54}$. Logo, nos testes realizados foram escolhidas lentes com distâncias focais longas; 250, 500, 750, 1000 e $1500 \mathrm{~mm}$, na tentativa de alcançarmos a geração do contínuo sem a geração de plasma.

A absorção linear da água deuterada foi medida com um espectrômetro Cary 17 e pode ser vista na figura 33, a medida foi realizada na região do infravermelho próximo que corresponde à faixa de interesse para o projeto (faixa espectral que serve como semente para o estágio de amplificação paramétrica).

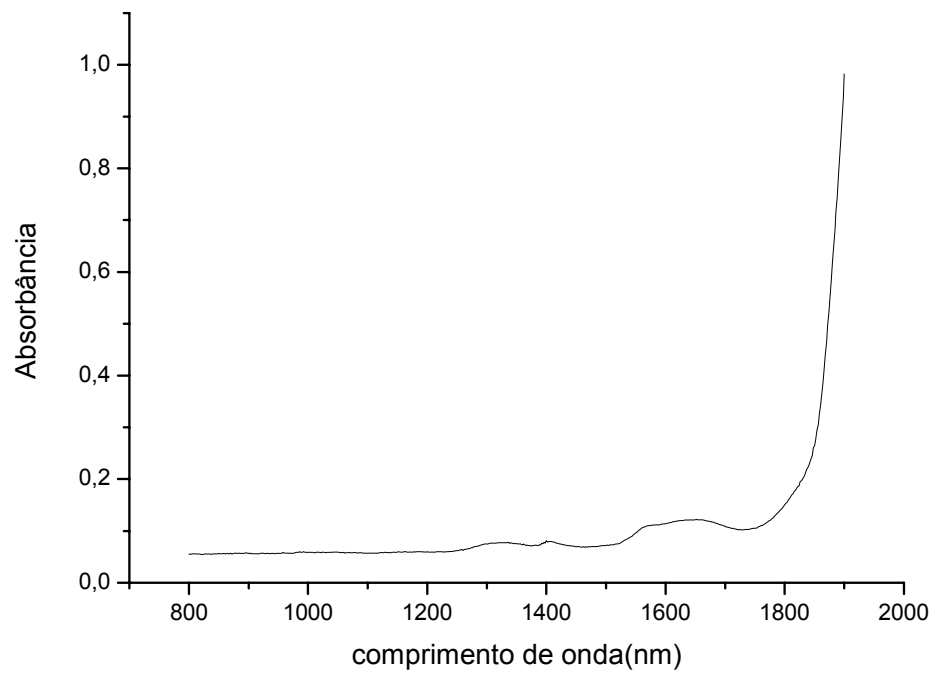

Figura 33 - Medida de absorção linear da água deuterada feita em uma cubeta de $2 \mathrm{~mm}$ de comprimento.

Analisando o espectro de absorção indicado na figura 33, pudemos observar que a água deuterada não apresenta grandes picos de absorção na região de interesse (1200 a 1800 nm). Resultado este que nos permitiu variar a posição do foco do feixe de bombeio por toda extensão da cubeta, sem nos preocuparmos com grandes absorções das frequências geradas.

Entre as lentes utilizadas para focalizar o bombeio dentro da cubeta, apenas com a de distância focal de $250 \mathrm{~mm}$ não conseguimos gerar o contínuo, contudo, a luz gerada para todas as demais lentes era muito instável. Para a lente de $1500 \mathrm{~mm}$ com uma energia de bombeio dada por:

$$
E_{0}=0,73 m J
$$

o contínuo piscava em um intervalo de aproximadamente quatro segundos, tornando inviável 
qualquer caracterização do espectro gerado.

Posteriormente voltamos a tentar a geração de luz supercontínua em água deuterada, mas utilizando telescópios no lugar da lente focalizadora. Porém, a duração temporal do feixe utilizado como bombeio passou de 25 para 54 ps. Testamos varias configurações diferentes de telescópios variando o diâmetro do feixe de bombeio, a melhor performance foi obtida utilizando-se uma lente convergente com distância focal de $400 \mathrm{~mm}$ e uma lente divergente com distância focal de $-60 \mathrm{~mm}$, com as quais obtivemos um feixe com diâmetro de 0,5 mm. A energia de bombeio necessária para observamos uma geração de "luz branca" contínua no tempo, foi:

$$
E_{0}=2,97 \mathrm{~mJ}
$$

A figura 34 apresenta uma foto da luz supercontínua gerada. Note que temos anéis concêntricos, onde o comprimento de onda de emissão do filamento depende do ângulo, sendo menor para ângulos maiores, além de uma região central mais intensa e de coloração mais branca.

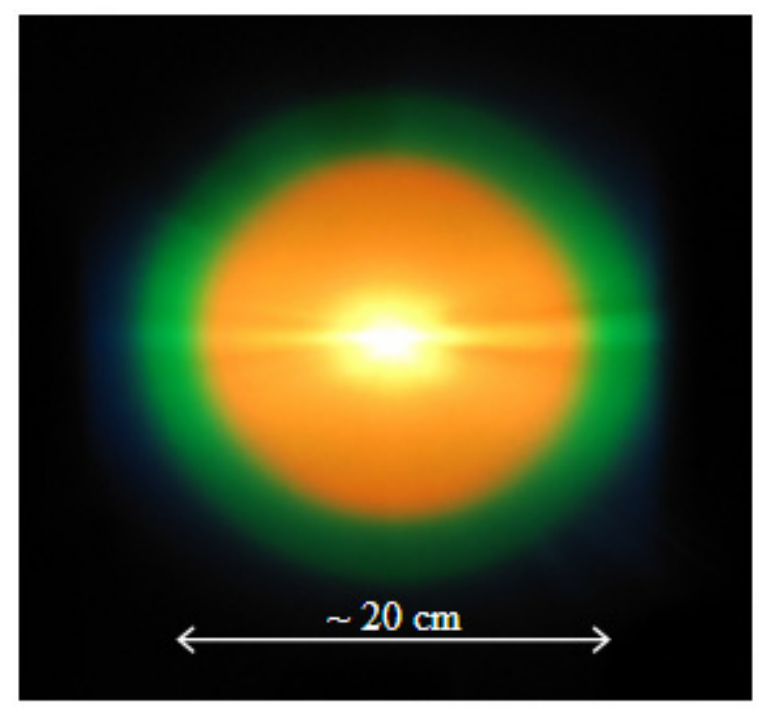

Figura 34 - Foto da projeção em um anteparo preto do supercontínuo gerado na água deuterada, observado a aproximadamente $50 \mathrm{~cm}$ da cubeta, onde a energia e a largura temporal do bombeio são respectivamente $2,97 \mathrm{~mJ}$ e $54 \mathrm{ps}$.

Com o auxilio de uma íris, medimos a energia $E_{C}$ e a estabilidade dessa parte central do contínuo (Tabela 6 ), tendo a energia do bombeio $\left(E_{0}=2,97 \mathrm{~mJ}\right)$ sido removida na saída da cubeta com um espelho dielétrico para $1064 \mathrm{~nm}$. A estabilidade é definida como a razão entre o desvio padrão da energia medida, $\sigma$, e seu valor médio, sendo tão melhor quanto 
menor for seu valor.

Tabela 6 - Medidas da energia e da estabilidade da parte central do espectro gerado.

\begin{tabular}{|cc|}
\hline$E_{C}(\mu J)$ & Estabilidade (\%) \\
\hline 0,584 & 58 \\
\hline
\end{tabular}

Também medimos a energia $E_{T}$ e a estabilidade de todo o contínuo (tabela 7):

Tabela 7 - Medidas da energia e da estabilidade de todo o contínuo gerado.

\begin{tabular}{|cc|}
\hline$E_{T}(\mu J)$ & Estabilidade (\%) \\
\hline 2,188 & 64 \\
\hline
\end{tabular}

Ao confrontarmos o valor de energia do bombeio para o contínuo gerado utilizando a lente de $1500 \mathrm{~mm}\left(E_{0}=0,73 \mathrm{~mJ}\right)$ com o valor de energia do bombeio do contínuo gerado utilizando o telescópio ( $E_{0}=2,97 \mathrm{~mJ}$ ), vemos que houve um aumento considerável desse valor, o que atribuímos em grande parte ao aumento da largura temporal do pulso de bombeio.

A figura 35 mostra o espectro medido com um espectrômetro NIR-512 (Ocean Optics Inc, EUA) da parte central do supercontínuo gerado (região central brilhante observada na figura 34). É importante ressaltar que foi colocado um filtro antes da entrada do espectrômetro para remover os comprimentos de onda gerados abaixo de $1000 \mathrm{~nm}$. 


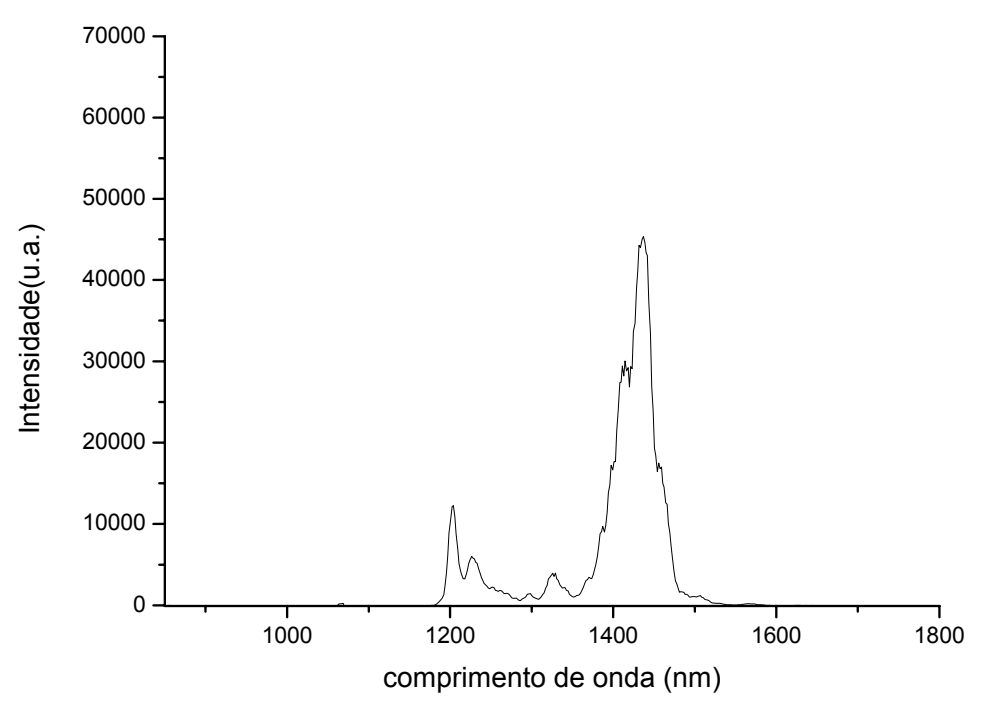

Figura 35 - Espectro medido da parte central do supercontínuo gerado em uma cubeta de $10 \mathrm{~cm}$ de comprimento contendo água deuterada, sendo a energia e a largura temporal do bombeio respectivamente $2,97 \mathrm{~mJ}$ e 54 ps. O espectrômetro utilizado para a medida foi um NIR-512.

O espectro medido de todo o supercontínuo gerado está ilustrado na figura 36. Os picos ao redor de $1444 \mathrm{~nm}$ e $1210 \mathrm{~nm}$ acreditamos advir do processo de Espalhamento Raman Estimulado, mencionado na seção 2.3.3, uma vez que as diferenças entre as frequências do feixe de bombeio e destes picos, estão próximas às frequências de estiramento e dobramento O-D da água deuterada $\left(\sim 2500 \mathrm{~cm}^{-1} \mathrm{e} \sim 1130 \mathrm{~cm}^{-1}\right.$, respectivamente $\left.{ }^{59}\right)$. Os dois espectros (figuras 35 e 36) são dominados por essa contribuição do espalhamento Raman estimulado, que não cobrem toda a região espectral necessária para servir de semente ao estágio de amplificação paramétrica (1200 a $1800 \mathrm{~nm})$. 


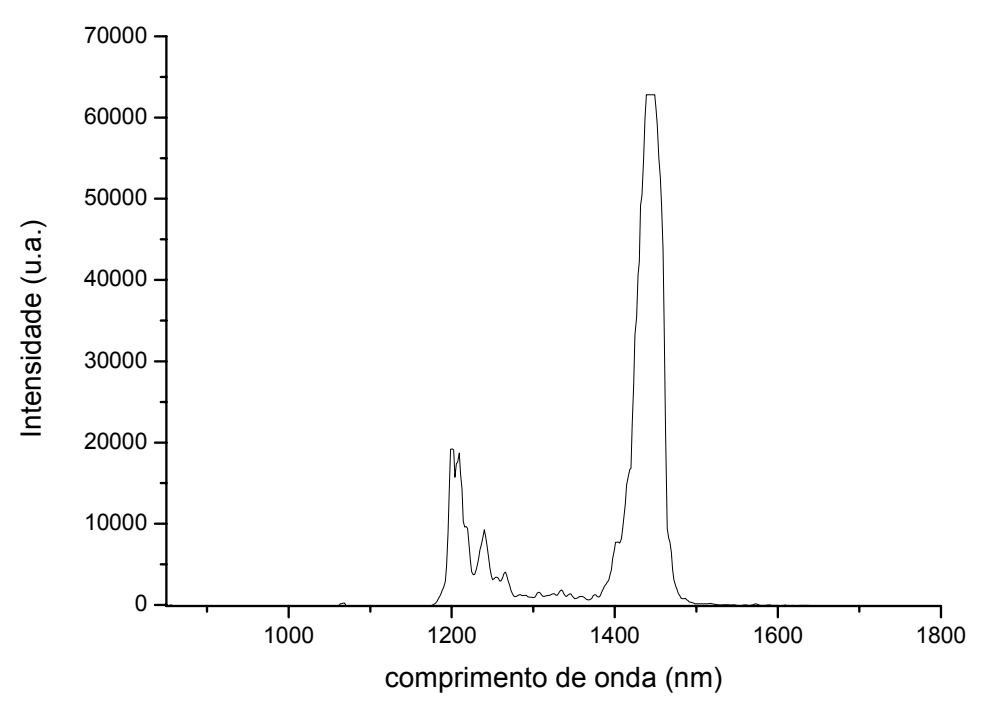

Figura 36 - Espectro medido do supercontínuo gerado em uma cubeta de $10 \mathrm{~cm}$ de comprimento contendo água deuterada com a energia e a largura temporal do bombeio dados respectivamente por $2,97 \mathrm{~mJ}$ e 54 ps. O espectrômetro utilizado para a medida foi um NIR-512.

A fim de determinar se há uma polarização preferencial, posicionamos um polarizador de calcita na saída da cubeta e realizamos as medidas dos espectros do supercontínuo em função da diferença angular entre a orientação do eixo de transmissão do polarizador e a direção da polarização do bombeio (ver figura 37).

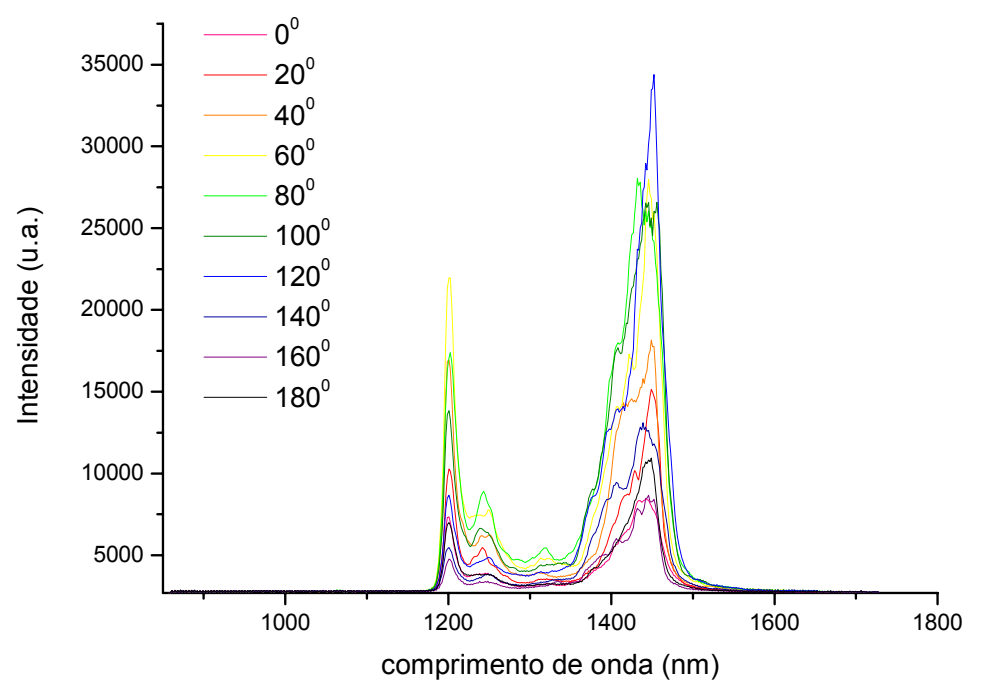

Figura 37 - Medidas espectrais do supercontínuo gerado em água deuterada em função da diferença angular entre o eixo do polarizador (posicionado na saída da cubeta) e a direção de polarização do bombeio. $\mathrm{O}$ espectrômetro utilizado para a medida foi um NIR-512.

Podemos observar pela figura 37 que a luz supercontínua emitida é menos polarizada 
que o feixe de bombeio (o mínimo de intensidade não é nulo) e sua polarização preferencial não é paralela à do bombeio, visto que para $80^{\circ}$ e $100^{\circ}$ (valores próximos a $90^{\circ}$ ) não temos as situações de menores intensidades como se esperava caso a polarização fosse a mesma que a do bombeio. Isto está em contraste com o relatado recentemente na literatura, onde afirma-se que a luz supercontínua gerada mantém a polarização do bombeio, quando este tem polarização linear ${ }^{60}$.

\section{Geração de luz supercontínua em água}

A água utilizada nos testes foi a "água ultrapura", com $\mathrm{pH} \sim 6$ e resistividade 18.2 $\mathrm{M} \Omega \cdot \mathrm{cm}$ fornecida por um sistema de purificação Millipore, contida em uma cubeta com 30 $\mathrm{cm}$ de comprimento e os testes realizados foram os mesmos que os descritos anteriormente para a água deuterada. Assim como para a água deuterada, foi medida a absorção linear da água, ilustrada na figura 38 .

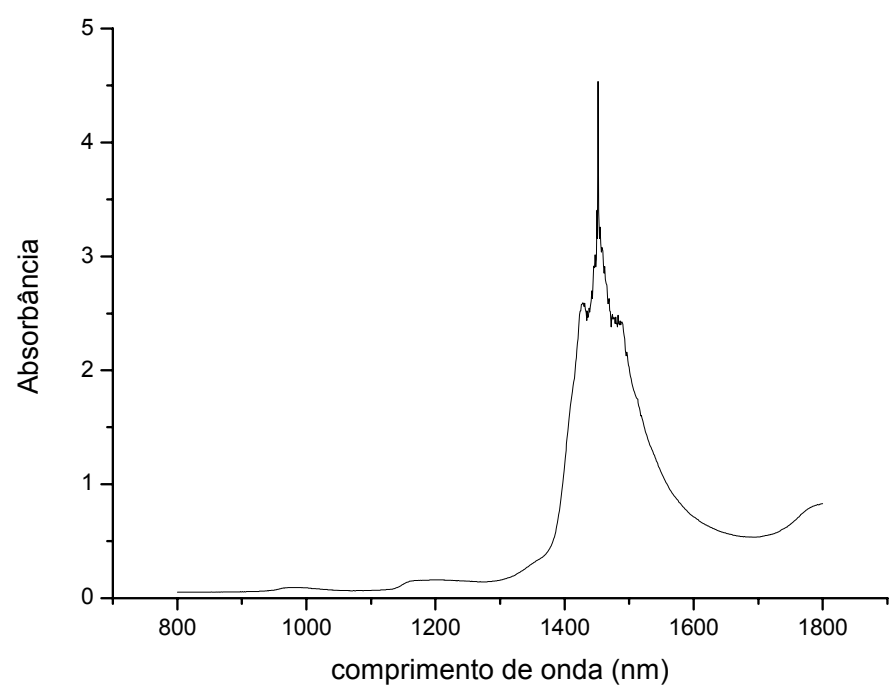

Figura 38 - Medida de absorção linear da água feita em uma cubeta de $2 \mathrm{~mm}$ de comprimento. O espectrômetro utilizado para a medida foi um Cary 17.

Como podemos notar na figura 38, a água apresenta uma alta absorção acima de 1400 nm, o que pode prejudicar a obtenção da semente do OPA nessa região, haja vista que, mesmo que essas frequências sejam geradas dentro da cubeta, elas poderão ser fortemente (ou 
totalmente) absorvidas pela água antes de alcançarem a saída da cubeta. Sendo assim, focalizamos o feixe de bombeio entre o centro e a janela de saída da cubeta, na tentativa de minimizar os efeitos de absorção nas frequências geradas.

O melhor resultado foi obtido com a lente de distância focal $1000 \mathrm{~mm}$, com uma energia de bombeio $E_{0}=1,5 \mathrm{~mJ}$ e largura temporal do pulso $25 \mathrm{ps}$. Contudo, o contínuo gerado era muito instável, apresentando-se completamente inviável para nossos objetivos.

Geração de luz supercontínua em mistura de água + água deuterada

Realizamos uma mistura de água e água deuterada na tentativa de alargarmos o espectro gerado na água deuterada (figuras 35 e 36). A idéia central é produzir uma mistura isotópica de grupos $\mathrm{OH}$ e $\mathrm{OD}$, com diferentes frequências de vibrações $\left(\mathrm{OH}\right.$ em $\sim 1600 \mathrm{~cm}^{-1}$ $\mathrm{e} \sim 3400 \mathrm{~cm}^{-1}$; OD em $\sim 1130 \mathrm{~cm}^{-1} \mathrm{e} \sim 2500 \mathrm{~cm}^{-1}$ ), produzindo assim mais picos largos no espectro do supercontínuo, via espalhamento Raman estimulado. Para tal fizemos duas soluções; a primeira constituiu-se de uma solução formada por $50 \%$ de água e $50 \%$ de água deuterada em uma cubeta com $30 \mathrm{~cm}$ de comprimento, a segunda constituiu-se de uma solução formada por $97 \%$ de água e $3 \%$ de água deuterada em uma cubeta com $10 \mathrm{~cm}$ de comprimento.

Mistura 50\% de água deuterada $+50 \%$ de água.

Os testes com a solução de "água + água deuterada" foram realizados utilizando telescópios para variar o diâmetro do feixe de bombeio e, foram realizados com o bombeio apresentando uma largura temporal de 54 ps. Entre os telescópios testados, o que proporcionou o melhor contínuo foi o constituído por duas lentes convergente de distâncias focais 400 e $50 \mathrm{~mm}$, onde o diâmetro do feixe obtido foi $0,65 \mathrm{~mm}$.

Posicionando uma íris na direção da luz emitida pelo filamento, medimos a energia apenas da região central do supercontínuo gerado. Para uma energia de bombeio de $E_{0}=4,3 \mathrm{~mJ}$ e uma cubeta de $30 \mathrm{~cm}$ de comprimento, a energia e a estabilidade medidas da 
parte central do contínuo estão dispostos na tabela 8 .

Tabela 8 - Medidas da energia e da estabilidade da parte central do espectro gerado em uma mistura de " $50 \%$ de água deuterada $+50 \%$ de água" em uma cubeta de $30 \mathrm{~cm}$ de comprimento.

\begin{tabular}{|cc|}
\hline$E_{C}(\mu J)$ & Estabilidade (\%) \\
\hline 5,9 & 26 \\
\hline
\end{tabular}

O espectro medido para essa mistura está ilustrado na figura 39. Na faixa espectral de interesse (1200 a $1800 \mathrm{~nm}$ ) não observamos nenhum pico, o que sugere que a concentração de água utilizada na solução foi muito alta e a água absorveu todas as frequências geradas nessa região antes que alcançassem a saída da cubeta.

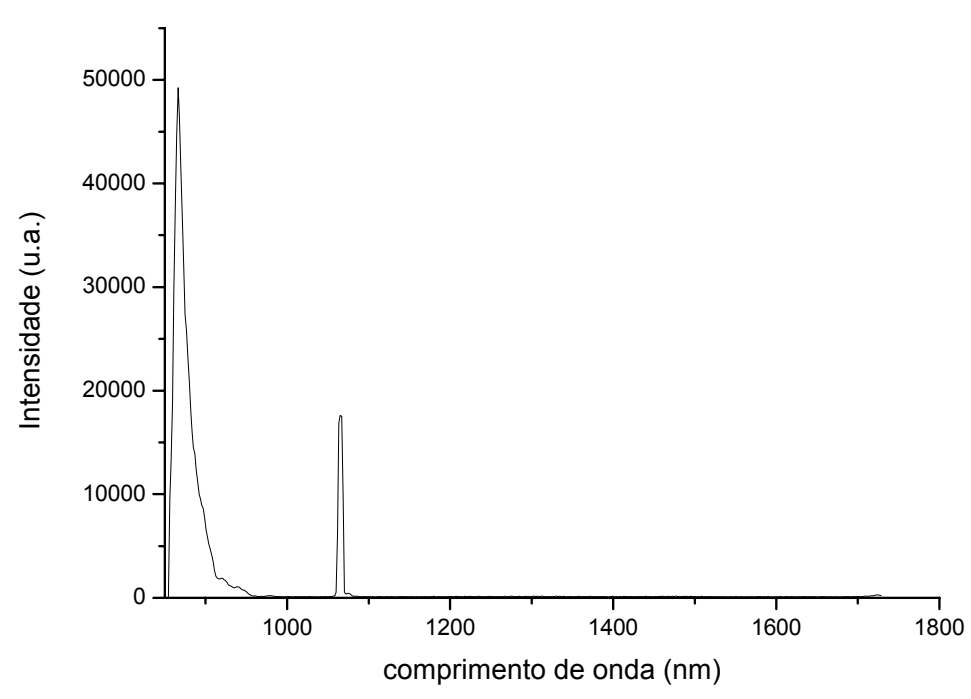

Figura 39 - Medida do espectro do supercontínuo gerado em uma cubeta de $30 \mathrm{~cm}$ de comprimento contendo " $50 \%$ de água deuterada $+50 \%$ de água" com a energia e a largura temporal do bombeio dados respectivamente por $4,3 \mathrm{~mJ}$ e 54 ps. O espectrômetro utilizado para a medida foi um NIR-512.

Também medimos o espectro da luz supercontínua na região do visível (figura 40), que como pode se visto mostra que foi obtido um alargamento espectral de cerca $450 \mathrm{~nm}$ para as componentes anti-Stokes. 


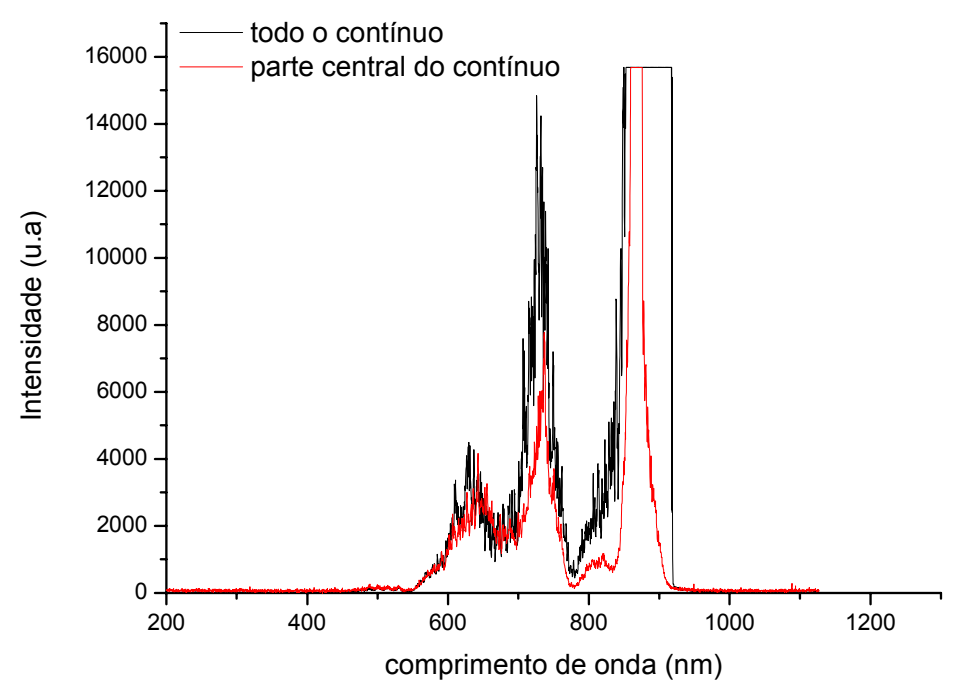

Figura 40 - Medidas espectrais no visível do supercontínuo gerado em uma cubeta de $30 \mathrm{~cm}$ de comprimento contendo " $50 \%$ de água deuterada $+50 \%$ de água" com a energia e a largura temporal do bombeio dados respectivamente por $4,3 \mathrm{~mJ}$ e 54 ps. O espectrômetro utilizado para a medida foi um USB2000 (Ocean Optics Inc, EUA).

Devido à combinação dos efeitos Espalhamento Raman e Mistura de quatro ondas, é possível conseguir espectros que se estendem desde o ultravioleta até infravermelho próximo $^{33}$.

Assim como para a água deuterada pura, a mistura também apresentou uma ligeira variação na amplitude dos picos do espectro em função da diferença entre as orientações de um polarizador (posicionado na saída da cubeta) e a polarização do feixe de bombeio (figura 41). Concluímos portanto que o supercontínuo gerado é fracamente polarizado. 


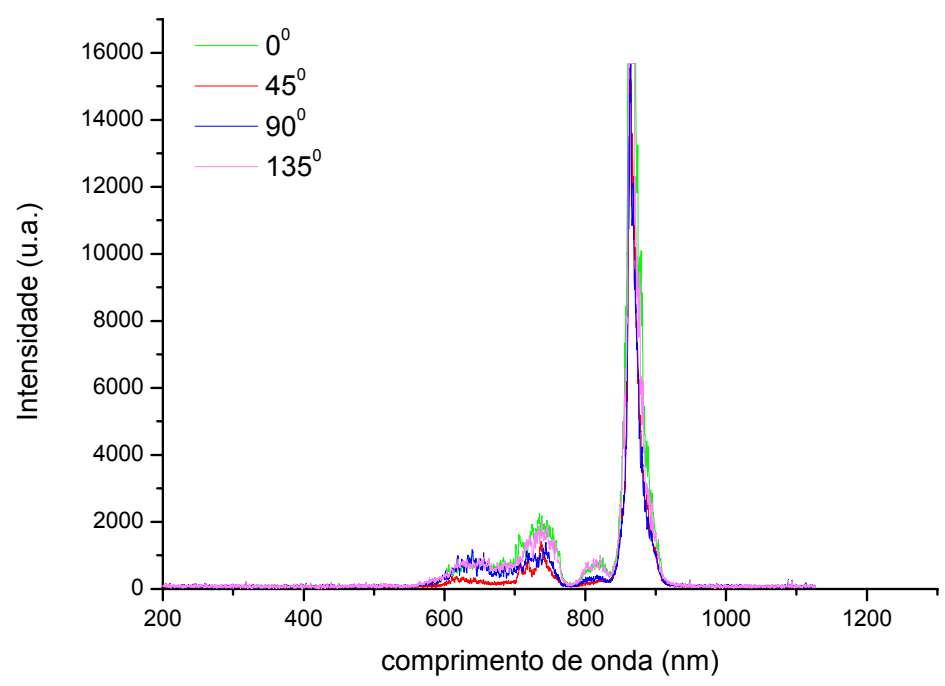

Figura 41 - Medidas espectrais do supercontínuo gerado em uma cubeta de $30 \mathrm{~cm}$ de comprimento contendo " $50 \%$ de água deuterada $+50 \%$ de água" em função da diferença angular entre o eixo do polarizador (posicionado na saída da cubeta) e a direção de polarização do bombeio. $\mathrm{O}$ espectrômetro utilizado para a medida foi um USB-200. A energia e a largura temporal do bombeio são respectivamente $4,3 \mathrm{~mJ}$ e 54 ps.

Embora a energia medida do espectro dessa mistura tenha sido bem mais alta que a da água deuterada pura, assim como a estabilidade obtida, o contínuo gerado não satisfaz as necessidades do projeto, uma vez que não há a detecção da semente na saída da cubeta (região espectral entre 1,2 e 1,8 nm).

Mistura 97\% de água deuterada $+3 \%$ de água.

Com o intuito de diminuir a absorção pela água das frequências geradas no infravermelho próximo, mudamos a concentração de água na mistura para apenas $3 \%$ em uma cubeta de $10 \mathrm{~cm}$ de comprimento. O espectro obtido dessa nova mistura, usando o mesmo telescópio do experimento com água deuterada (feixe com diâmetrode 0,5 mm), está disponível na figura 42. 


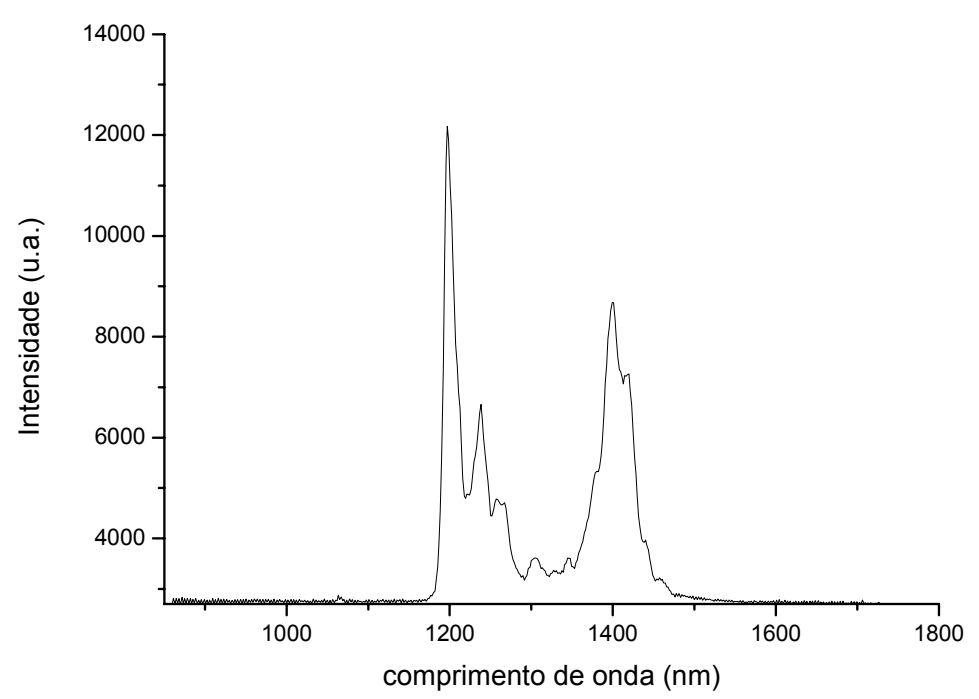

Figura 42 - Espectro medido do supercontínuo gerado em uma cubeta de $10 \mathrm{~cm}$ de comprimento contendo uma mistura de " $97 \%$ de água deuterada $+3 \%$ de água" com a energia e a largura temporal do bombeio dados respectivamente por $3 \mathrm{~mJ}$ e 54 ps. O espectrômetro utilizado para a medida foi um NIR-512.

Comparando a figura 42 com a figura 36, notamos que a intensidade ficou distribuída de forma mais uniforme entre os picos em 1200 e $1440 \mathrm{~nm}$ para a mistura do que para a água deuterada pura. A energia e a estabilidade medidas da parte central do contínuo gerado estão disponíveis na tabela 9.

Tabela 9 - Medidas da energia e da estabilidade da parte central do contínuo gerado em uma cubeta de 10 cm de comprimento contendo uma mistura de "97\% de água deuterada + 3\% de água".

\begin{tabular}{|cc|}
\hline$E_{C}(\mu J)$ & Estabilidade (\%) \\
\hline 0,509 & 55 \\
\hline
\end{tabular}

Como podemos observar, a luz gerada por essa nova mistura ainda é muito instável, contudo, apresenta uma parte da região espectral necessária como semente para o estágio de amplificação paramétrica. 


\section{Geração de luz supercontínua em vidro}

A geração de luz supercontínua em vidro utilizando pulsos de bombeio no regime de picossegundos é conhecida há tempos pela comunidade científica ${ }^{25,61}$. Em nosso experimento a geração de supercontínuo foi testada em um bastão de vidro BK7 com $20 \mathrm{~cm}$ de comprimento e $15 \mathrm{~mm}$ de diâmetro. Variamos a distância focal da lente utilizada para focalizar o feixe de bombeio, a distância entre o foco da lente e a superfície de entrada do bastão e a energia do pulso de bombeio, para que pudéssemos obter a geração do supercontínuo, melhorar sua performance e minimizar os danos ópticos no material.

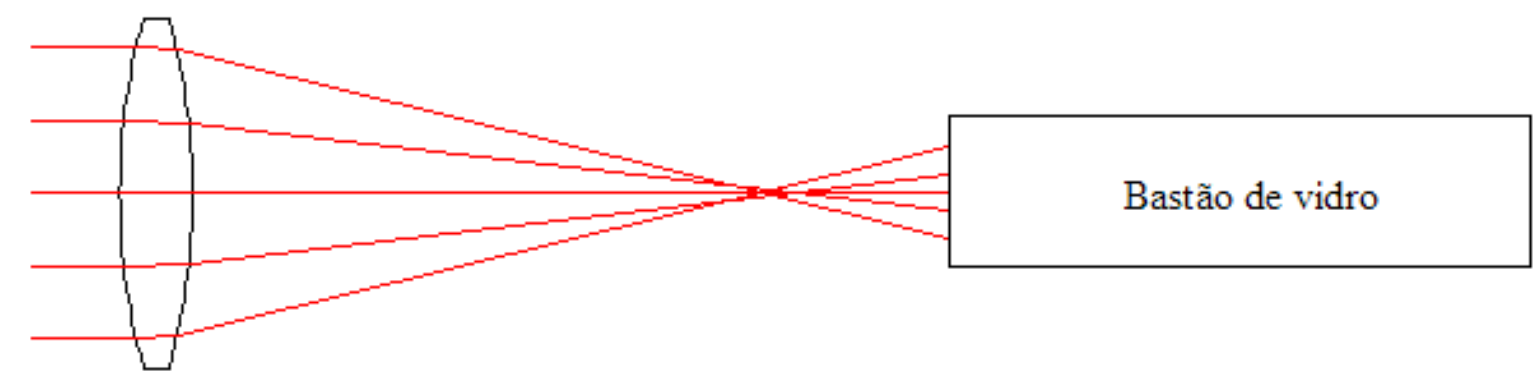

\section{Lente focalizadora}

Figura 43 - Esquema do arranjo experimental utilizado na geração de luz supercontínua no bastão de vidro.

Utilizamos lentes com distâncias focais de 250, 500, 750, 1000 e $1500 \mathrm{~mm}$ e, apenas com a lente de $250 \mathrm{~mm}$ não foi possível gerar supercontínuo. Contudo, mesmo posicionando as lentes de forma que estas focalizassem o feixe antes da entrada do bastão, não foi possível evitar o dano do material com o tempo. O melhor resultado foi obtido com a lente de 1000 $\mathrm{mm}$, estando a entrada do bastão posicionada a cerca de $1 \mathrm{~cm}$ do plano focal da lente, onde a geração do supercontínuo foi observada para energias acima de aproximadamente 0,26 mJ. 

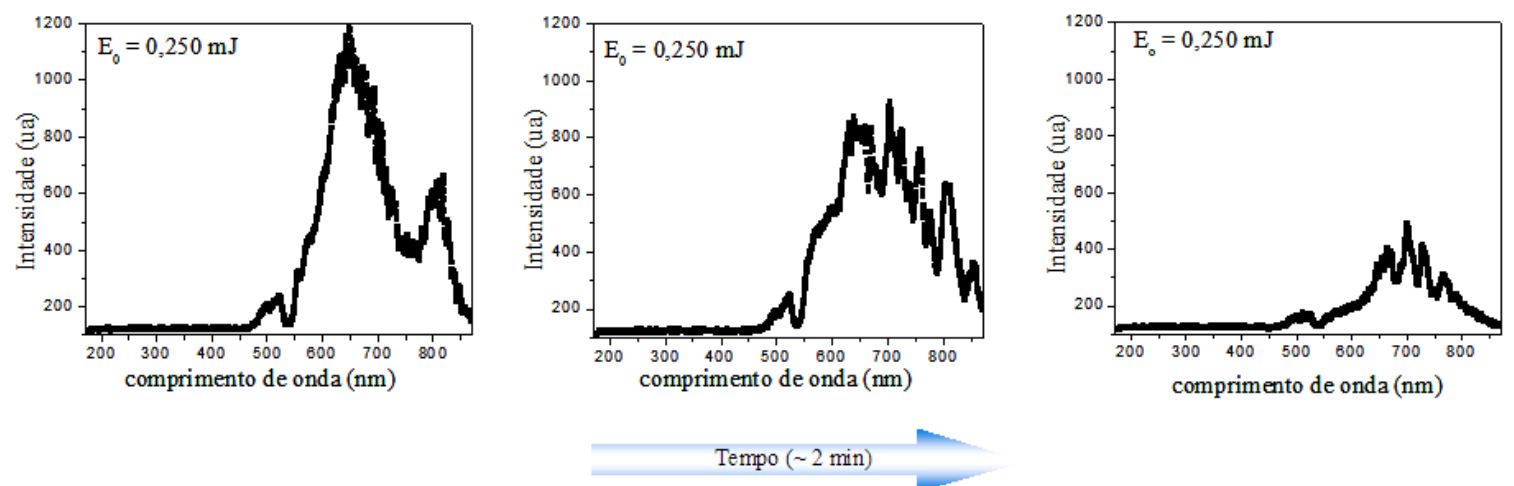

Figura 44 - Evolução temporal do espectro da luz supercontínua gerada em um bastão de BK7. $\mathrm{E}_{0}$ corresponde a energia de bombeio e a largura temporal do mesmo é 25 ps.

A figura 44 corresponde ao espectro da luz gerada no bastão de vidro na região visível, para a situação descrita acima (com a lente de $1000 \mathrm{~mm}$ ). O espectro foi medido com um espectrômetro Ocean Optics USB-2000. Podemos observar um alargamento espectral com intensidades consideráveis até $550 \mathrm{~nm}$, o que corresponde a um alargamento espectral para comprimentos de onda mais curtos (componentes anti-Stokes) que o bombeio de cerca de $500 \mathrm{~nm}$. Contudo, devido aos danos ópticos provocados no material pelo bombeio, a luz supercontínua gerada apresentava um tempo de vida bastante curto, cerca de 2 minutos apenas, tornando inviável o uso do vidro como meio para gerar a semente do OPA.

Numa segunda tentativa de utilizarmos o vidro como meio para gerar o supercontínuo, substituímos a lente focalizadora da figura 43 por um telescópio. Foram testadas algumas configurações de lentes de forma a variarmos o diâmetro do feixe que incidia sobre a face do bastão, assim com descrito para a água deuterada, para esta configuração a largura temporal do pulso de bombeio era de 54 ps. Não foram para todos os telescópios montados que observamos a geração do supercontínuo, a configuração que se mostrou mais eficiente foi a formada por duas lentes convergentes de distâncias focais 400 e $50 \mathrm{~mm}$ promovendo um feixe com diâmetro igual a $\sim 0,65 \mathrm{~mm}$ na entrada do bastão. Na figura 45 apresentamos fotos mostrando a evolução temporal da luz supercontínua gerada no bastão de vibro BK7. A distância entre o anteparo e o bastão era de aproximadamente $3,5 \mathrm{~cm}$, enquanto que o diâmetro do espote formado no anteparo era em torno de $6 \mathrm{~mm}$. 

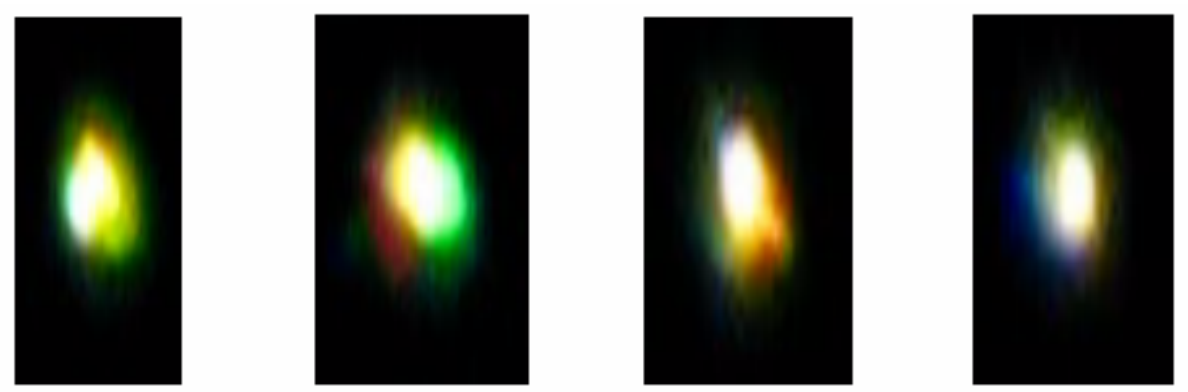

Tempo $(\sim 1 \mathrm{~s})$

Figura 45 - Fotos do supercontínuo gerado em um bastão BK7 com $20 \mathrm{~cm}$ de comprimento. A duração e energia do laser de bombeio são respectivamente 54 ps e $5 \mathrm{~mJ}$.

A eficiência na geração do supercontínuo melhorou de forma significativa com a nova configuração, uma vez que a degradação do material foi evitada e passamos a ter "luz branca" constantemente gerada. Porém, a estabilidade espacial da luz gerada era muito aquém da necessária para a semente do OPA, instabilidade essa que atribuímos à formação de múltiplos filamentos no bastão. Tendo em vista que essa flutuação na posição da semente acarretaria em uma instabilidade no estágio de amplificação paramétrica uma vez que a superposição espacial dos feixes de bombeio e semente estaria comprometida, o vidro não se mostrou eficaz na geração do supercontínuo com as características necessárias ao projeto.

\section{Geração de luz supercontínua em fluoreto de bário}

Uma alta eficiência na geração de luz branca em $\mathrm{BaF}_{2}$ já havia sido reportada para o caso em que o bombeio é realizado com pulsos de femtossegundos ${ }^{62,63}$, o que nos estimulou a testar a geração de luz branca em um bastão de $\mathrm{BaF}_{2}$ com $10 \mathrm{~mm}$ de diâmetro e $150 \mathrm{~mm}$ de comprimento, com o bombeio operando no regime de picossegundos. O teste realizado foi o mesmo descrito para o caso do bastão de vidro. Entretanto, não foi possível encontrar nenhum conjunto de variáveis que resultassem na geração do supercontínuo. Para todas as situações testadas o limiar de dano do material foi alcançado antes que conseguíssemos gerar luz supercontínua. 
Geração de luz supercontínua em cloreto de potásssio

Para o monocristal de cloreto de potássio ( $8 \mathrm{~cm}$ de comprimento) os testes realizados também foram idênticos aos realizados com o vibro BK7, e os resultados obtidos (assim como os do fluoreto de bário) foram todos negativos quanto a geração de luz supercontínua. Para todas as configurações montadas o limiar de dano do material foi alcançado sem que houvesse a observação da geração da luz supercontínua.

\section{Geração de luz supercontínua em fibra óptica de baixa não-linearidade}

A fibra utilizada no experimento foi a fibra fotônica endlessly single mode "SMJ33633-41225-3-1" (WesternTek Inc, EUA) com núcleo de diâmetro igual a $12 \mu \mathrm{m}$. A objetiva utilizada para acoplar a luz na fibra foi uma objetiva de 10X com abertura numérica $A N=0,25$.

A tentativa de geração de luz supercontínua em uma fibra fotônica de baixa nãolinearidade foi realizada em função da disponibilidade da mesma e motivada pela idéia que talvez pudéssemos compensar o baixo coeficiente não-linear com uma alta potência de pico. Mesmo sem o suporte adequado para o acoplamento de luz em fibras, conseguimos com muito esforço um acoplamento em torno de quarenta por cento. Então, variamos a intensidade do pulso incidente na fibra até alcançarmos o limiar de dano da mesma, mas não detectamos qualquer alargamento espectral significativo.

Geração de luz supercontínua em fibra óptica de alta não-linearidade

A Fibra utilizada foi a Nonlinear Photonic Fiber - SC-5.0-1040 (Crystal Fibre, Reino Unido) com 2 m de comprimento, e seus parâmetros estão listados na tabela 2 na seção 3.1.1. A maior dificuldade na geração de supercontínuo em fibras ópticas fotônicas está no acoplamento do feixe de bombeio com o núcleo dessas fibras, que muitas vezes possuem um 
núcleo extremamente pequeno. O núcleo da SC-5.0-1040 tem diâmetro igual a 4,8 $\mu \mathrm{m}$ e a objetiva utilizada para acoplar a luz nessa fibra foi uma objetiva de 10X com abertura numérica $A N=0,25$. Conseguimos acoplamentos entre 27 e $47 \%$; esses valores variavam haja vista que a eficiência de acoplamento da luz de bombeio na fibra dependia de alguns fatores, como a qualidade do modo transversal do feixe de bombeio, qualidade de clivagem da fibra, qualidade dos filtros utilizados para atenuar o bombeio.

Como primeiro teste, verificamos o intervalo de energia de bombeio que poderíamos trabalhar com a fibra, ou seja, o intervalo de energia em que pudéssemos gerar a luz supercontínua sem estar perto do limiar de dano da fibra. Os valores medidos de energia do bombeio para o limiar de geração do supercontínuo $E_{L S}$ e para o limiar de dano da fibra $E_{L D}$, estão dispostos na tabela 10.

Tabela 10 - Valores medidos do limiar de energia do bombeio para gerar supercontínuo e limiar de energia do bombeio que danifica a fibra "SC-5.0-1040". O acoplamento do bombeio na fibra era de $40 \%$.

\begin{tabular}{|cc|}
\hline$E_{L S}(\mu J)$ & $E_{L D}(\mu J)$ \\
\hline 0,292 & 2,10 \\
\hline
\end{tabular}

Tendo em vista os valores $E_{L S}$ e $E_{L D}$, optamos então por trabalhar com uma energia de bombeio em torno de $1,5 \mu \mathrm{J}$. Na figura 46 mostramos uma foto tirada do contínuo gerado com uma energia de bombeio dada por $E_{0}=1,6 \mu J$ e largura temporal de 54 ps, com acoplamento do feixe de bombeio de $\sim 42 \%$. A distância do anteparo à saída da fibra era de $20 \mathrm{~mm}$, enquanto que o diâmetro do espote formado no centro era de $\sim 5 \mathrm{~mm}$. 


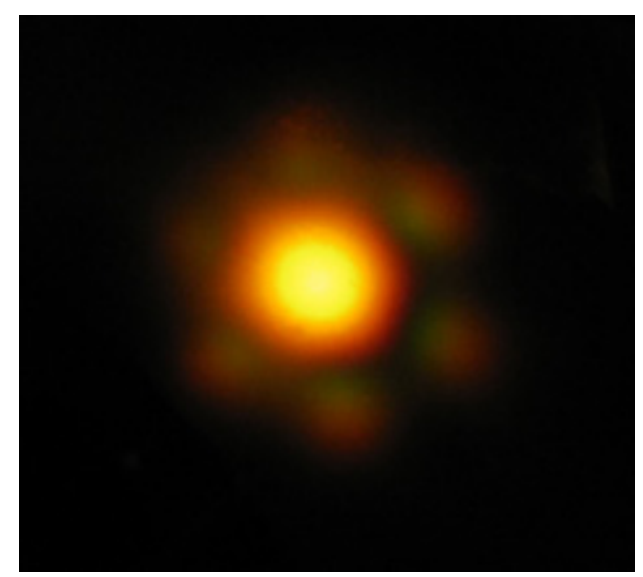

Figura 46 - Foto do supercontínuo gerado na fibra Nonlinear Photonic Fiber - SC-5.0-1040. Com a energia e a largura temporal do bombeio dados respectivamente por $1,6 \mu \mathrm{J}$ e $54 \mathrm{ps}$.

Para determinar o espectro do contínuo gerado na região do infravermelho próximo, fizemos o feixe de "luz branca" produzido por um bombeio de 1,4 $\mu \mathrm{J}$ passar por um monocromador (Mini-Chrom Model E - gold coated, Edmond Optics, EUA) cuja eficiência em função do comprimento de onda é dado pelo gráfico da figura 47.

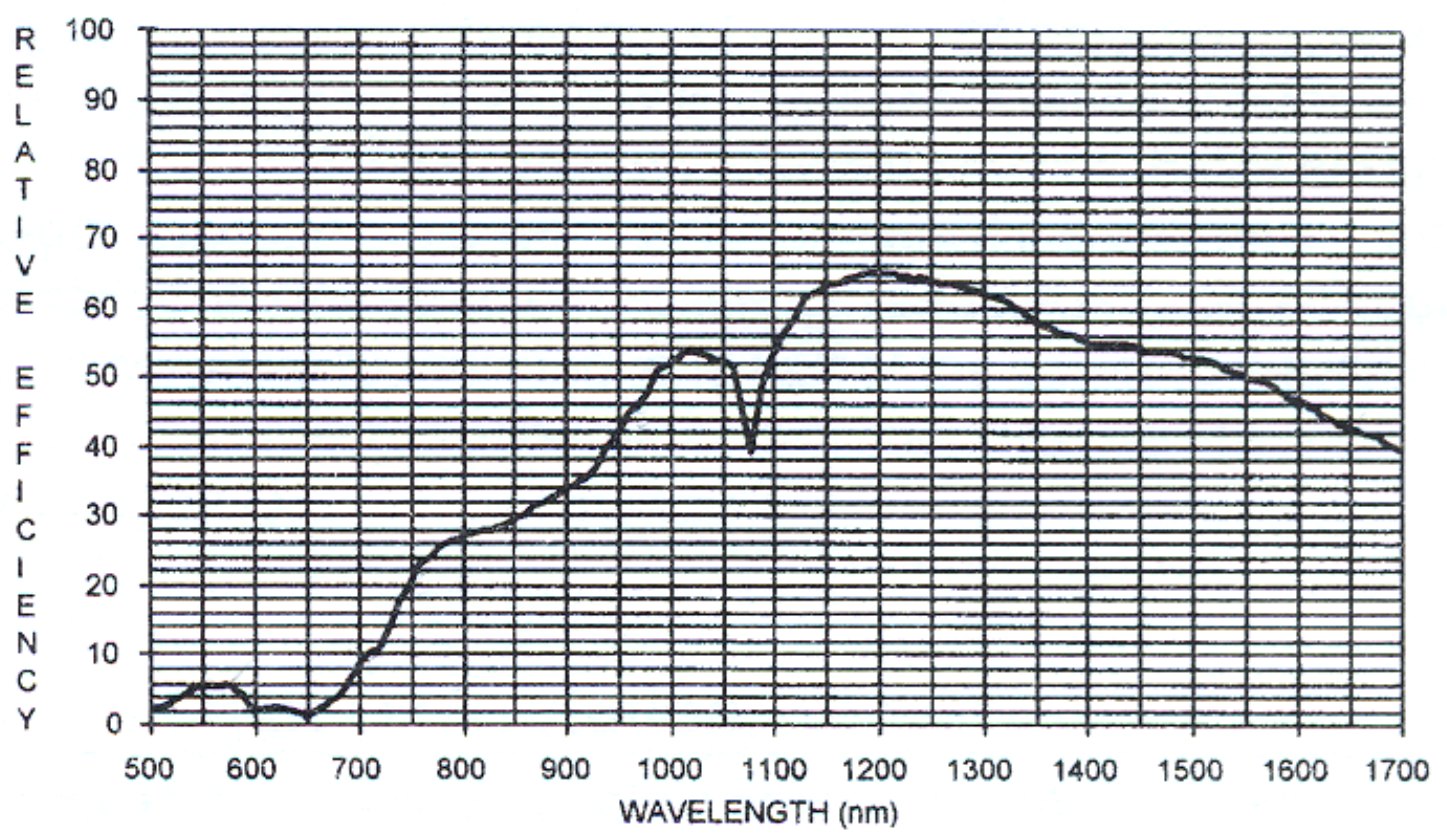

Figura 47 - Eficiência do monocromador como função do comprimento de onda (do manual do equipamento).

A faixa espectral do feixe selecionada pelo monocromador foi focalizada em um fotodiodo de InGaAs (Thorlabs, modelo FGA-10), cuja resposta espectral está ilustrada na figura 48. 


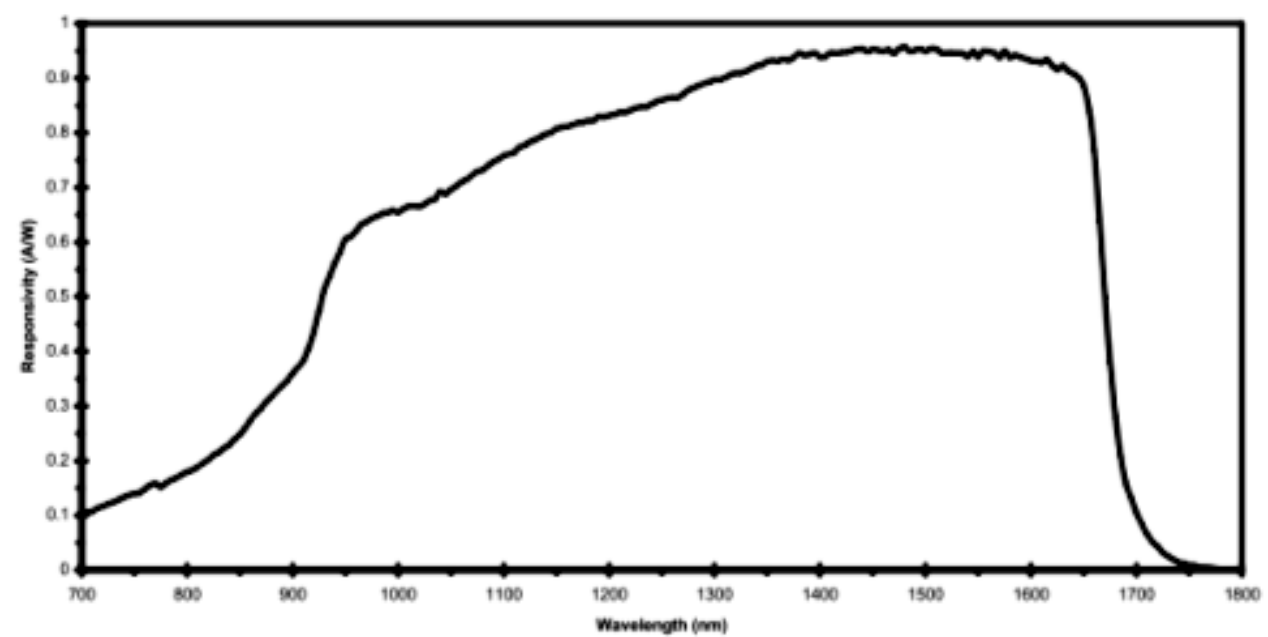

Figura 48 - Responsividade espectral do foto-diodo em função do comprimento de onda (do manual do fotodiodo).

Normalizando o sinal medido pelas respostas do fotodiodo e do monocromador, o espectro medido da luz supercontínua é o ilustrado na figura 49.

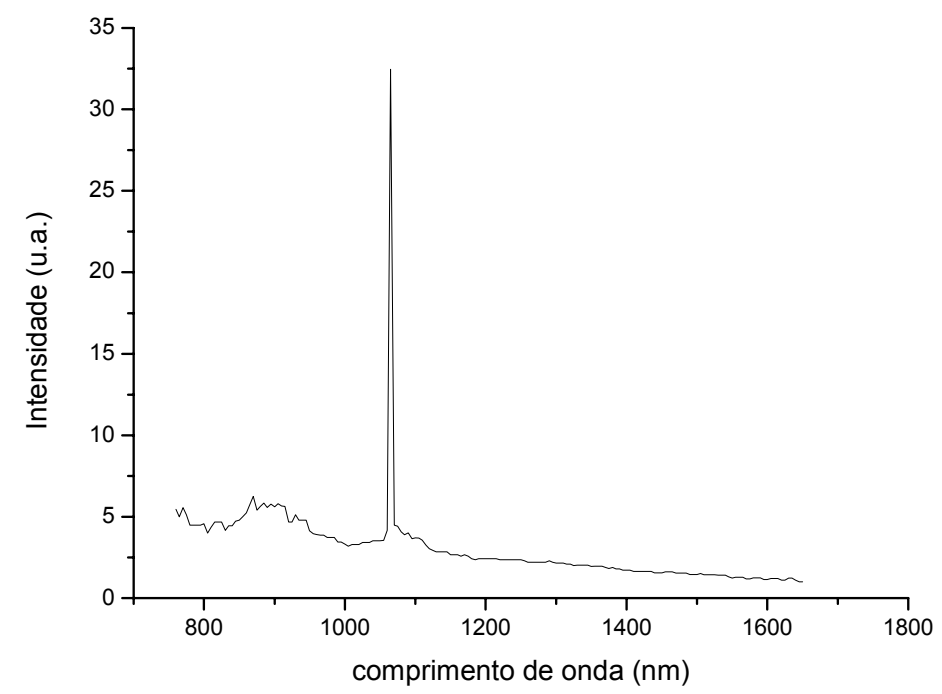

Figura 49 - Espectro medido da luz supercontínua gerada na fibra Nonlinear Photonic Fiber - SC-5.0-1040. Com a energia e a largura temporal do bombeio dados respectivamente por $1,42 \mu \mathrm{J}$ e $54 \mathrm{ps}$, e um acoplamento do feixe de bombeio dado por $\sim 41 \%$.

A energia e a estabilidade do contínuo gerado por essa fibra foram medidos (ver tabela 11) na situação em que a energia do feixe de bombeio era $E_{0}=1,4 \mu J$ e sua estabilidade era de $2,6 \%$, tendo a energia do bombeio sido removida na saída da fibra com o auxilio de um espelho dielétrico para $1064 \mathrm{~nm}$. 
Tabela 11 - Valores medido para a energia e estabilidade do contínuo gerado na fibra Nonlinear Photonic Fiber - SC-5.0-1040. Com a energia e a estabilidade do bombeio sendo 1,4 $\mu \mathrm{J}$ e $10 \%$ respectivamente.

\begin{tabular}{|cc|}
\hline$E_{C}(\mu J)$ & Estabilidade (\%) \\
\hline 0,198 & 10 \\
\hline
\end{tabular}

Nota-se que o espectro obtido é largo e uniforme, estendendo-se do visível ao infravermelho próximo (pelo menos até $1650 \mathrm{~nm}$, o limite de sensibilidade do nosso fotodiodo). O supercontínuo é também extremamente estável, em termos da estabilidade espacial do feixe e da flutuação pulso a pulso. A única desvantagem desse meio para a geração de supercontínuo é o baixo limiar de dano, que limita a energia total do bombeio utilizado e, portanto, do supercontínuo gerado. Logo, este é o melhor sistema testado para a geração de supercontínuo no infravermelho próximo no regime de picossegundos, com a finalidade de ser utilizado como semente para o estágio de amplificação paramétrica.

\subsection{Seleção da semente do OPA pelo monocromador}

Não foi possível realizar um primeiro teste do estágio de amplificação paramétrica com a abertura posicionada entre as lentes $L_{2}$ e $L_{3}$ do monocromador, visto que ela limitava bastante a energia disponível no feixe semente. Então, a mesma foi removida possibilitando que a semente chegasse ao cristal não-linear com uma energia maior, porém com uma resolução espectral diferente da que havíamos calculado. Para calcularmos a resolução espectral esperada do monocromador sem a abertura, primeiramente calculamos a posição e o tamanho da imagem do cristal formada pelo telescópio (lentes $L_{3}$ e $L_{2}$, veja a figura 18). Usando a distância de $400 \mathrm{~mm}$ do cristal a $L_{3}$ e as respectivas distâncias focais $\left(f_{3}=+200\right.$ $\mathrm{mm}$ e $f_{2}=+150 \mathrm{~mm}$ ), os valores calculados a partir da óptica geométrica para o diâmetro da imagem do cristal $\left(y^{\prime}\right)$ e para sua posição em relação à lente $L_{2}\left(z\right.$, situada entre $L_{2}$ e a grade de difração) foram respectivamente:

$$
y^{\prime}=6 \mathrm{~mm}
$$


Então, calculamos a dispersão linear da grade na posição em que a imagem do cristal é formada, $\mathscr{D}_{L}=\frac{d \theta}{d \lambda}(\ell-z)$, onde $\ell=600 \mathrm{~mm}$ é a distância entre a grade de difração e $L_{2}$. Determina-se a resolução espectral $\Delta \lambda$ dessa configuração pela largura espectral que se superpõem sobre a imagem do cristal, dada pela relação $\mathcal{D}_{L} \Delta \lambda=y^{\prime}$. Usando a eq. (3.7), obtemos então a relação:

$$
\Delta \widetilde{v}=\frac{y^{\prime}}{2(\ell-z) \lambda \tan \alpha}
$$

Podemos então a partir da eq. (4.5) utilizar os valores acima de $y^{\prime}$ e z para estimar a largura espectral da semente para os extremos da faixa de sintonia $(1,2 \mu \mathrm{m}$ e $1,8 \mu \mathrm{m})$ :

$$
\begin{array}{ll}
\Delta \tilde{v}=116 \mathrm{~cm}^{-1}, & \lambda_{\mathrm{S}}=1,2 \mu \mathrm{m} \\
\Delta \tilde{v}=46 \mathrm{~cm}^{-1}, & \lambda_{\mathrm{S}}=1,8 \mu \mathrm{m}
\end{array}
$$

\subsection{Geração do idler}

Na seção 4.1, listamos todos os materiais testados como meio material para geração de supercontínuo, também descrevemos os resultados obtidos com esses materiais. E como pudemos observar, apenas o contínuo gerado pela mistura de água deuterada e água $(97: 3 \mathrm{v} / \mathrm{v})$ e pela fibra Nonlinear Photonic Fiber - SC-5.0-1040 mostrou-se passível de testes para o estágio de amplificação paramétrica. 
$>$ Teste de amplificação paramétrica utilizando a mistura de água deuterada e água (97:3 v/v) como meio gerador do contínuo.

O aparato experimental montado para obtermos a amplificação paramétrica da faixa espectral selecionada pelo monocromador e a geração do feixe idler é o ilustrado na figura 28. Removeu-se a abertura no monocromador para aumentar a energia disponível no feixe sinal (semente), com o intuito de facilitar a observação de amplificação paramétrica. O procedimento adotado para esse teste foi: (a) selecionar (através da rotação da grade de difração) como semente o comprimento de onda $1400 \mathrm{~nm}$ que corresponde à situação de orientação do cristal para incidência aproximadamente normal, e também de alta intensidade no espectro do supercontínuo gerado (veja figura 42); (b) encontrar a superposição temporal entre os feixes sinal e bombeio (através da posição do prisma) e, (c) posteriormente otimizar a orientação do cristal de forma a obtermos a condição de casamento de fase. A energia do feixe utilizado para bombear a cubeta foi $3 \mathrm{~mJ}$, provendo uma semente com energia total de 0,59 $\mu \mathrm{J}$, a energia utilizada como bombeio do cristal foi $7 \mathrm{~mJ}$ e a largura temporal do pulso era 54 ps.

Entretanto, tivemos muita dificuldade em obter a posição exata do prisma que promovesse uma superposição temporal perfeita entre os feixes. Atribuímos essa dificuldade à alta instabilidade da semente utilizada. E infelizmente não conseguimos detectar o processo de amplificação paramétrica, embora acreditemos ser possível conseguir tal processo com essa semente melhorando a estabilidade da mesma, o que pode ser conseguido diminuindo a largura temporal do bombeio. Ademais, durante o teste foi observado o processo de geração paramétrica espontânea no cristal, fato este que nos faz acreditar que a intensidade do bombeio seja suficiente para verificarmos a amplificação paramétrica da semente.

$>$ Teste de amplificação paramétrica utilizando a fibra fotônica SC-5.0-1040 como meio gerador do contínuo.

A energia do feixe utilizado para bombear a fibra foi $1,64 \mu \mathrm{J}$, a energia utilizada como bombeio no cristal foi $5,7 \mathrm{~mJ}$ e a largura temporal do pulso era $54 \mathrm{ps}$. O teste foi realizado da mesma forma que descrito para o caso da mistura de água e água deuterada. Ao contrário do 
caso anterior, tivemos uma facilidade maior em detectar a posição exata do prisma que permitia a superposição temporal perfeita entre os feixes sinal e bombeio no cristal. A amplificação paramétrica foi observada com o auxilio de um foto-diodo de InGaAs (Thorlabs, modelo FGA-10). Para tal, posicionamos espelhos para $1064 \mathrm{~nm}$ depois do cristal para remover o restante do bombeio e focalizamos a semente no fotodiodo. Medimos a energia do feixe-sinal após passar pelo cristal na ausência do feixe de bombeio, $E_{S A}$, e a energia do mesmo na presença do feixe de bombeio, $E_{C A}$; os valores estão disponíveis na tabela 12 .

Tabela 12 - Energias medidas do feixe-sinal nas situações sem e com amplificação paramétrica.

\begin{tabular}{|cc|}
\hline$E_{S A}(n J)$ & $E_{C A}(n J)$ \\
\hline 0,0126 & 3,3158 \\
\hline
\end{tabular}

É possível notar, comparando os valores dispostos na tabela 12 para a energia do feixe-sinal não amplificado $\left(E_{S A}\right)$ e para a energia do feixe-sinal amplificado $\left(E_{C A}\right)$, que obtivemos uma amplificação da ordem de 260 vezes. No entanto, o valor obtido para $E_{C A}$ é muito baixo para a aplicação que temos em mente (espectroscopia SFG). Isso se deve em grande parte ao baixo valor de energia usado para bombeio da fibra. A energia medida do espectro total do supercontínuo foi apenas $0,453 \mu \mathrm{J}$. 


\section{Conclusões}

Nesse trabalho projetamos e testamos uma configuração inovadora para um amplificador paramétrico óptico (OPA) operando no infravermelho médio no regime de picossegundos, que utiliza a geração de supercontínuo de "luz branca" como semente para o estágio de amplificação paramétrica. Todos os suportes e estágios de rotação utilizados na montagem do OPA foram desenhados e seus movimentos simulados no programa de CAD SolidWorks. Projetou-se também o monocromador, que serve para reduzir a largura de banda dos pulsos de saída do OPA, e calculou-se as especificações do cristal utilizado na amplificação paramétrica.

A geração de luz supercontínua usada como semente no estágio de amplificação paramétrica do OPA foi testada em diversos materiais; água, água deuterada, vidro (BK7), fluoreto de bário, cloreto de potássio, fibra fotônica de baixa não-linearidade e fibra fotônica de alta não-linearidade. Porém, para o fluoreto de bário, para o cloreto de potássio e para a fibra fotônica de baixa não-linearidade não obtivemos a geração de supercontínuo; nos três casos o limiar de dano do material foi alcançado sem que pudéssemos observar qualquer indício de alargamento espectral. Já o vidro BK7 se mostrou bastante eficiente no que se refere ao alargamento do espectro do bombeio, haja vista que o espectro da luz emitida pelo filamento formado pelo self-trapping apresentou uma largura de $\sim 500 \mathrm{~nm}$ para as componentes anti-Stokes, porém o contínuo emitido era muito instável, sendo inviável seu uso como semente no estágio de amplificação. A solução formada por " $50 \%$ de água $+50 \%$ de água deuterada" apresentou um alargamento espectral considerável na região do visível e uma estabilidade razoável, contudo, devido a forte absorção pela água das frequências no infravermelho próximo, não foi possível captar a semente para o OPA (infravermelho próximo) utilizando essa mistura. A solução formada por “3\% de água $+97 \%$ de água deuterada" por sua vez se mostrou mais eficiente em promover a geração das frequências necessárias na região do infravermelho próximo, embora, não cobrisse toda a faixa de interesse e a estabilidade da luz gerada fosse bem inferior à da solução anterior. Quanto ao contínuo gerado pela fibra fotônica de alta não-linearidade, pode-se afirmar que foi o que apresentou os melhores resultados: seu espectro na região do infravermelho cobria uma boa parte da faixa de sintonia da semente, alcançando o limite de medida do fotodiodo $(1600 \mathrm{~nm})$, 
a luz gerada era extremamente estável, tendo como único problema o baixo limiar de dano, limitando o bombeio da fibra a energias muito baixas.

O estágio de amplificação paramétrica foi testado com duas sementes; o contínuo gerado pela mistura de água deuterada e água $(97: 3 \mathrm{v} / \mathrm{v})$ e o gerado pela fibra fotônica de alta não-linearidade. Com a solução de água e água deuterada, não conseguimos observar o processo de amplificação paramétrica com uma semente com energia total de $0,59 \mu \mathrm{J}$, embora tenhamos observado o fenômeno de geração paramétrica. Já com a fibra fotônica de alta nãolinearidade obtivemos o processo de amplificação paramétrica (ganho de $\sim 260$ vezes) utilizando uma semente com energia total de $0,453 \mu \mathrm{J}$, embora a energia obtida da semente amplificada fosse muito aquém da desejada. No entanto, por serem muito próximos os valores de energia utilizados como semente para os dois casos, acreditamos que só não foi possível observar a amplificação paramétrica no caso da mistura de água e água deuterada devido a maior instabilidade da luz gerada por essa solução em relação à fibra.

Uma vez que todo o aparato experimental do OPA se encontra montado e alinhado no laboratório, temos como perspectivas três possibilidades para melhorar a performance desse OPA: a) utilizar dois cristais de $\mathrm{AgGaS}_{2}$ para amplificar a semente gerada pela fibra nãolinear, aumentando o caminho de interação não-linear; b) diminuir a duração de pulso do laser de bombeio e assim melhorar a estabilidade da luz supercontínua gerada na água deuterada e no vidro; c) utilizar a configuração OPG/OPA ${ }^{6}$, onde a semente para o OPA é produzida por geração paramétrica espontânea (OPG), uma vez que observamos geração paramétrica no cristal $\mathrm{AgGaS}_{2}$. Nessa última configuração, ainda teríamos como inovação em OPAs de picossegundos o fato de usar o mesmo cristal de $\mathrm{AgGaS}_{2}$ para os estágios de geração/amplificação paramétrica, produzindo diretamente um feixe no infravermelho médio e eliminando o estágio DFG adicional. 


\section{Referências}

1 ZHANG, J. Y. et al. Optical parametric generation and amplification in barium borate and lithium triborate crystals. Journal of the Optical Society of America B-Optical Physics, v.10, n.9, p.1758-1764, Sept.1993.

2 ARMSTRONG, J. A. et al. Interactions between light waves in a nonlinear dielectric. Physical Review, v.127, n.6, p.1918-1939, 1962.

3 WANG, C. C.; RACETTE, G. W. Measurement of parametric gain accompanying optical difference frequency generation. Applied Physics Letters, v.6, n.8, p.169-171, 1965.

4 BOYD, G. D.; ASHKIN, A. Theory of parametric oscillator threshold with single-mode optical masers and observation of amplification in linbo3. Physical Review, v.146, n.1, p.187-198, 1966.

5 BAUMGARTNER, R. A.; BYER, R. L. Optical parametric amplification. IEEE Journal of Quantum Electronics, v.15, n.6, p.432-444, 1979.

6 ELSAESSER, T. et al. Parametric generation of tunable picosecond pulses in the medium infrared using $\mathrm{AgGaS}_{2}$ crystals. Applied Physics Letters, v.44, n.4, p.383-385, 1984.

7 ZHOU, H. et al. Picosecond, narrow-band, widely tunable optical parametric oscillator using a temperature-tuned lithium borate crystal. Applied Physics Letters, v.62, n.13, p.1457-1459, Mar. 1993.

8 FINSTERBUSCH, K.; BAYER, A. ;ZACHARIAS, H. Tunable, narrow-band picosecond radiation in the mid-infrared by difference frequency mixing in GaSe and CdSe. Applied Physics B-Lasers and Optics, v.79, n.4, p.457-462, Sept. 2004.

9 MEJEAN, G. et al. Towards a supercontinuum-based infrared lidar. Applied Physics BLasers and Optics, v.77, n.2-3, p.357-359, Sept. 2003.

10 VAICIKAUSKAS, V. et al. Mobile spectroscopic system for trace gas detection using a tunable mid-IR laser. Review of Scientific Instruments, v.78, n.2, p.6, Feb.2007. 
11 LIU, Q. L.; WANG, J. K.; ZEWAIL, A. H. Femtosecond dynamics of dissociation and recombination in solvent cages. Nature, v.364, n.6436, p.427-430, July 1993.

12 GADERMAIER, C.; LANZANI, G. Photophysics of conjugated polymers: the contribution of ultrafast spectroscopy. Journal of Physics: Condensed Matter, v. 14, p.9785-9802, Oct. 2002.

13 COWAM, M. L. et al. Ultrafast memory loss and energy redistribution in the hydrogen bond network of liquid $\mathrm{H}_{2} \mathrm{O}$. Nature, v.434, n.10, p.199-202, Mar. 2005.

14 SHEN, Y. R. Surface-properties probed by 2nd-harmonic and sum-frequency generation. Nature, v.337, n.6207, p.519-525, Feb. 1989.

15 MIRANDA, P. B.; SHEN, Y. R. Liquid interfaces: a study by sum-frequency vibrational spectroscopy. Journal of Physical Chemistry B, v.103, n.17, p.3292-3307, Apr. 1999.

16 VANHERZEELE, H. Picosecond laser system continuously tunable in the $0.6-4-\mu \mathrm{m}$ range. Applied Optics, v.29, n.15, p.2246-2258, May 1990.

17 FENDT, A. et Al.. Efficient generation of tunable subpicosecond pulses in the infrared. Optics Communications, v.28, n.1, p.142-146, 1979.

18 HUANG, J. Y. et al. High-power, widely tunable, picosecond coherent source from optical parametric amplification in barium borate. Applied Physics Letters, v.57, n.19, p.1961-1963, Nov. 1990.

19 CERULLO, G.; DE SILVESTRI, S. Ultrafast optical parametric amplifiers. Review of Scientific Instruments, v.74, n.1, p.1-18, Jan. 2003.

20 CUSSAT-BLANC, S. et al. $\mathrm{KTiOPO}_{4}, \mathrm{KTiOAsO}_{4}$, and $\mathrm{KNbO}_{3}$ crystals for mid-infrared femtosecond optical parametric amplifiers: analysis and comparison. Applied Physics B Lasers and Optics, v.70, p.247-252, June 2000.

21 BOYD, R. W. Nonlinear optics. San Diego: Academic Press Inc., 1992.

22 SHEN, Y. R. Principles of nonlinear optics. New Jersey: John Wiley \& Sons Inc., 1984. 
23 ZHANG, J.; HUANG, Y. J.; SHEN, Y. R. Optical parametric generation and amplification. United States: Harwood Academic Publishers, 1995.

24 DMITRIEV, V. G.; GURZADYAN, G. G.; NIKOGOSYAN, D. N. Handbook of nonlinear optical crystals. 2nd ed. Berlin: Springer-Verlag, 1997.

25 ALFANO, R. R.; SHAPIRO, S. L. Observation of self-phase modulation and small-scale filaments in crystals and glasses. Physical Review Letters, v.24, n.11, p.592, 1970.

26 GOLUB, I. Optical characteristics of supercontinuum generation. Optics Letters, v.15, n.6, p.305-307, Mar. 1990.

$27 \mathrm{KAWANO}$, H. et al. Stimulated raman scattering and four-wave raman mixing seeded by a supercontinuum generated in dibromomethane using picosecond and femtosecond laser sources. Optics Communications, v.160, n.4-6, p.277-282, Feb. 1999.

28 LEE, S. M. et al. Optical parametric spectral broadening of picosecond laser pulses in $\beta$ barium borate. Applied Physics Letters, v.83, n.9, p.1722-1724, Sept. 2003.

29 CORKUM, P. B.; ROLLAND, C.; SRINIVASANRAO, T. Supercontinuum generation in gases. Physical Review Letters, v.57, n.18, p.2268-2271, Nov. 1986.

$30 \mathrm{JIMBO}, \mathrm{T}$. et al. Enhancement of ultrafast supercontinuum generation in water by the addition of $\mathrm{Zn}^{2+}$ and $\mathrm{K}^{+}$cations. Optics Letters, v.12, n.7, p.477-479, July 1987.

31 YU, W. et al. Spectral broadening of picosecond $1.06 \mu \mathrm{m}$ pulse in Kbr. Optics Communications, v.14, n.3, p.344-347, 1975.

32 KUDLINSKI, A. et al. Zero-dispersion wavelength decreasing photonic crystal fibers for ultraviolet-extended supercontinuum generation. Optics Express, v.14, n.12, p.5715-5722, June 2006.

33 ZIANE, O.; ZAIBA, S.; MELIKECHI, N. Continuum generation in water and carbon tetrachloride using a picosecond Nd:YAG laser pulse. Optics Communications, v.273, n.1, p.200-206, May 2007.

34 AGRAWAL, G. P. Nonlinear fiber optics. San Diego: Academic Press Inc., 2007. 
35 DUDLEY, J. M.; GENTY, G.; COEN, S. Supercontinuum generation in photonic crystal fiber. Reviews of Modern Physics, v.78, n.4, p.1135-1184, Oct-Dec. 2006.

36 LIN, J. H. et al. Supercontinuum generation in a microstructured optical fiber by picosecond self Q-switched mode-locked Nd:GdVO 4 laser. Laser Physics Letters, v.4, n.6, p.413-417, June 2007.

37 NUNES, F. D. Fibras e dispositivos para comunicação óptica. São Paulo: Renovarum, 2001.

38 SUPERCONTUUM generation in photonics crystal fibers. Produced by Thorlabs. Disponível em: <http://www.thorlabs.com/ThorCat/10700/10736-A02.pdf >. Acesso em: 09 jan. 2010.

39 KNIGHT, J. C.; et al. Photonic band cap guidance in optical fibers. Science, v.282, n.5393, p.1476-1478, Nov. 1998.

40 RUSSELL, P. Photonic crystal fibers. Science, v.299, n.5605, p.358-362, Jan. 2003.

41 RANKA, J. K.; WINDELER, R. S. ; STENTZ, A. J. Visible continuum generation in airsilica microstructure optical fibers with anomalous dispersion at $800 \mathrm{~nm}$. Optics Letters, v.25, n.1, p.25-27, Jan. 2000.

42 ARKHIREEV, V. A. et al. High-efficiency generation of a supercontinuum in an optical fiber. Optics and Spectroscopy, v.94, n.4, p.632-637, Apr. 2003.

43 COEN, S. et al. White-light supercontinuum generation with 60-ps pump pulses in a photonic crystal fiber. Optics Letters, v.26, n.17, p.1356-1358, Sept. 2001.

44 SEREBRYANNIKOV, E. E.; ZHELTIKOV, A. M. Supercontinuum generation through cascaded four-wave mixing in photonic-crystal fibers: When picoseconds do it better. Optics Communications, v.274, n.2, p.433-440, June 2007.

45 SEEFELDT, M.; HEUER, A. ; MENZEL, R. Compact white-light source with an average output power of $2.4 \mathrm{~W}$ and $900 \mathrm{~nm}$ spectral bandwidth. Optics Communications, v.216, n.13, p.199-202, Feb. 2003. 
46 ZIANE, O.; ZAIBA, S.; MELIKECHI, N. Continuum generation in water and carbon tetrachloride using a picosecond Nd-YAG laser pulse. Optics Communications, v.273, n.1, p.200-206, May 2007.

47 COEN, S. et al. Supercontinuum generation by stimulated raman scattering and parametric four-wave mixing in photonic crystal fibers. Optical Society of América, v.19, n.4, p.753$764,2001$.

48 SCHREIBER, T. et al. High average power supercontinuum generation in photonic crystal fibers. Optics Communications, v.228, n.1-3, p.71-78, Dec. 2003.

49. PETROV, G. I.; YAKOVLEV, V. V.; MINKOVSKI, N. I. Near-infrared continuum generation of femtosecond and picosecond pulses in doped optical fibers. Applied Physics BLasers and Optics, v.77, n.2-3, p.219-225, Sept. 2003.

50 HIGHLY nonlinear photonic crystal fiber. Produced by Thorlabs. Disponível em: $<$ http://www.thorlabs.com/catalogPages/v20/877.pdf>. Acesso em: 03 ago. 2009.

51 SC-5.0-1040 nonlinear fiber for supercontinuum generation. Produced by Thorlabs. Disponível em: <http://www.thorlabs.com/Thorcat/10700/10736-M01.pdf >. Acesso em: 03 ago. 2009.

52 COMPACT ultra-bright supercontinuum light source. Produced by NKT Photonics. Disponível em: $\quad<$ http://www.nktphotonics.com/files/files/Application_noteSupercontinuum\%20-\%20SC-5.0-1040.pdf>. Acesso em: 03 ago. 2009.

53 SHARMA, D. K.; YIP, R. W. Superbroadening of single $1.06 \mu \mathrm{m}$ picosecond pulses in $\mathrm{H}_{2} \mathrm{O}$ and $\mathrm{D}_{2} \mathrm{O}$ : on the concurrence of dielectric-breakdown and superbroadening. Optics Communications, v.30, n.1, p.113-118, 1979.

54 SMITH, W. L.; LIU, P.; BLOEMBERGEN, N. Superbroadening in $\mathrm{H}_{2} \mathrm{O}$ and $\mathrm{D}_{2} \mathrm{O}$ by selffocused picosecond pulses from a YALG:Nd laser. Physical Review A, v.15, n.6, p.23962403, 1977.

55 PALMER, C. Difraction grating handbook. New York: Newport, 2005.

56 DEMTRODER, W. Laser spectroscopy: basic concepts and instrumentation. 2nd ed. Berlin : Springer Verlag, 1996. 
57 ABRAMOWITZ, M.; STEGUN, I. A. Handbook of mathematical functions: with formulas, graphs, and mathematical tables. Canadá: General Publishing Company Ltd, 1965.

58 ZHANG, J. Y. et al. Picosecond optical parametric amplification in lithium triborate. Applied Physics Letters, v.58, n.3, p.213-215, Jan.1991.

59 COLTHUP, N. B.; DALY, L. H.; WIBERLEY, S. E. Introduction to infrared and Raman spectroscopy. 3nd ed. New York: Academic Press, 1990.

60 DE BONI, L.; TORO, C.; HERNANDEZ, F. E. Pump polarization-state preservation of picosecond generated white-light supercontinuum. Optics Express, v.16, n.2, p.957-964, Jan. 2008.

61 ALFANO, R. R.; SHAPIRO, S. L. Emission in region 4000 to $7000 \AA$ via four-photon coupling in glass. Physical Review Letters, v.24, n.11, p.584-587, 1970.

62 DHARMADHIKARI, A et al. Highly efficient white light generation from barium fluoride. Optics Express, v.12, n.4, p.695-700, Feb. 2004.

63 DHARMADHIKARI, A. K.; RAJGARA, F. A.; MATHUR, D. Plasma effects and the modulation of white light spectra in the propagation of ultrashort, high-power laser pulses in barium fluoride. Applied Physics B-Lasers and Optics, v.82, n.4, p.575-583, Mar.2006. 